\title{
Controlled Hydrogen Fleet and Infrastructure Demonstration and Validation Project
}

Technical Report NREL/TP-560-44256

October 2008

\section{Fall 2008}

Composite Data Products Final Version September 24, 2008

Keith Wipke, Sam Sprik, Jennifer Kurtz, and Todd Ramsden 


\section{Disclaimer and Government License}

This work has been authored by Midwest Research Institute (MRI) under Contract No. DE-AC3699GO10337 with the U.S. Department of Energy (the "DOE"). The United States Government (the "Government") retains and the publisher, by accepting the work for publication, acknowledges that the Government retains a non-exclusive, paid-up, irrevocable, worldwide license to publish or reproduce the published form of this work, or allow others to do so, for Government purposes.

Neither MRI, the DOE, the Government, nor any other agency thereof, nor any of their employees, makes any warranty, express or implied, or assumes any liability or responsibility for the accuracy, completeness, or usefulness of any information, apparatus, product, or process disclosed, or represents that its use would not infringe any privately owned rights. Reference herein to any specific commercial product, process, or service by trade name, trademark, manufacturer, or otherwise does not constitute or imply its endorsement, recommendation, or favoring by the Government or any agency thereof. The views and opinions of the authors and/or presenters expressed herein do not necessarily state or reflect those of MRI, the DOE, the Government, or any agency thereof. 


\section{Controlled Hydrogen Fleet and Infrastructure Demonstration and Validation Project}

\section{Fall 2008 \\ Composite Data Products September 24, 2008 (Final)}

Keith Wipke, Sam Sprik, Jennifer Kurtz, Todd Ramsden 


\section{CDP\#1: Hours Accumulated and}

\section{Projected Hours to $10 \%$ Stack Voltage Degradation}

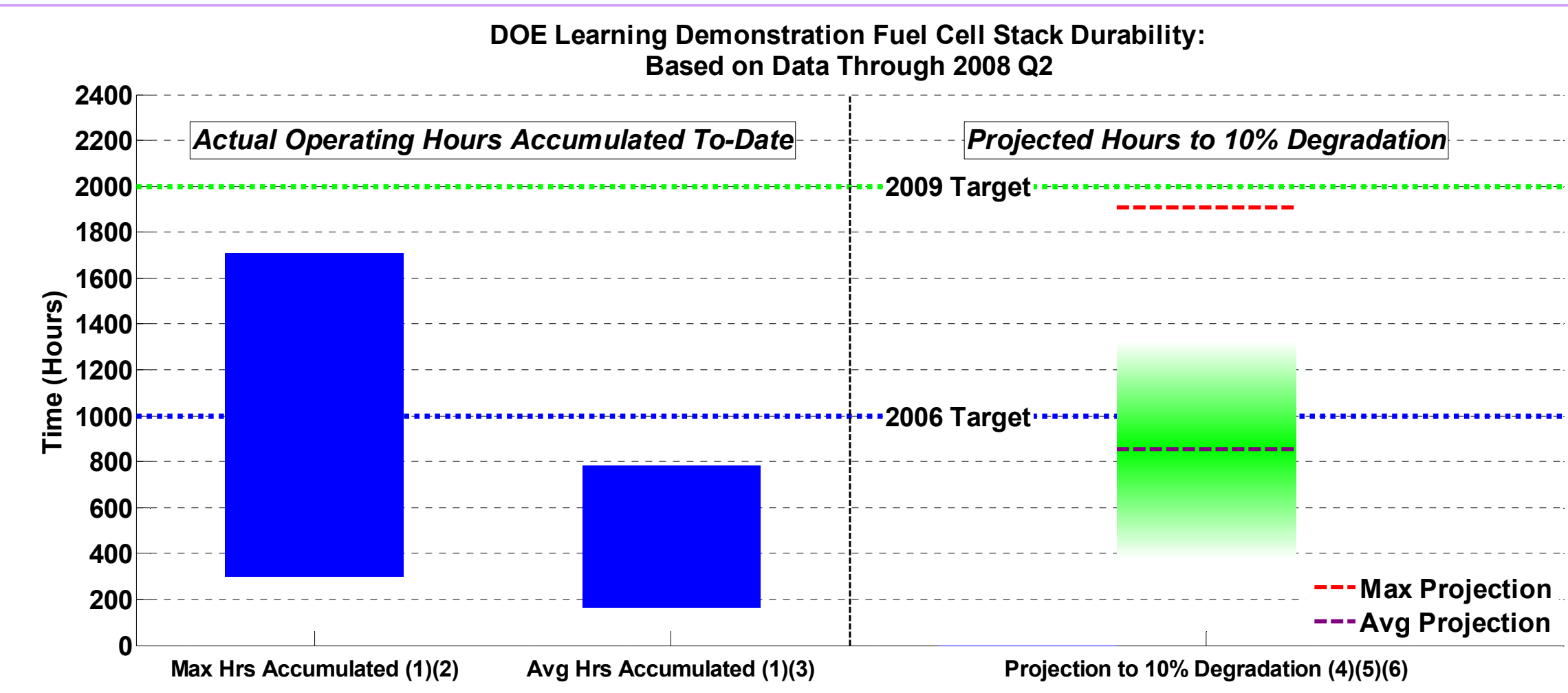

(1) Range bars created using one data point for each OEM. Some stacks have accumulated hours beyond $10 \%$ voltage degradation.

(2) Range (highest and lowest) of the maximum operating hours accumulated to-date of any OEM's individual stack in "real-world" operation.

(3) Range (highest and lowest) of the average operating hours accumulated to-date of all stacks in each OEM's fleet.

(4) Projection using on-road data -- degradation calculated at high stack current. This criterion is used for assessing progress against DOE targets, may differ from OEM's end-of-life criterion, and does not address "catastrophic" failure modes, such as membrane failure.

(5) Using one nominal projection per OEM: "Max Projection" = highest nominal projection, "Avg Projection" = average nominal projection.

The shaded green bar represents an engineering judgment of the uncertainty on the "Avg Projection" due to data and methodology limitations.

Projections will change as additional data are accumulated.

(6) Projection method was modified beginning with 2008 Q2 data. 


\section{CDP\#2: Vehicle Range}

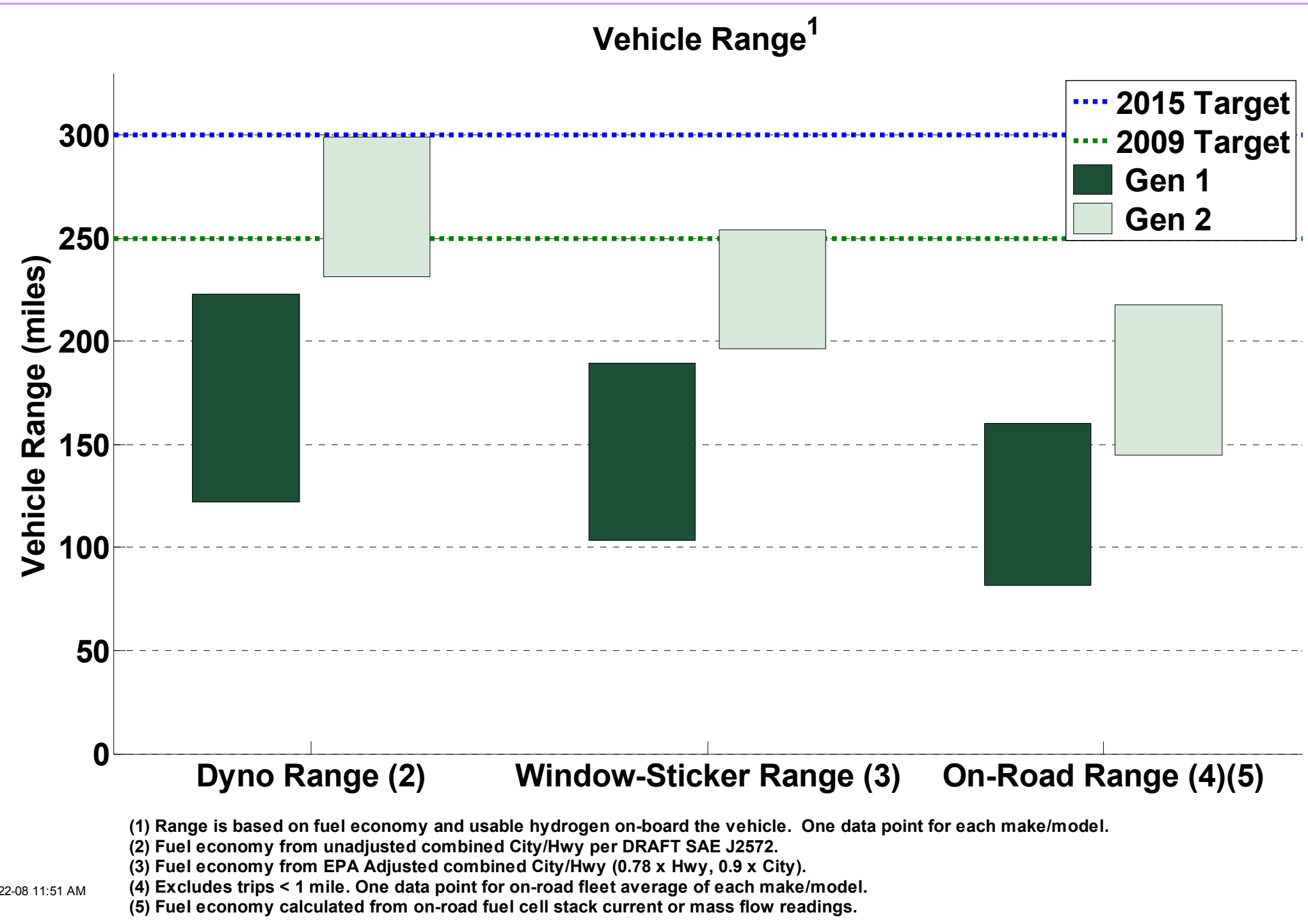




\section{CDP\#6: Fuel Economy}

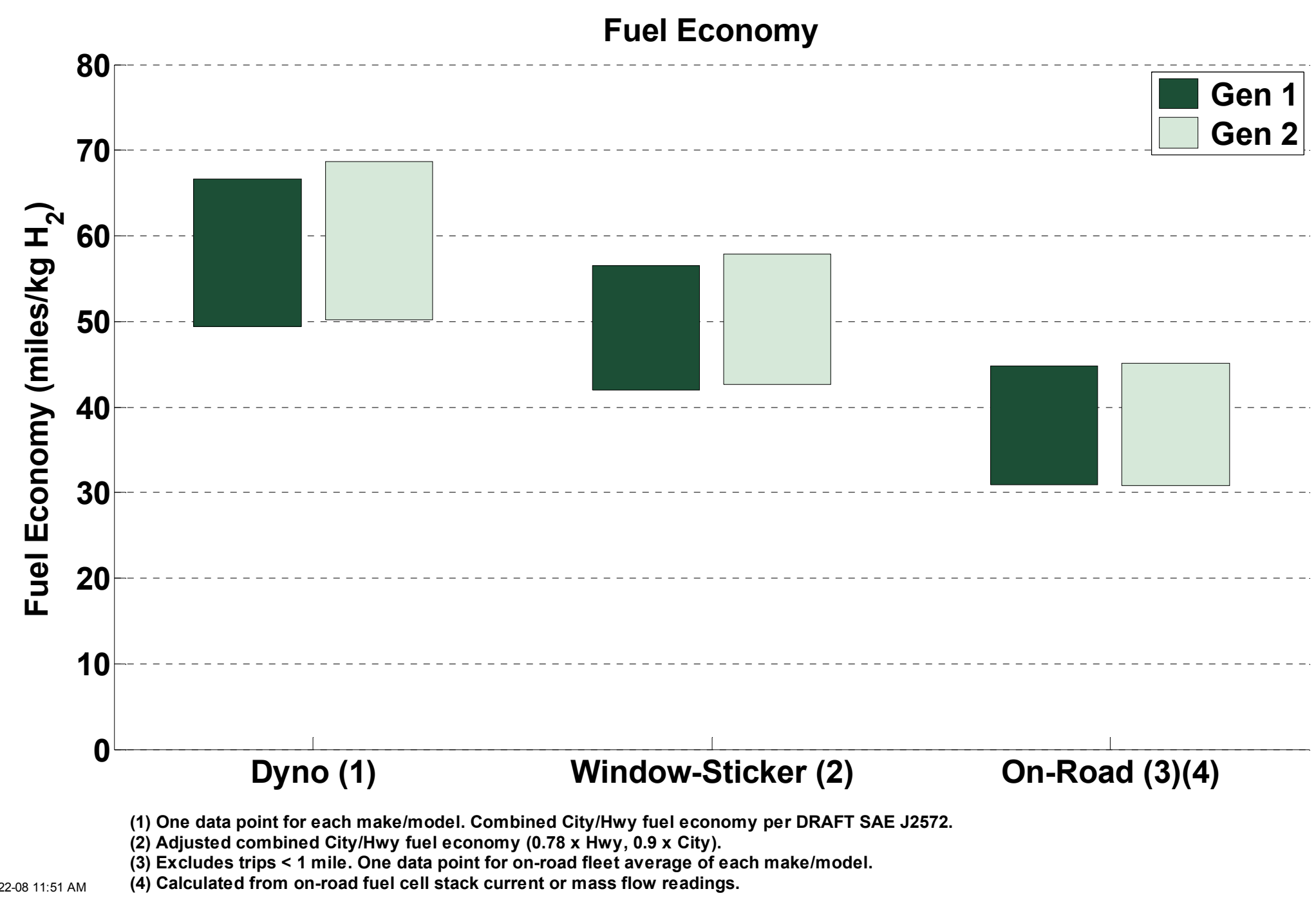

3) Excludes trips $<1$ mile. One data point for on-road fleet average of each make/model.

(3) Excludes trips $<1$ mile. One data point for on-road fleet average of each
(4) Calculated from on-road fuel cell stack current or mass flow readings. 


\section{CDP\#8: FC System Efficiency}

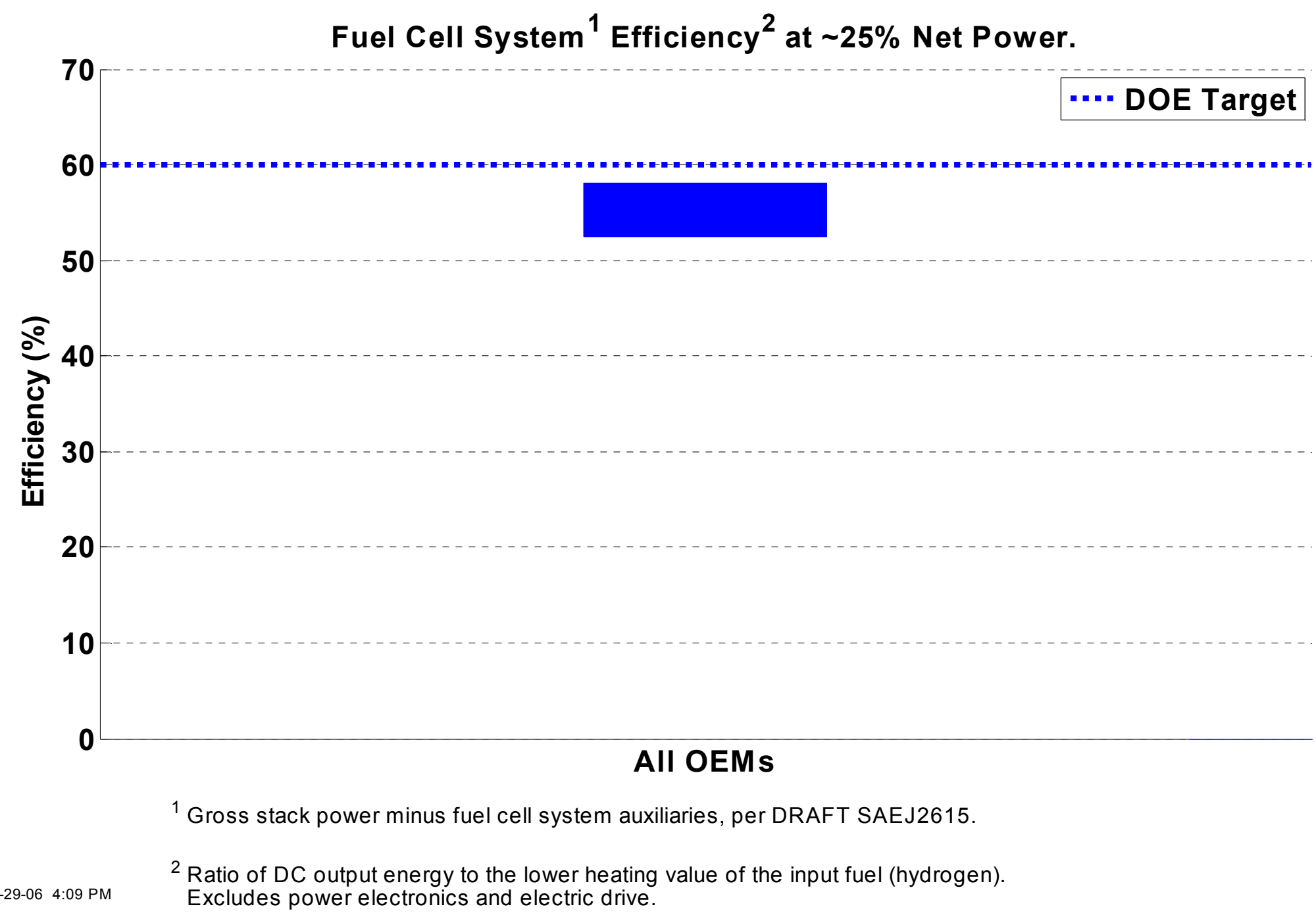




\section{CDP\#9: Safety Reports - Vehicles}

\section{Safety Reports - Vehicle Operation}

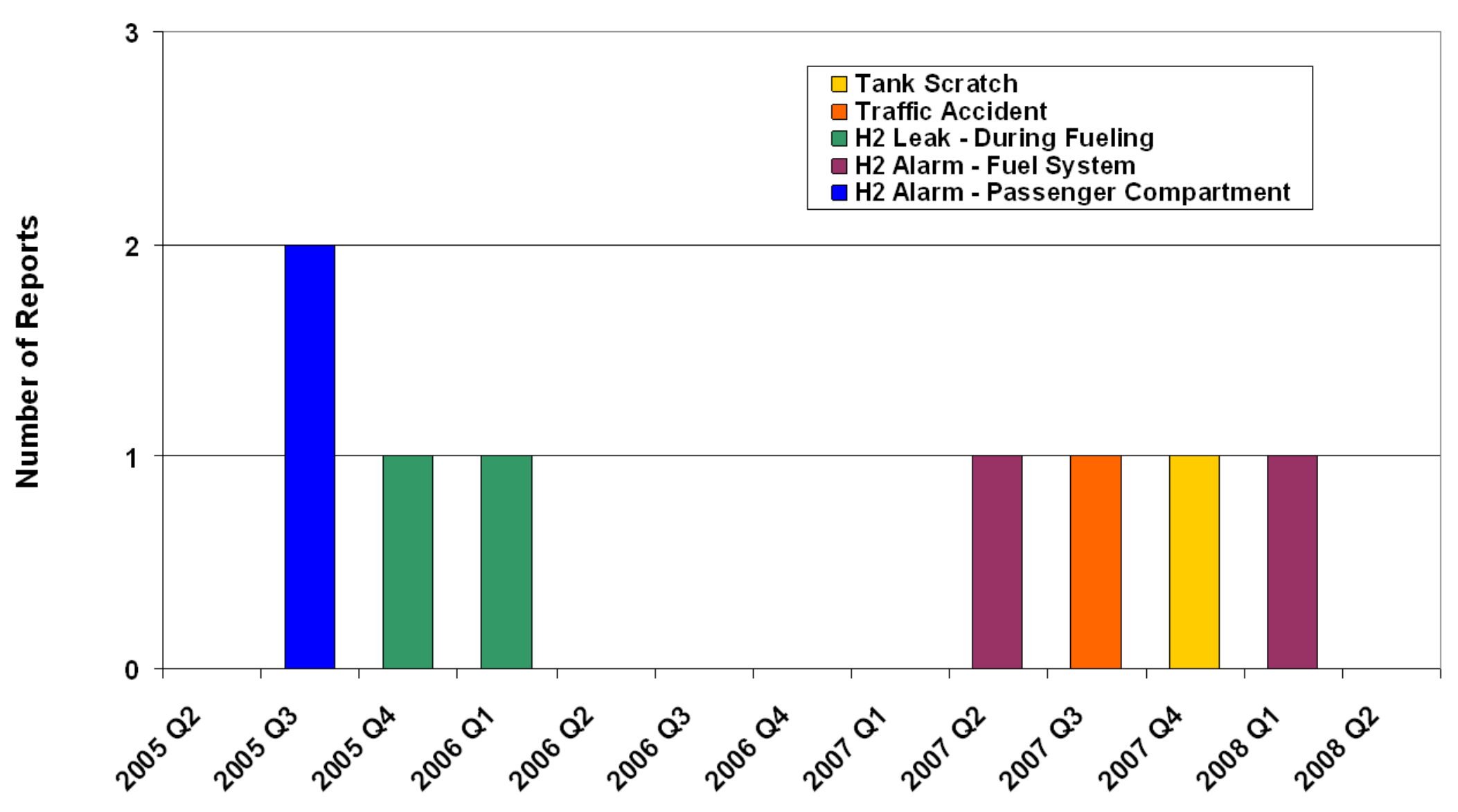




\section{CDP\#10: Storage Weight \% Hydrogen}

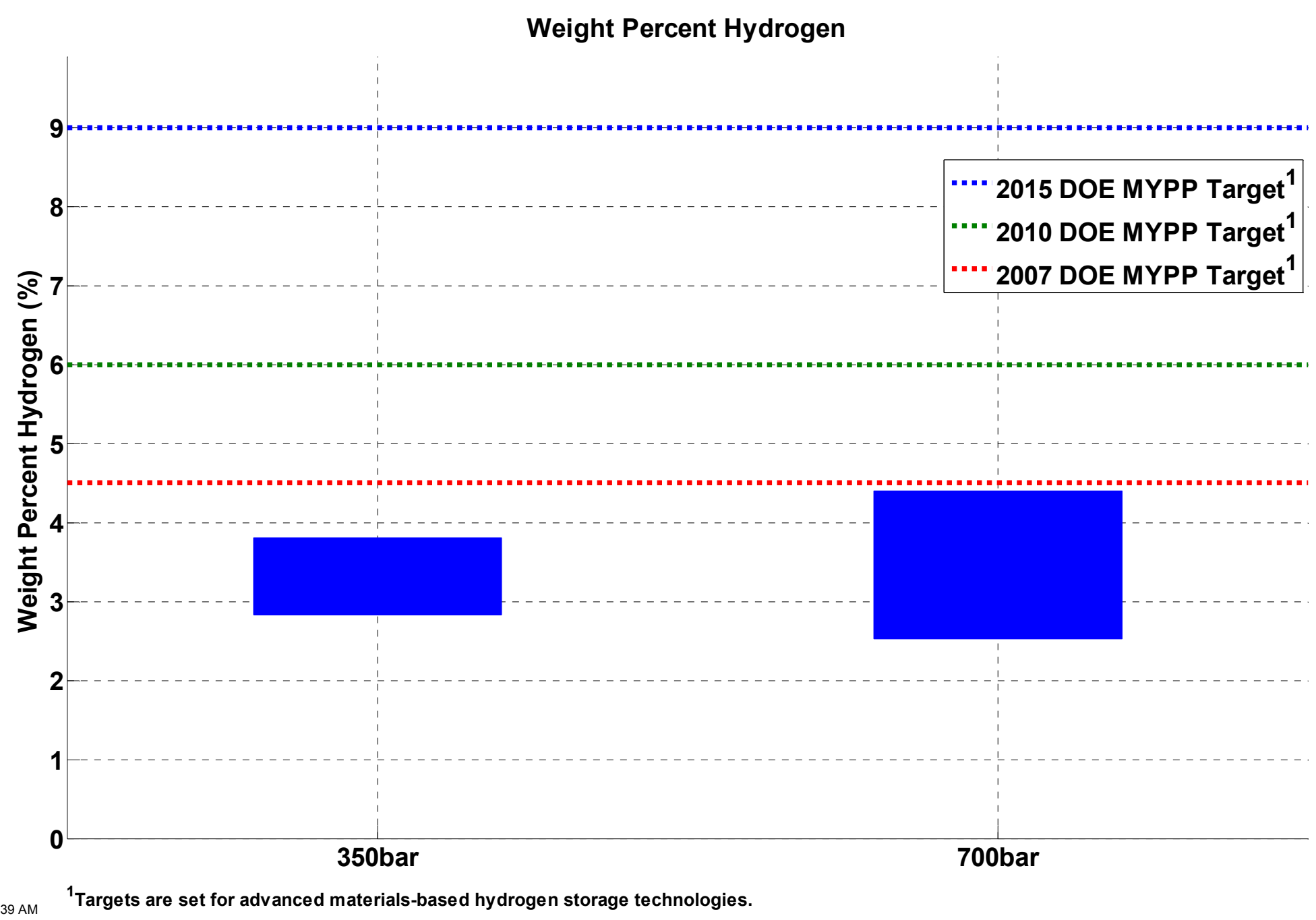

Targets are set for advanced materials-based hydrogen storage technologies. 


\section{CDP\#11: Volumetric Capacity of H2 Storage}

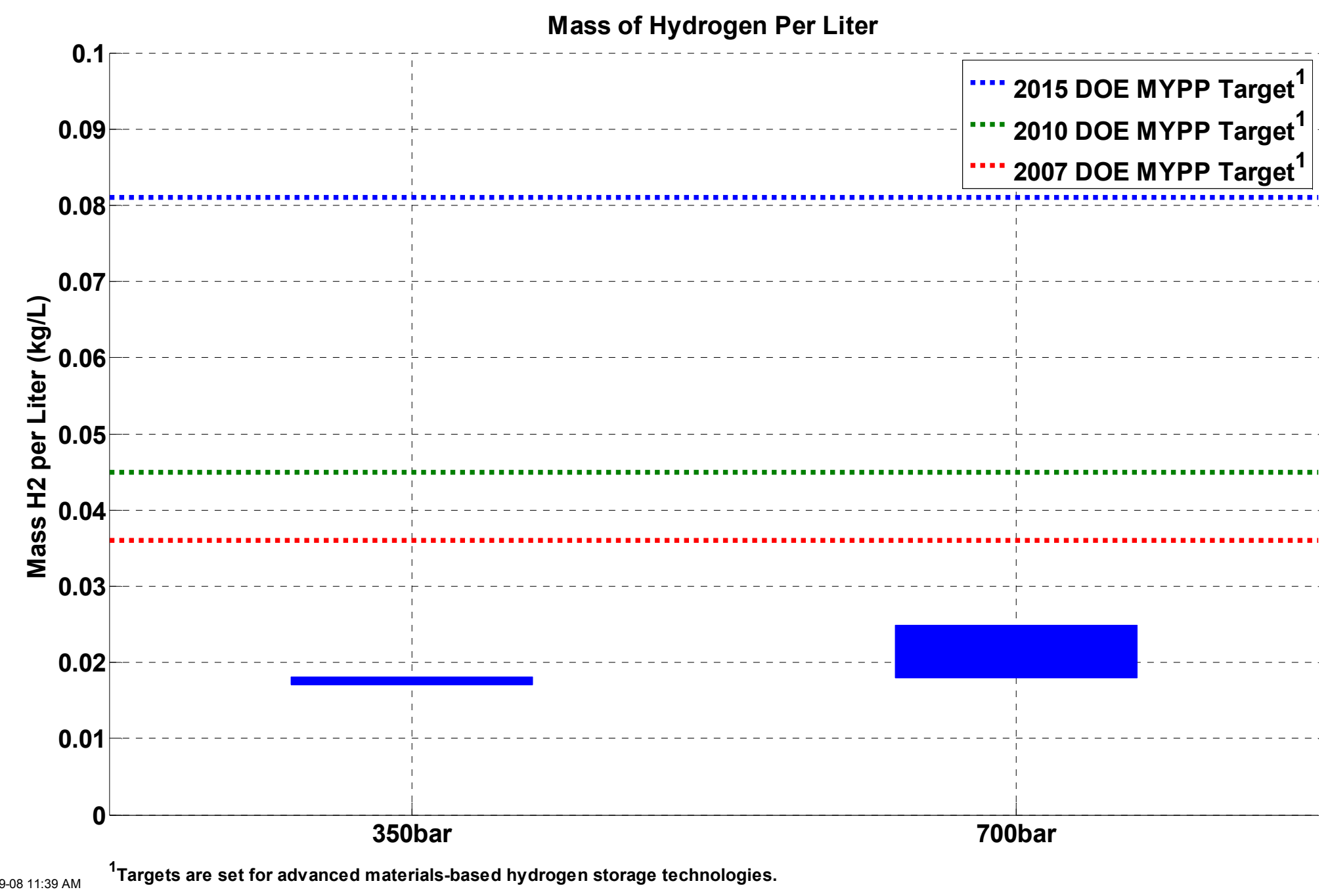

Targets are set for advanced materials-based hydrogen storage technologies. 


\section{CDP\#12: Vehicle Hydrogen Tank Cycle Life}

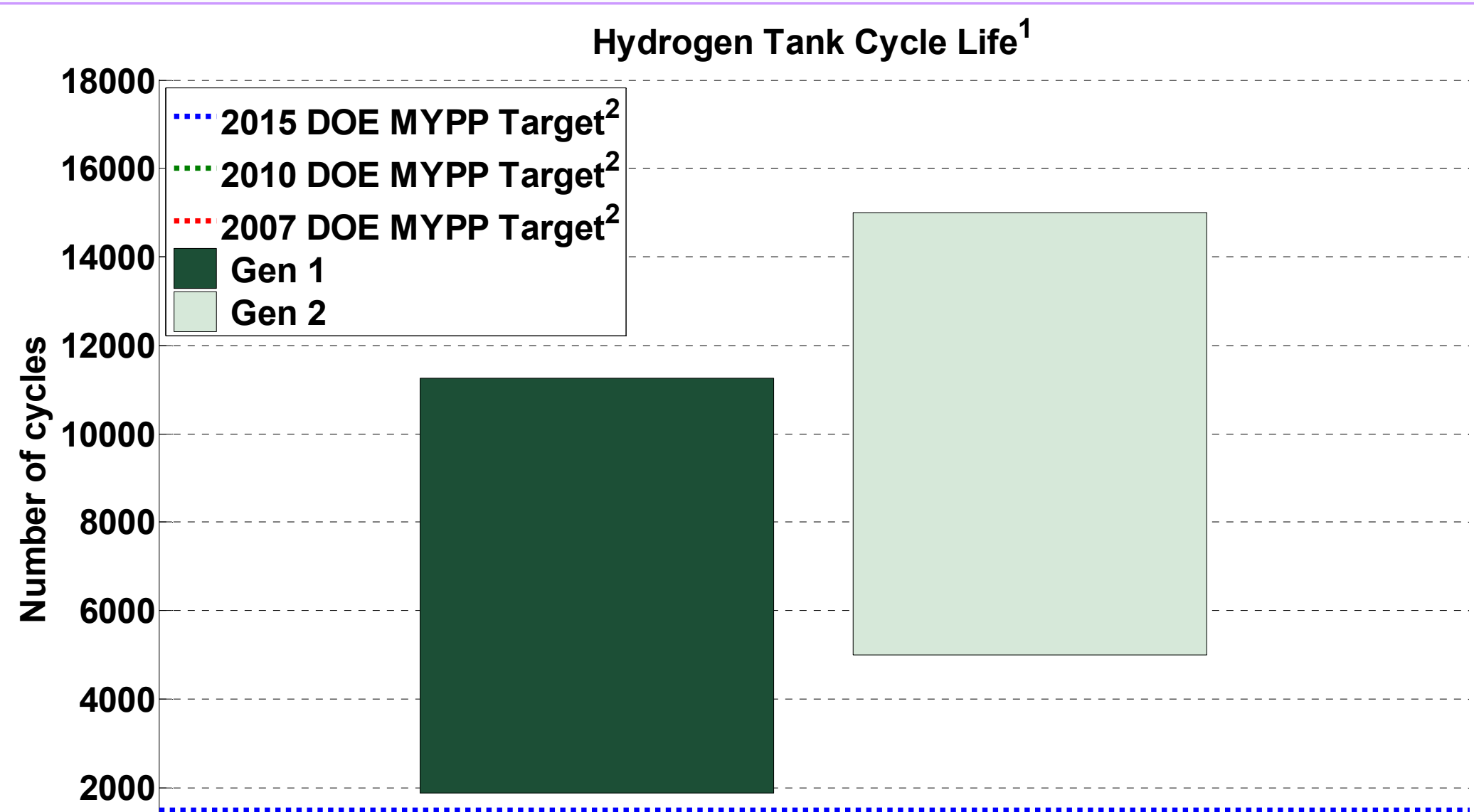

0

\section{All OEMs}

${ }^{1}$ Data reported reference NGV2, HGV2, or EIHP standards.

${ }^{2}$ Some near-term targets have been achieved with compressed and liquid tanks. Emphasis is on advanced materials-based technologies. 


\section{CDP\#13: On-Site Hydrogen Production Efficiency}

\section{Hydrogen Production Conversion Efficiency ${ }^{1}$}

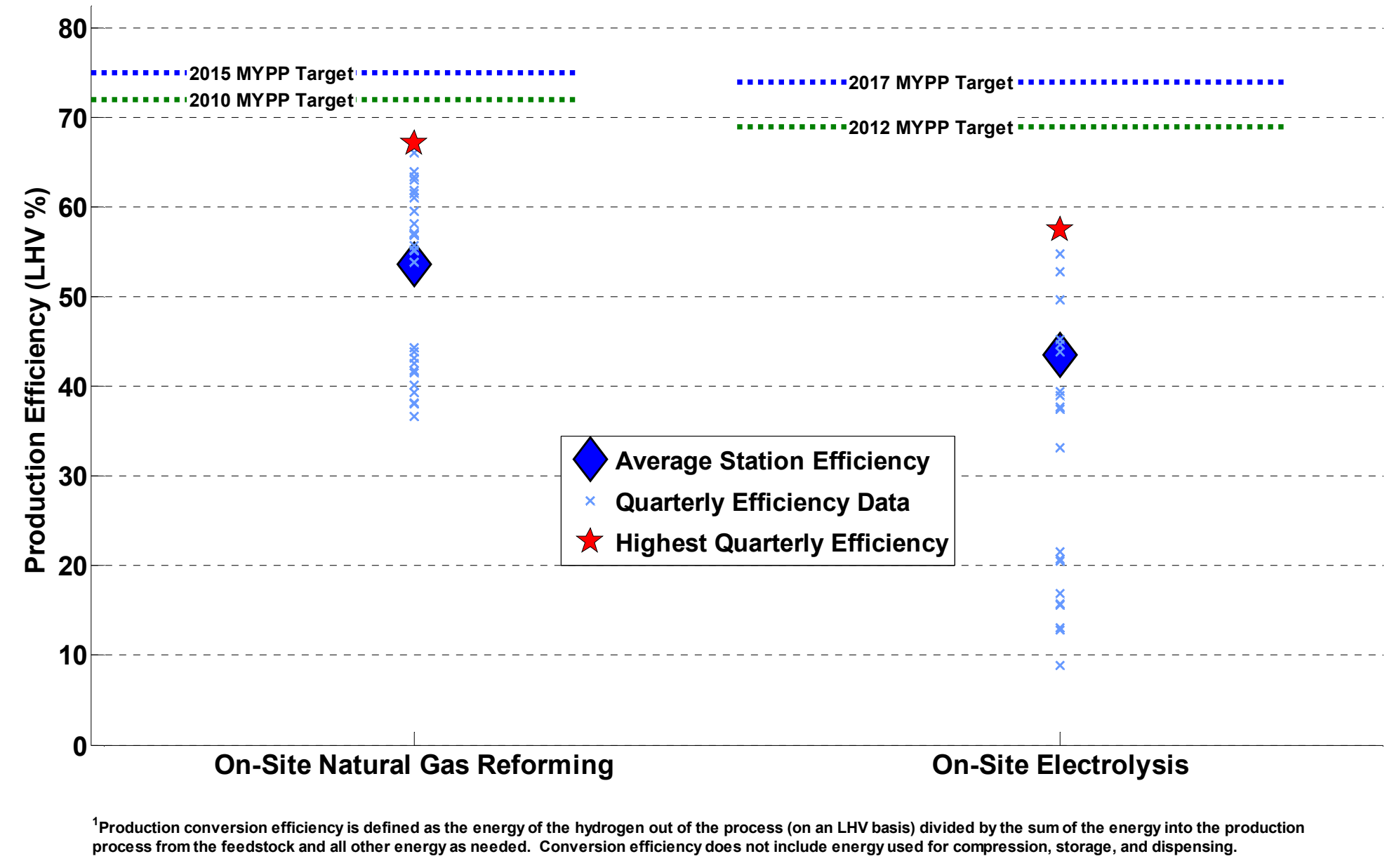




\section{CDP\#18: Refueling Rates}

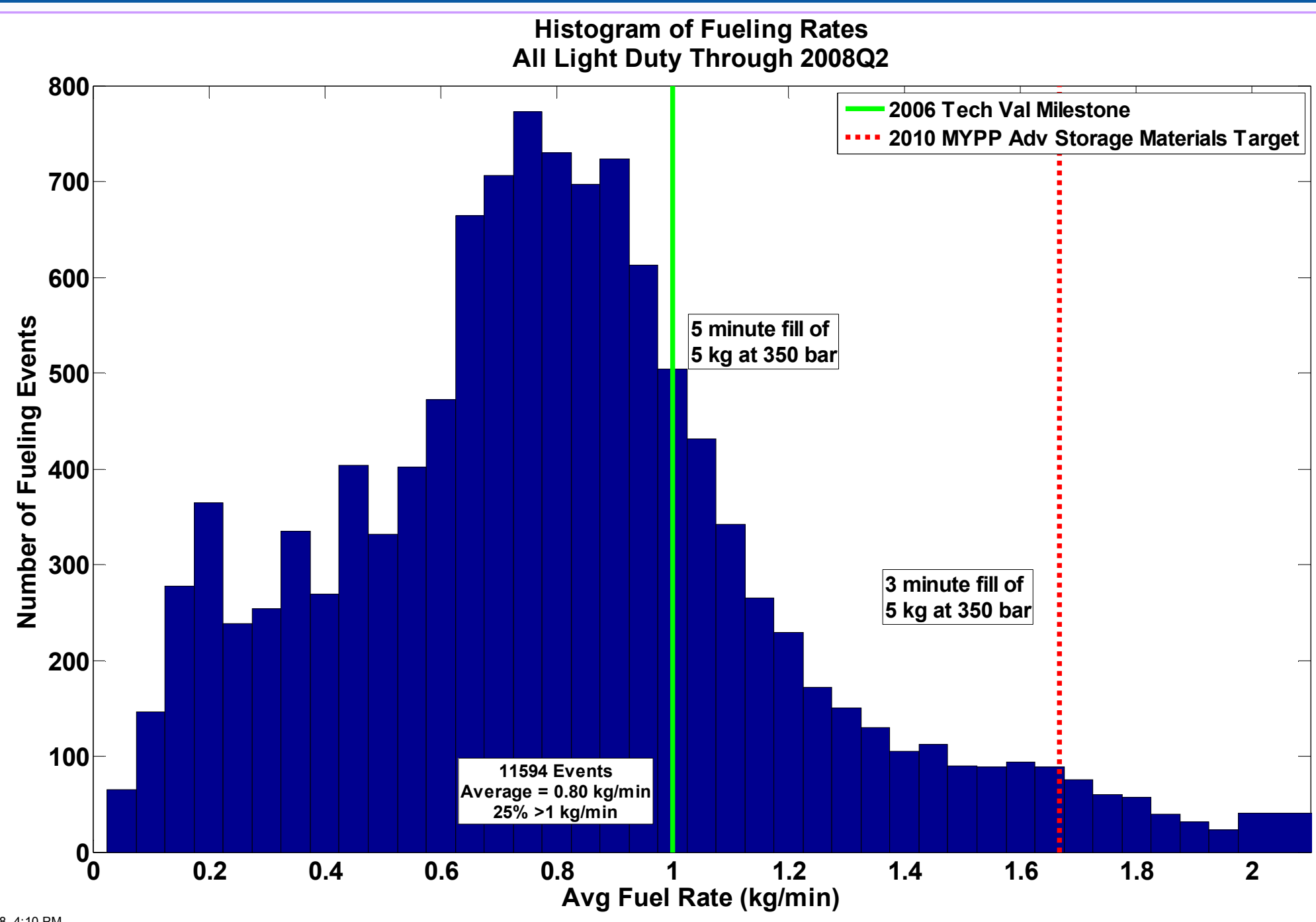




\section{CDP\#20: Safety Reports - Infrastructure}

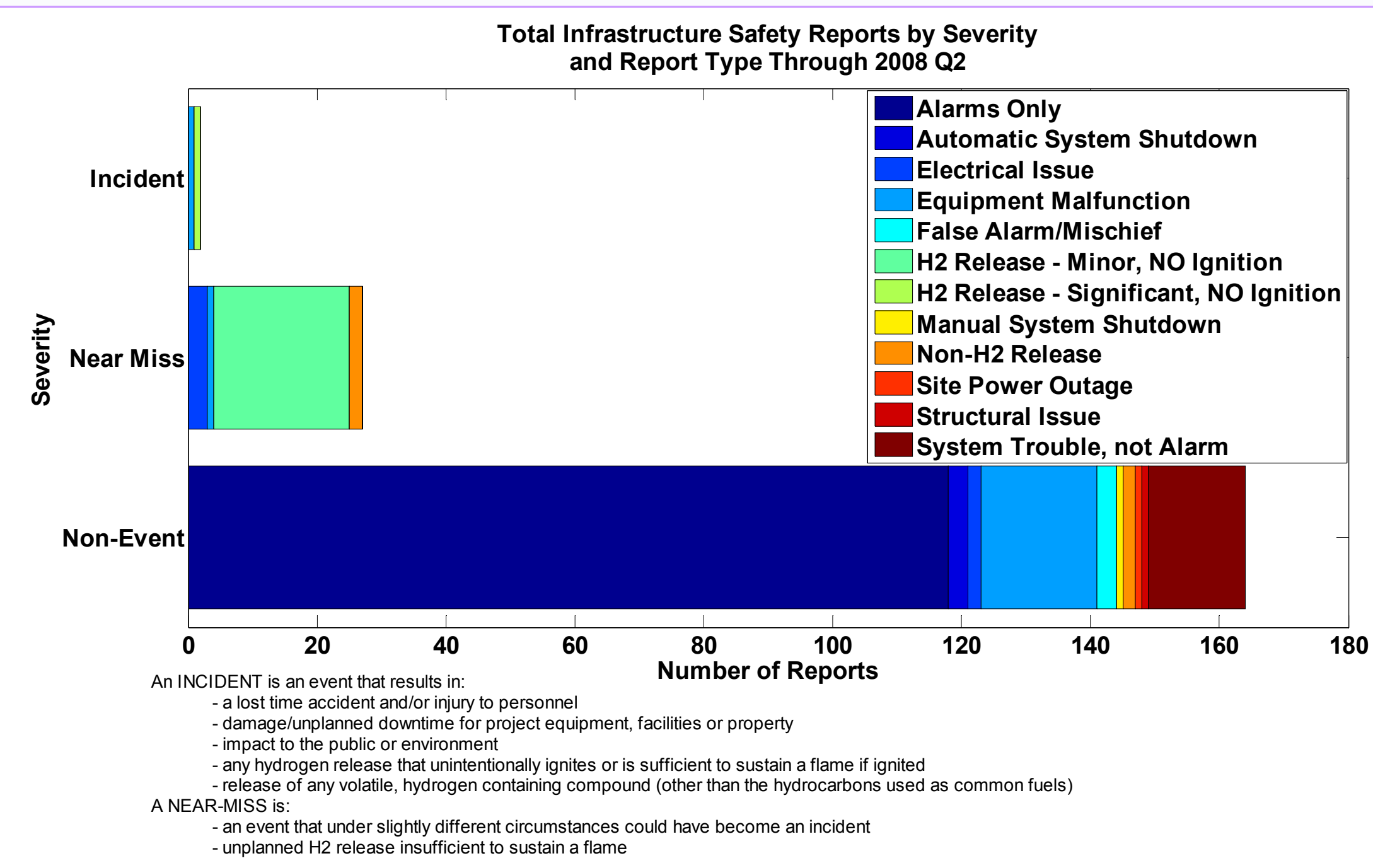




\section{CDP\#21: Range of Ambient Temperature During Vehicle Operation}

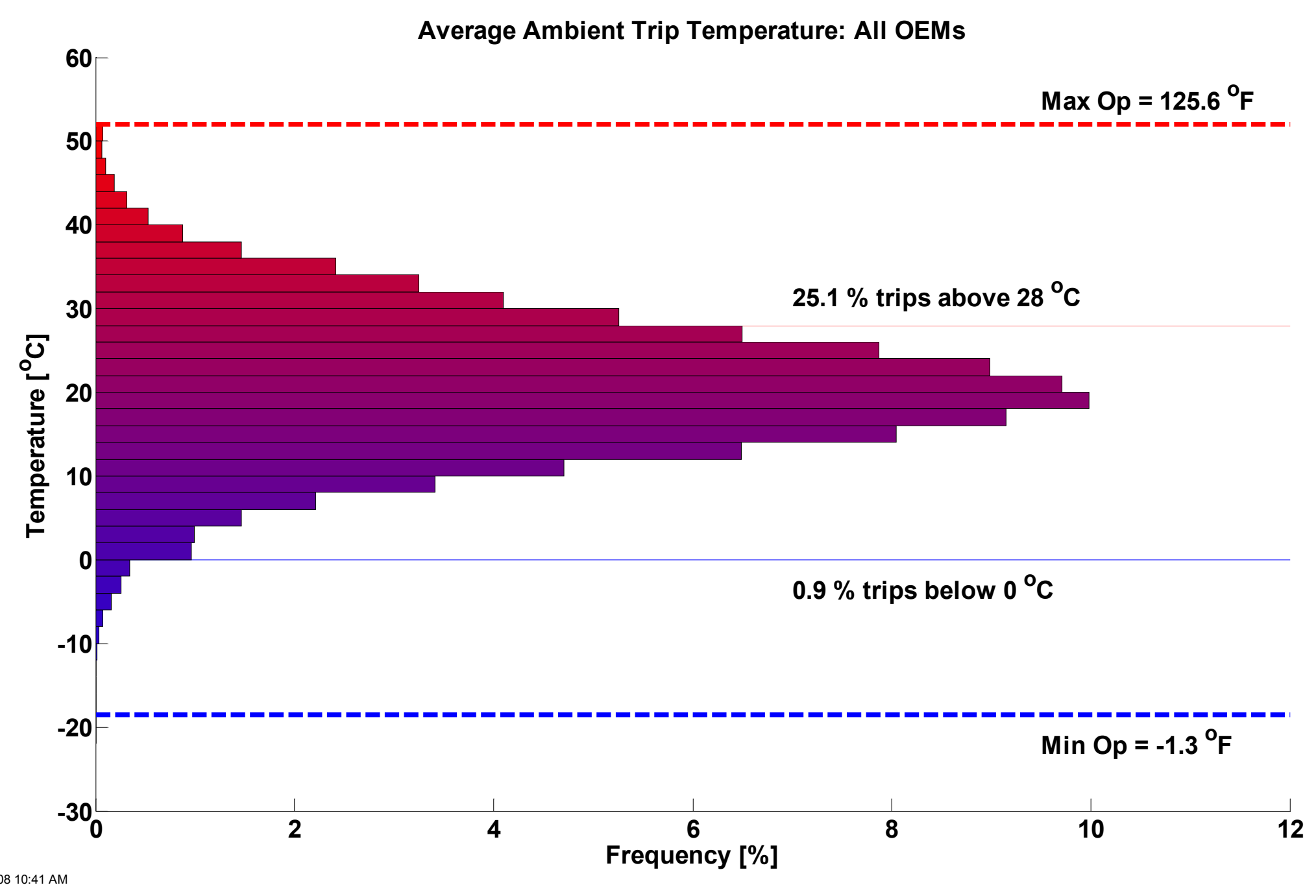




\section{CDP\#22: Vehicle Operating Hours}

Vehicle Hours: All OEMs, Gen 1 and Gen 2

Through 2008 Q2

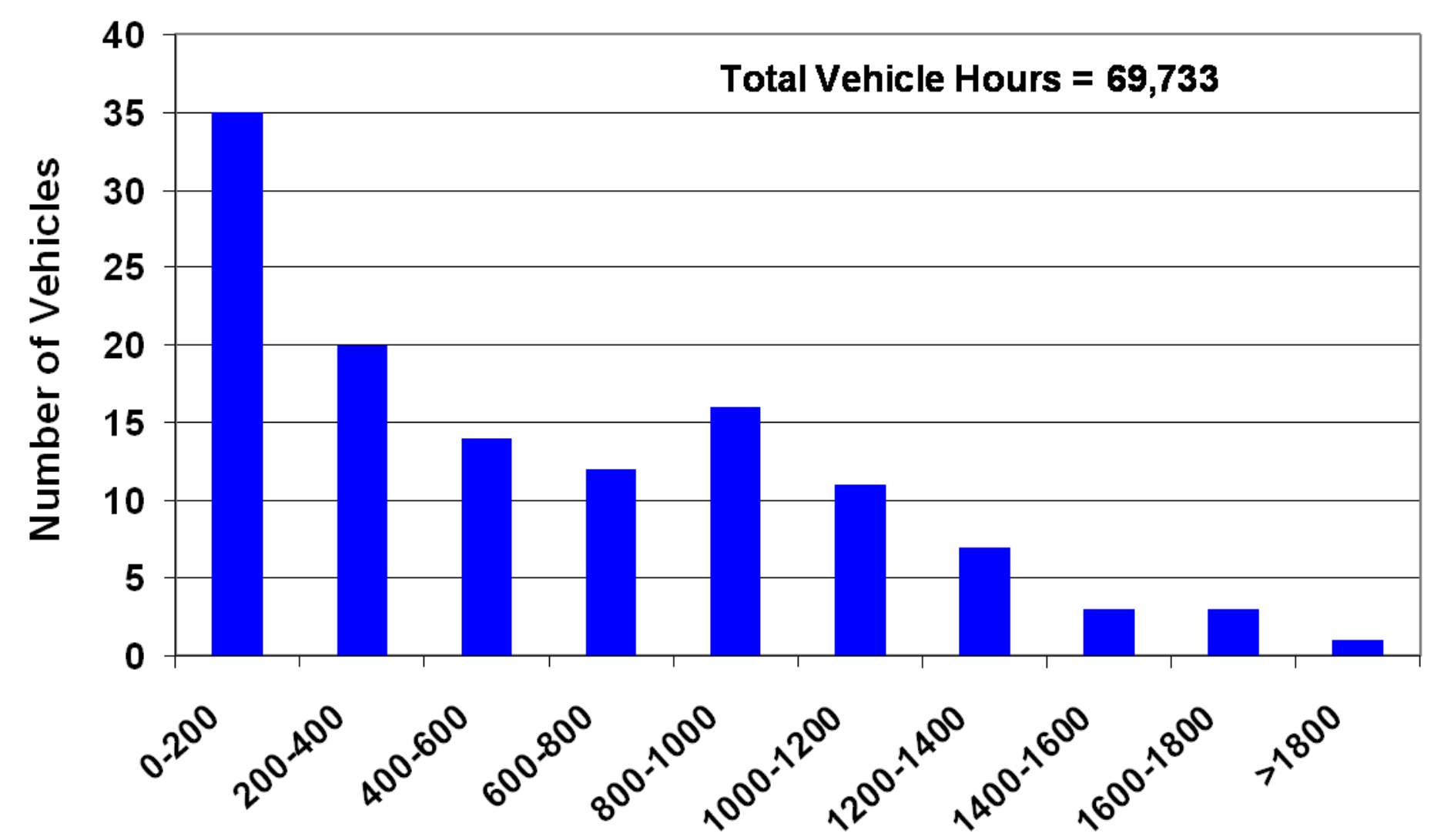

Total Vehicle Hours 


\section{CDP\#23: Vehicles vs. Miles Traveled}

Vehicle Miles: All OEMs, Gen 1 and Gen 2

Through 2008 Q2

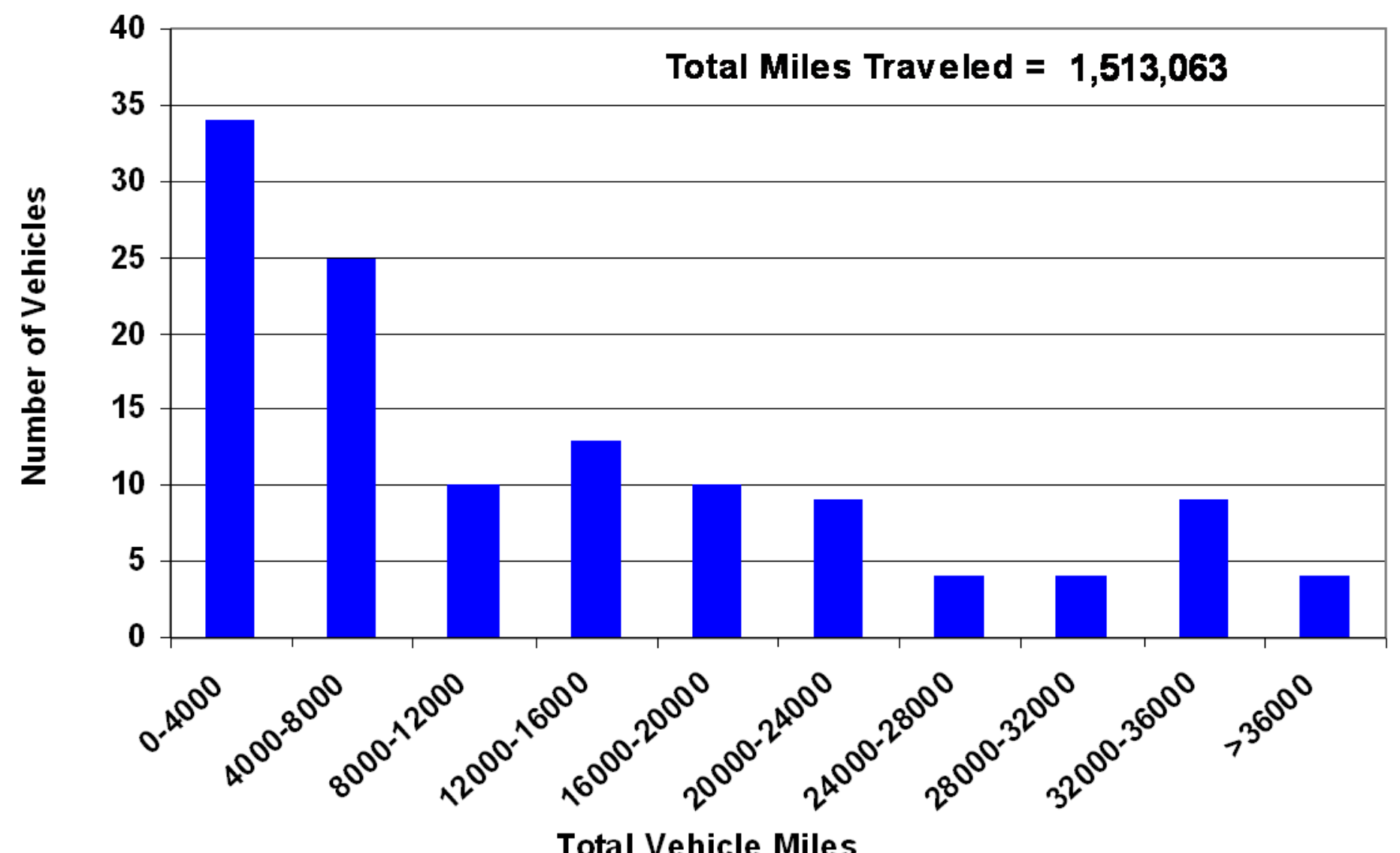

Total Vehicle Miles 


\section{CDP\#24: Cumulative Vehicle Miles Traveled}

Cumulative Vehicle Miles: All OEMs, Gen 1 and Gen 2

Through 2008 Q2

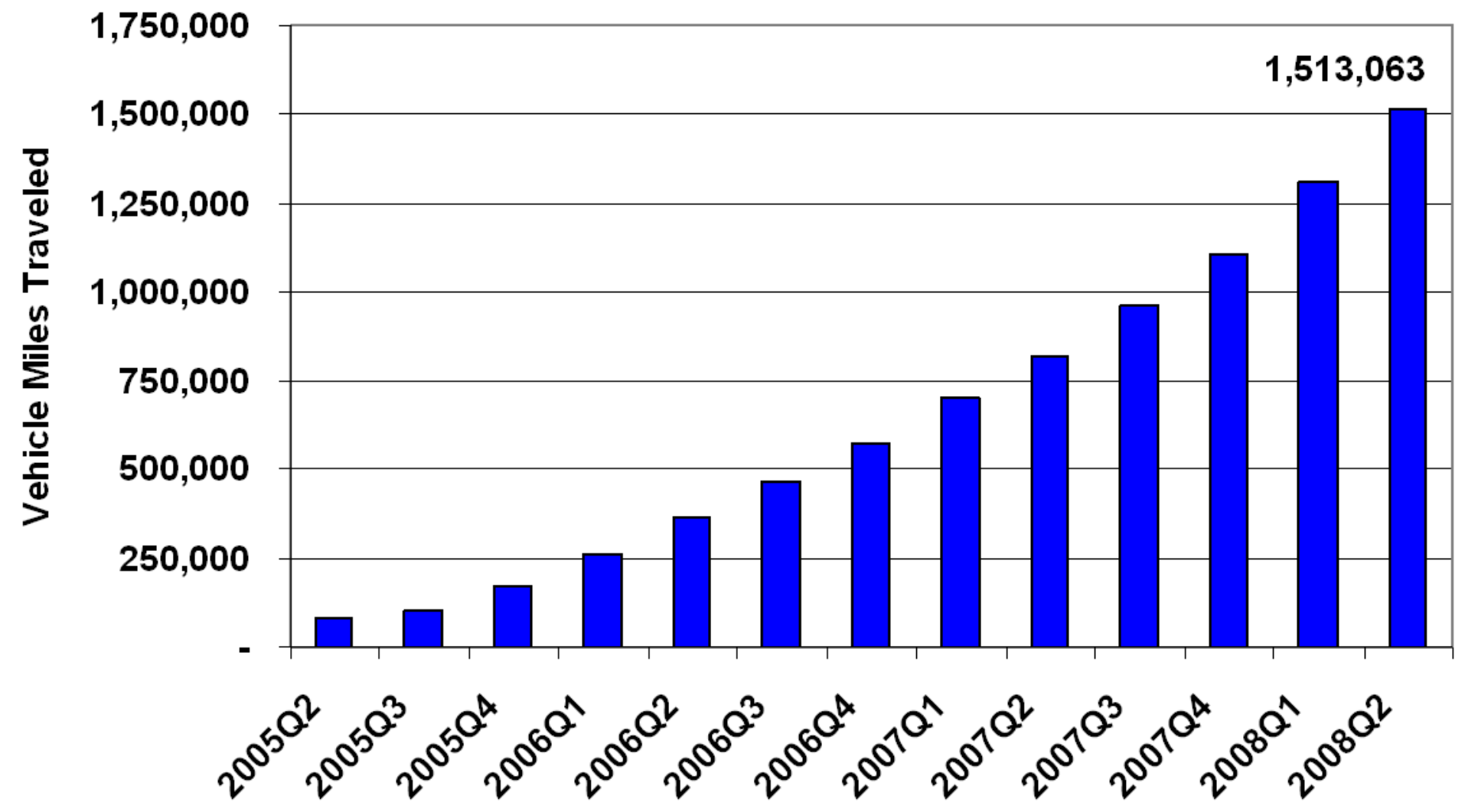

Created: Sep-22-08 02:00 PM 


\section{CDP\#25: Vehicle H2 Storage Technologies}

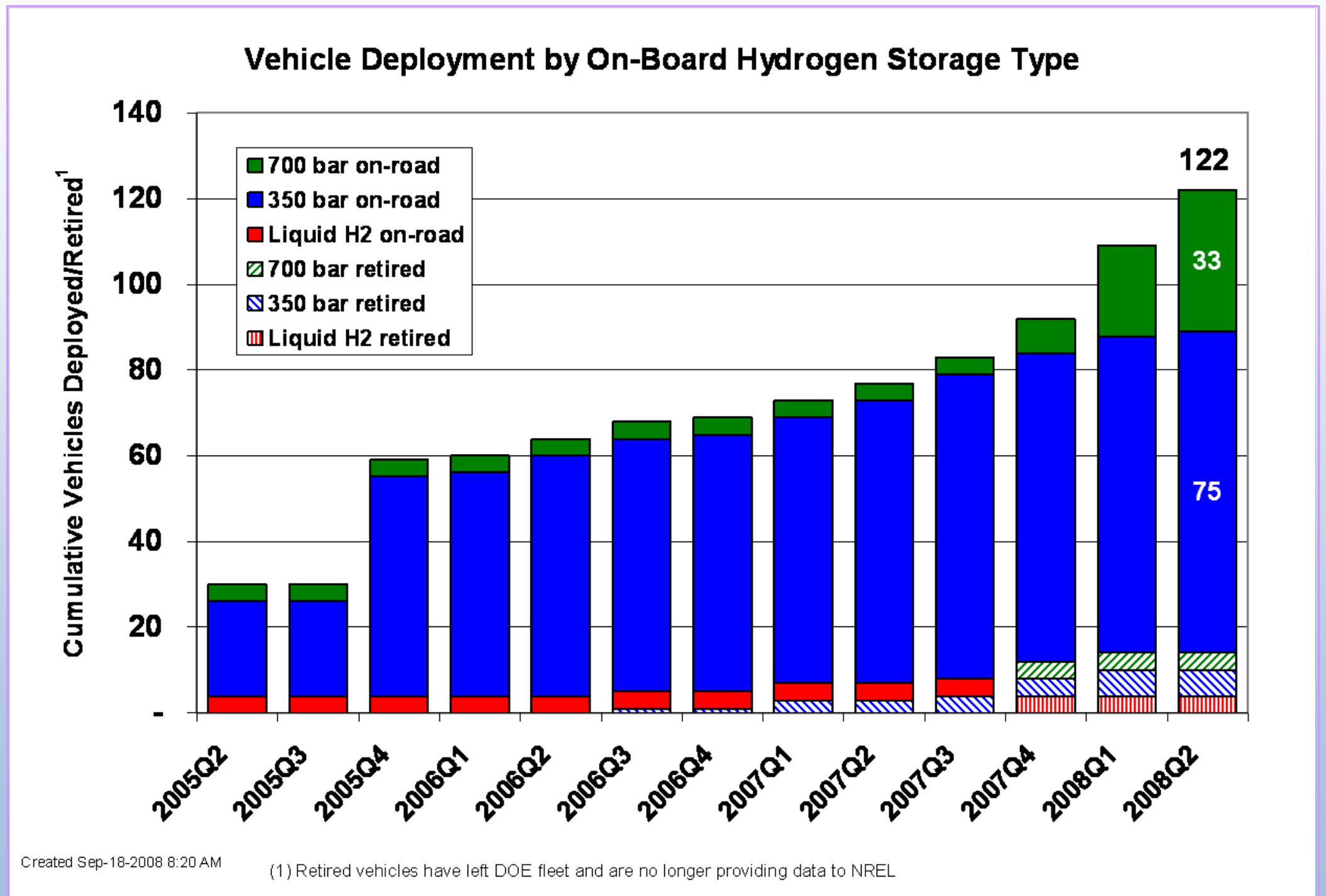




\section{CDP\#26: Cumulative H2 Produced or Dispensed}

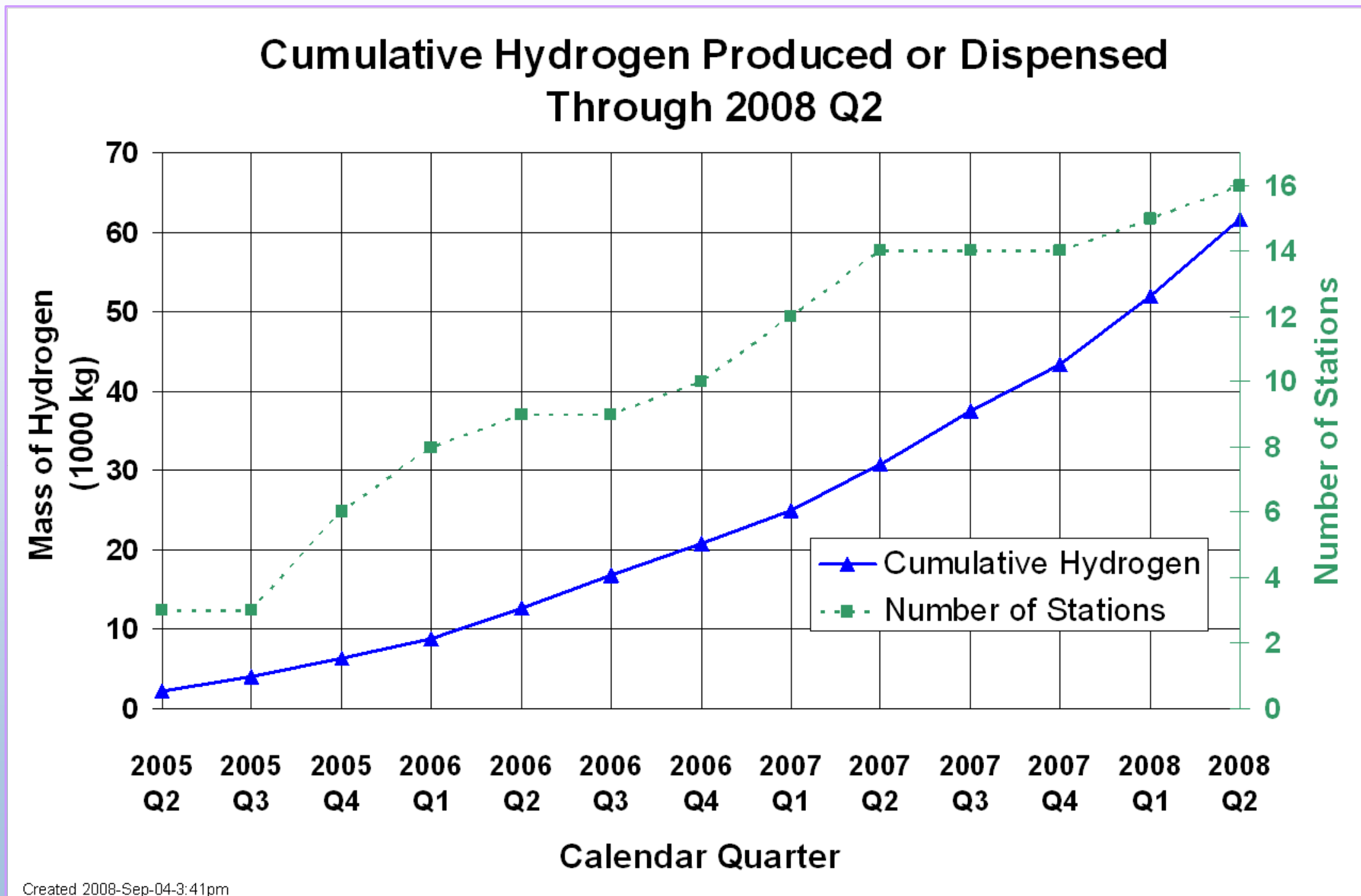




\section{CDP\#27: Hydrogen Quality Index}

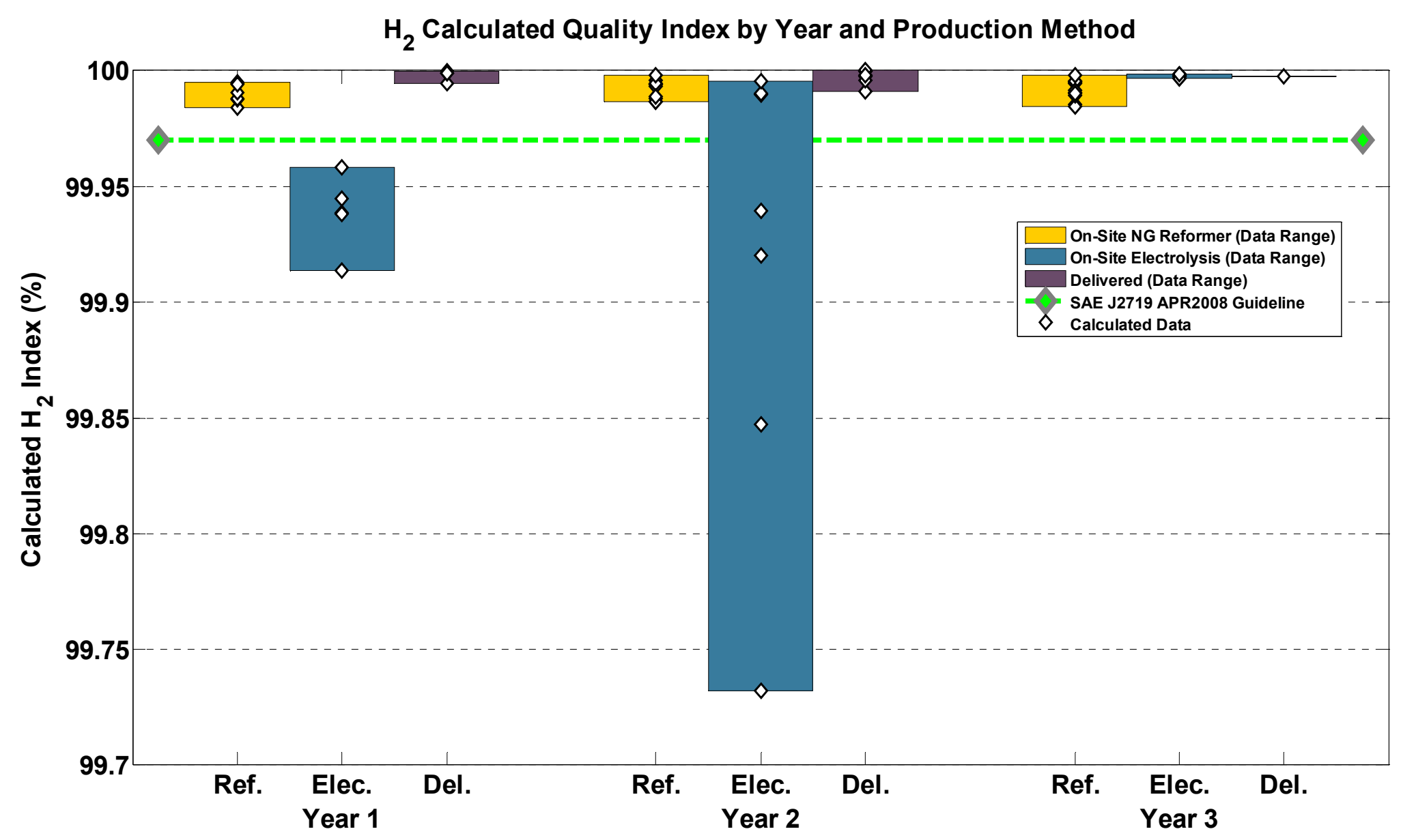




\section{CDP \#28: Hydrogen Impurities}

\section{$\mathrm{H}_{2}$ Impurities}
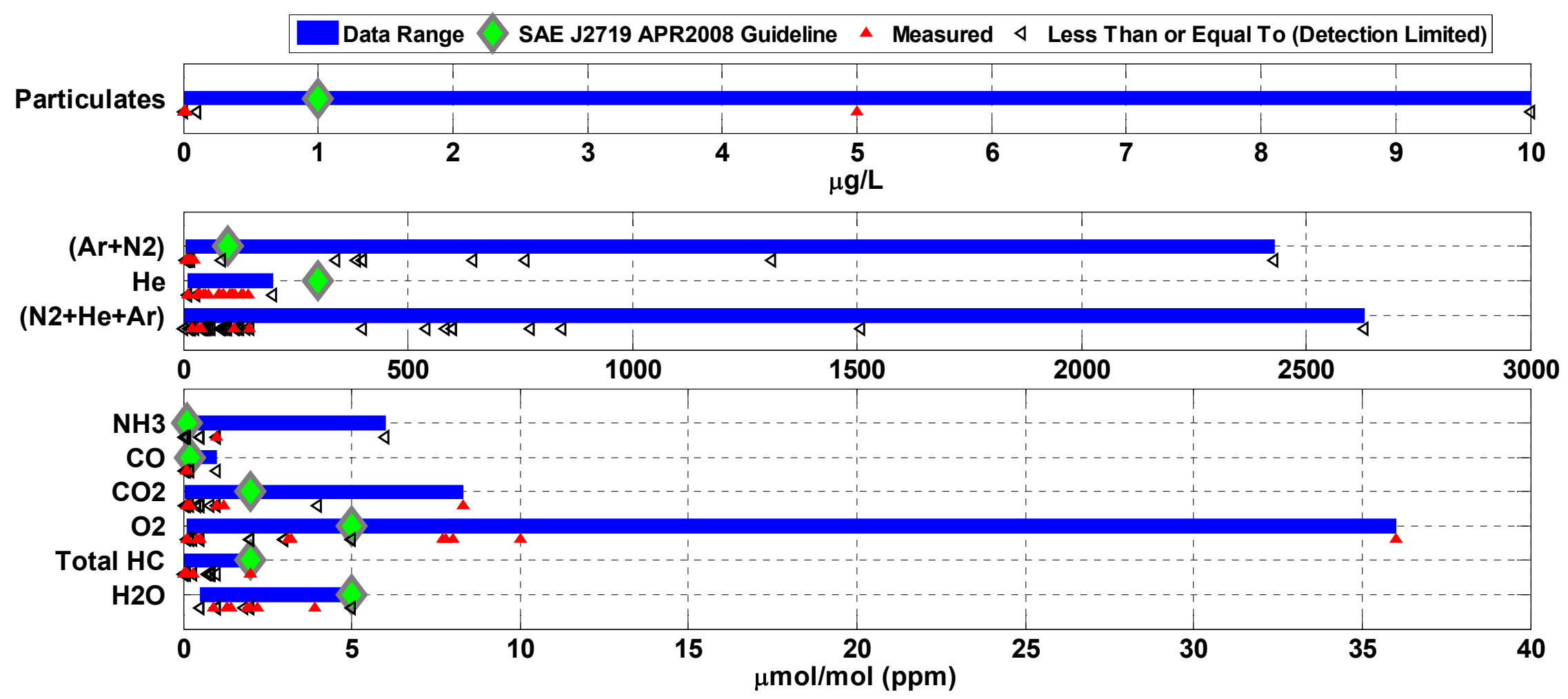
Total S

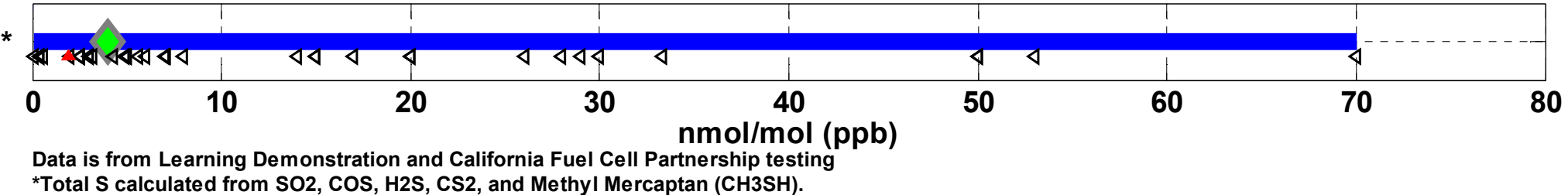




\section{CDP\#28 Supplemental: Hydrogen}

\section{Impurities by Year and Production Method}

Particulate Concentration ( $\mu \mathrm{g} / \mathrm{L})$

$\mathrm{H}_{2}$ Impurities by Year and Production Method

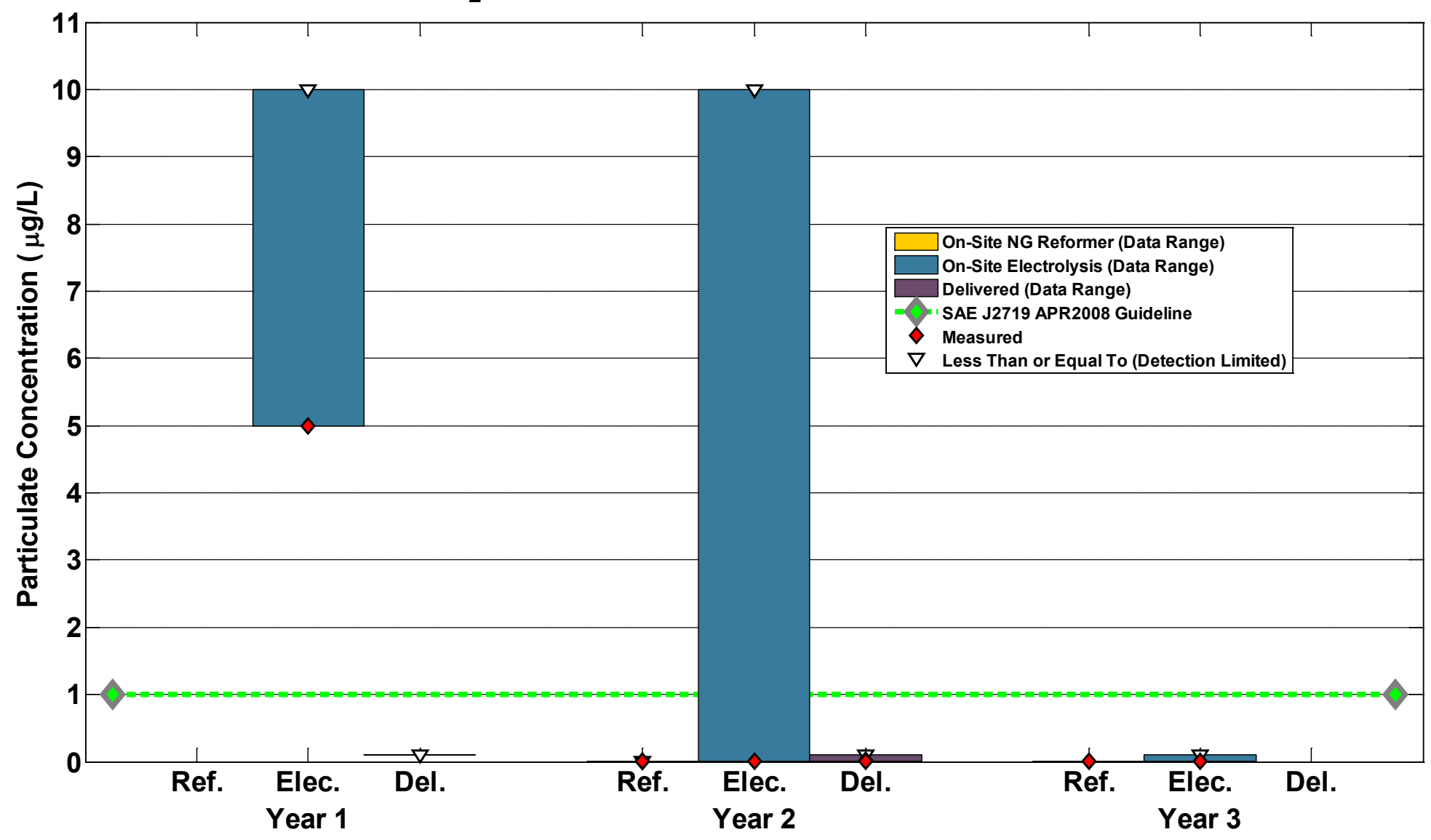

Data is from Learning Demonstration and California Fuel Cell Partnership testing

Year 1 is 2005Q3-2006Q2, Year 2 is 2006Q3-2007Q2, and Year 3 is 2007Q3-2008Q2 


\section{CDP\#28 Supplemental: Hydrogen}

\section{Impurities by Year and Production Method}

Calcultated Total Impurities $(\mu \mathrm{mol} / \mathrm{mol})(\mathrm{ppm})$

$\mathrm{H}_{2}$ Impurities by Year and Production Method

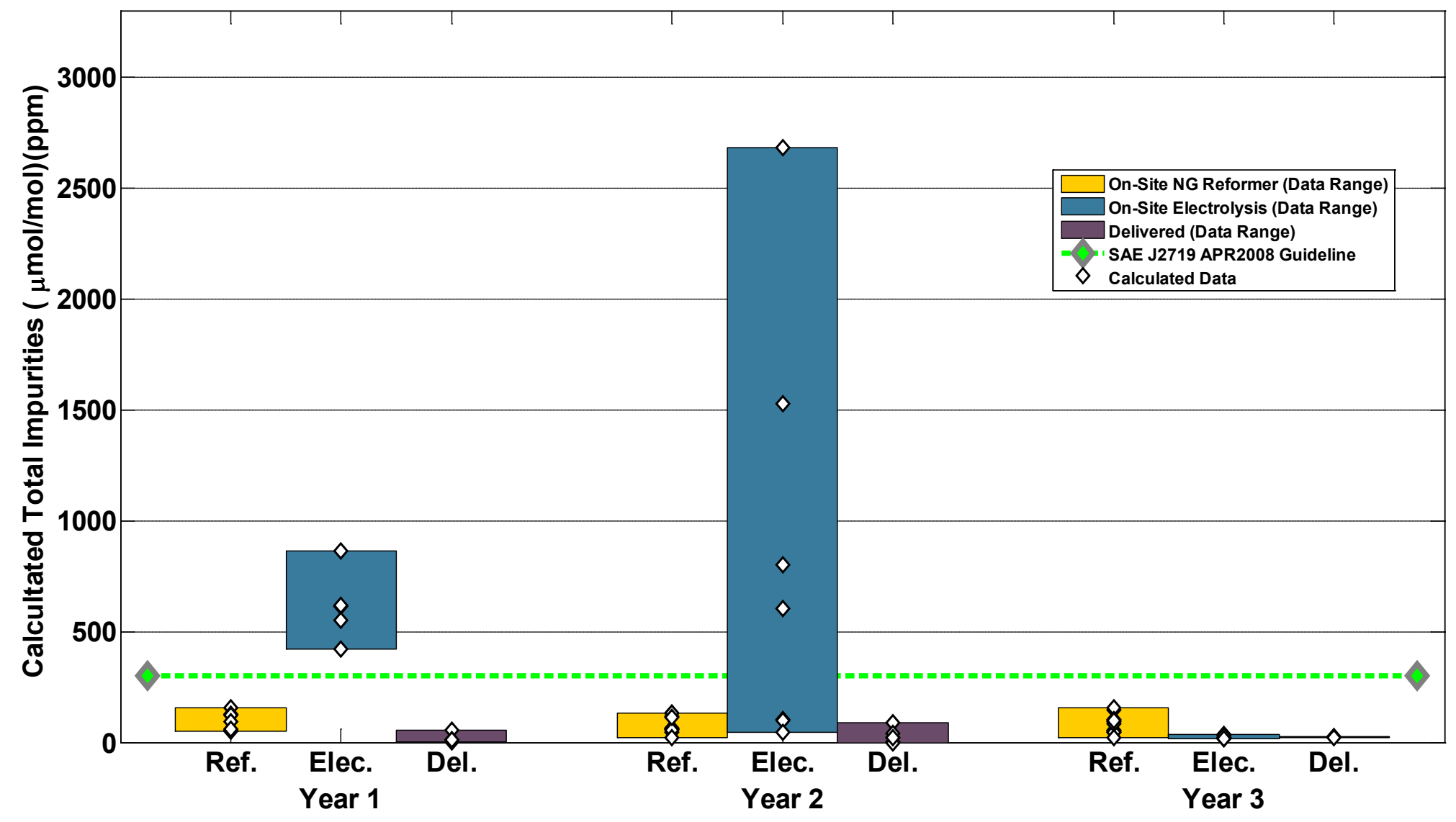

Data is from Learning Demonstration and California Fuel Cell Partnership testing

Year 1 is 2005Q3-2006Q2, Year 2 is 2006Q3-2007Q2, and Year 3 is 2007Q3-2008Q2 


\section{CDP\#28 Supplemental: Hydrogen}

\section{Impurities by Year and Production Method}

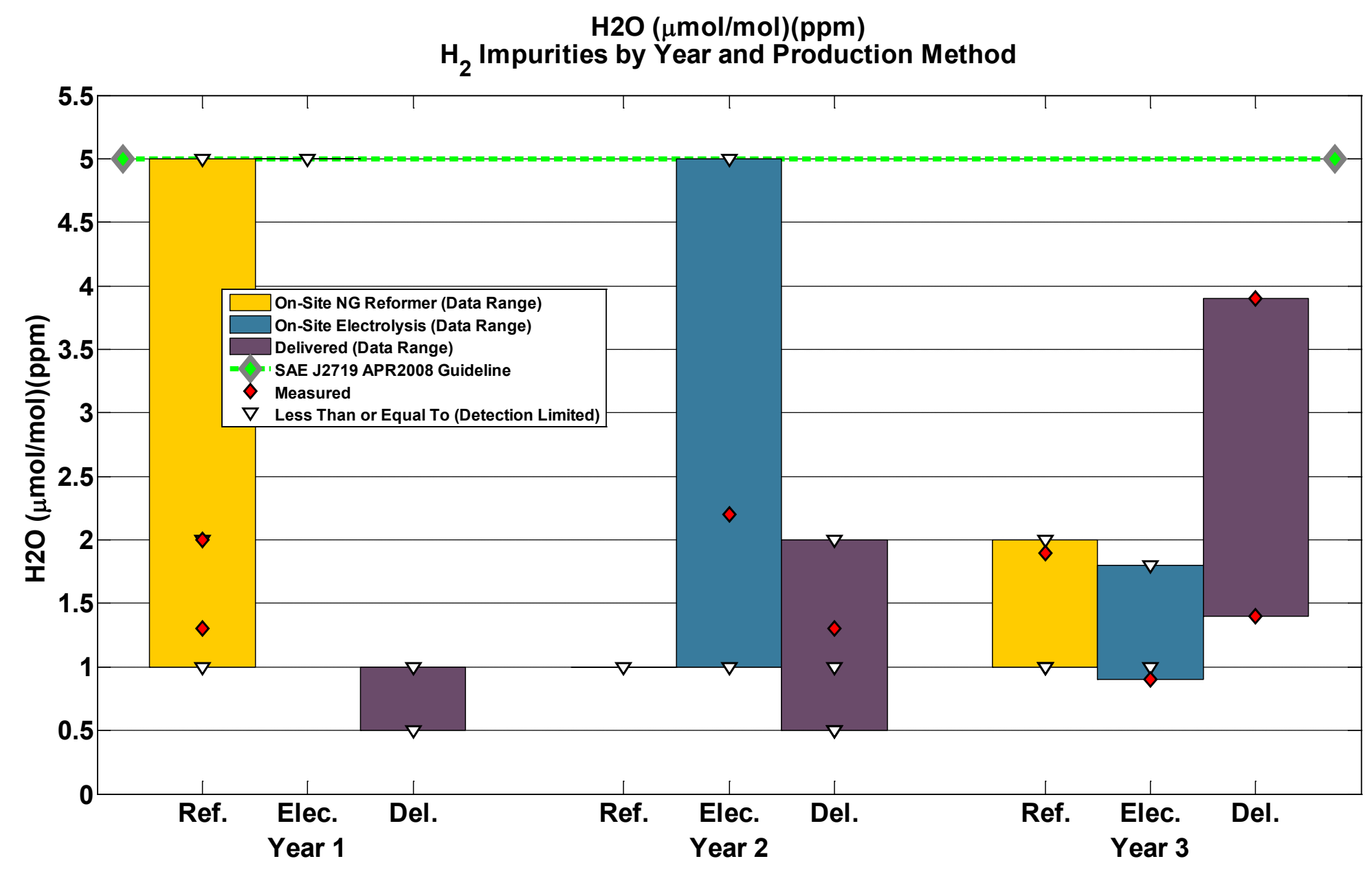

Data is from Learning Demonstration and California Fuel Cell Partnership testing Year 1 is 2005Q3-2006Q2, Year 2 is 2006Q3-2007Q2, and Year 3 is 2007Q3-2008Q2 


\section{CDP\#28 Supplemental: Hydrogen}

\section{Impurities by Year and Production Method}

Total HC $(\mu \mathrm{mol} / \mathrm{mol})(\mathrm{ppm})$

$\mathrm{H}_{2}$ Impurities by Year and Production Method

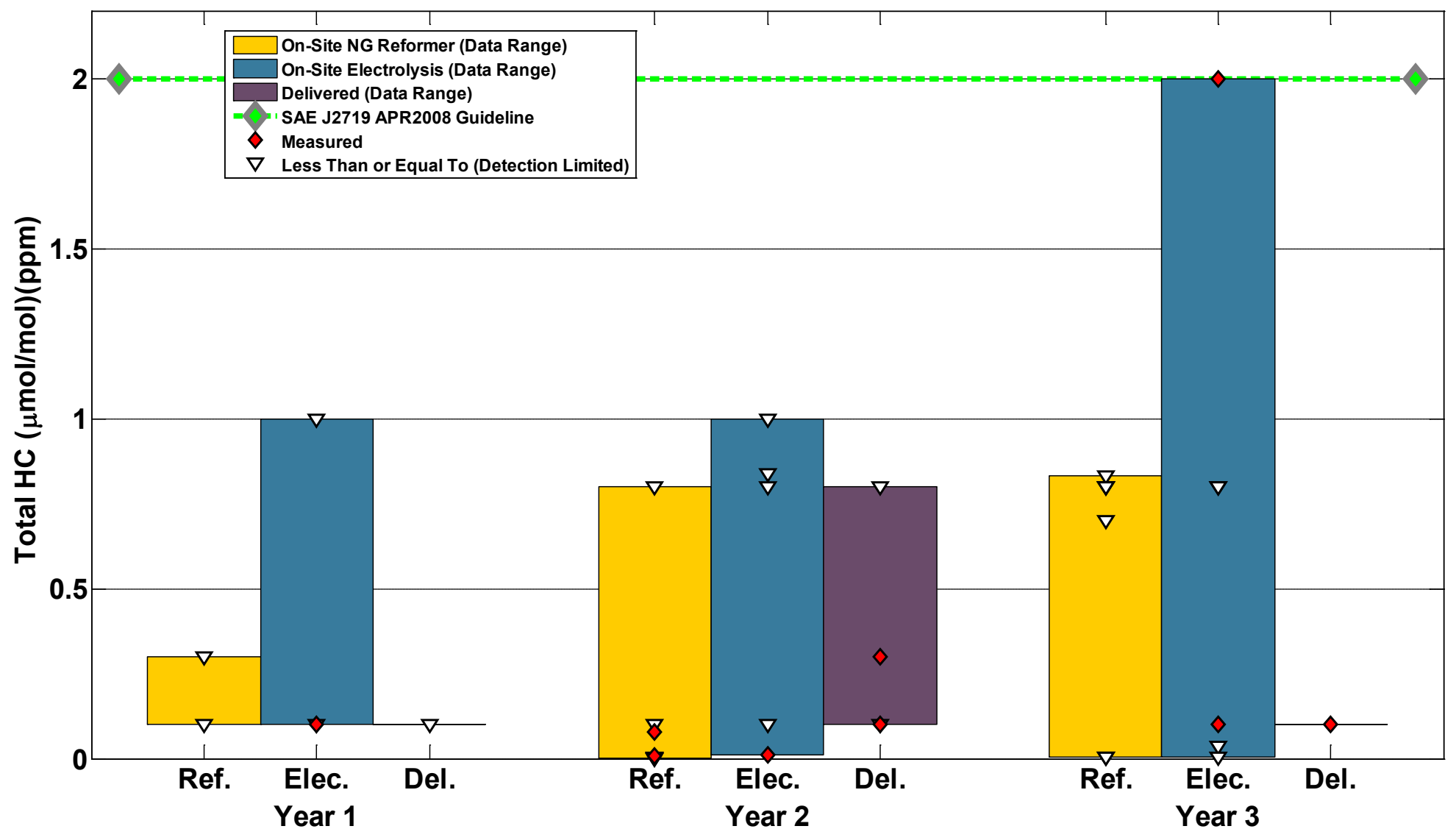

Data is from Learning Demonstration and California Fuel Cell Partnership testing Year 1 is 2005Q3-2006Q2, Year 2 is 2006Q3-2007Q2, and Year 3 is 2007Q3-2008Q2 


\section{CDP\#28 Supplemental: Hydrogen}

\section{Impurities by Year and Production Method}

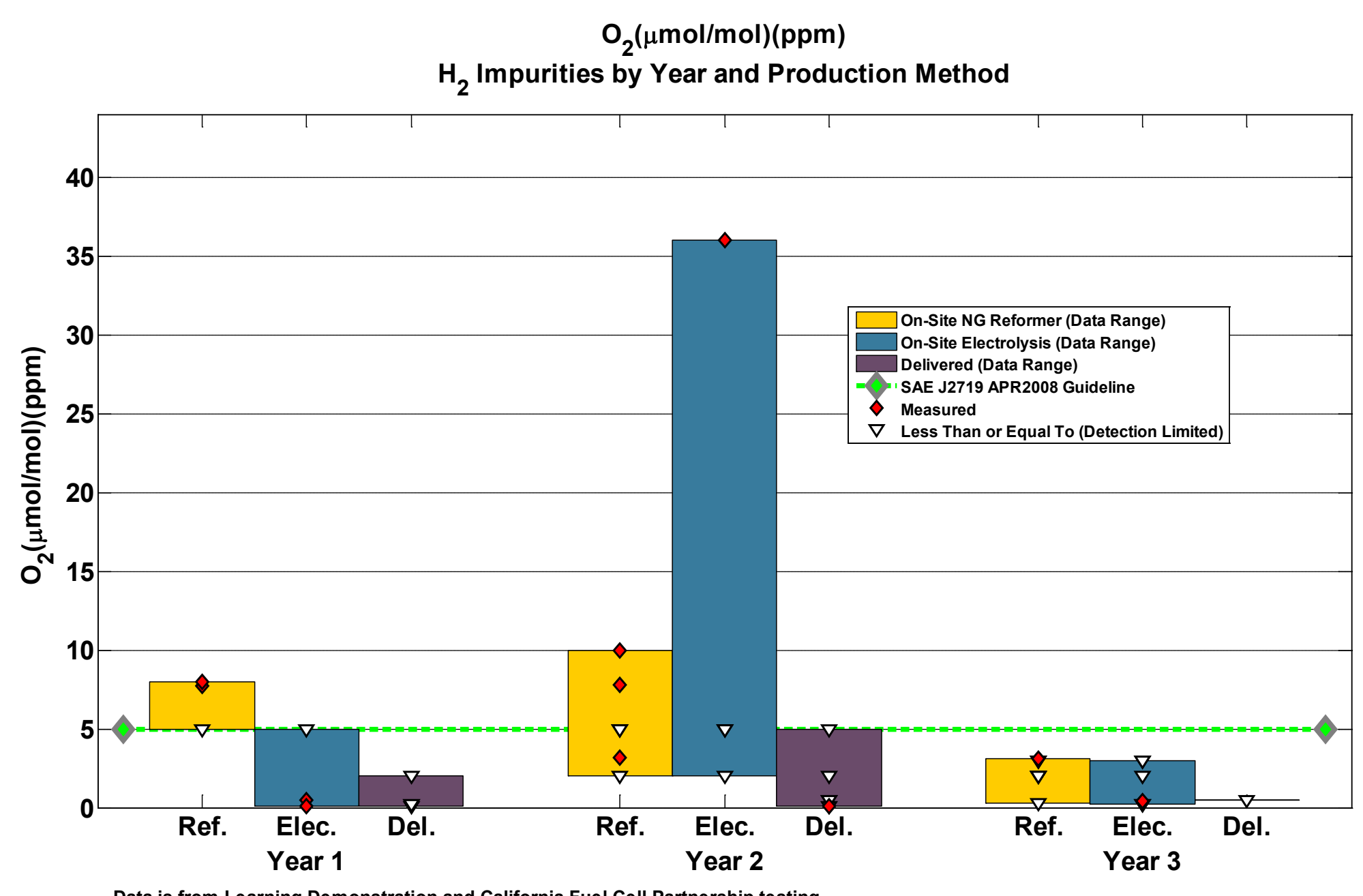

Data is from Learning Demonstration and California Fuel Cell Partnership testing

Year 1 is 2005Q3-2006Q2, Year 2 is 2006Q3-2007Q2, and Year 3 is 2007Q3-2008Q2 


\section{CDP\#28 Supplemental: Hydrogen}

\section{Impurities by Year and Production Method}

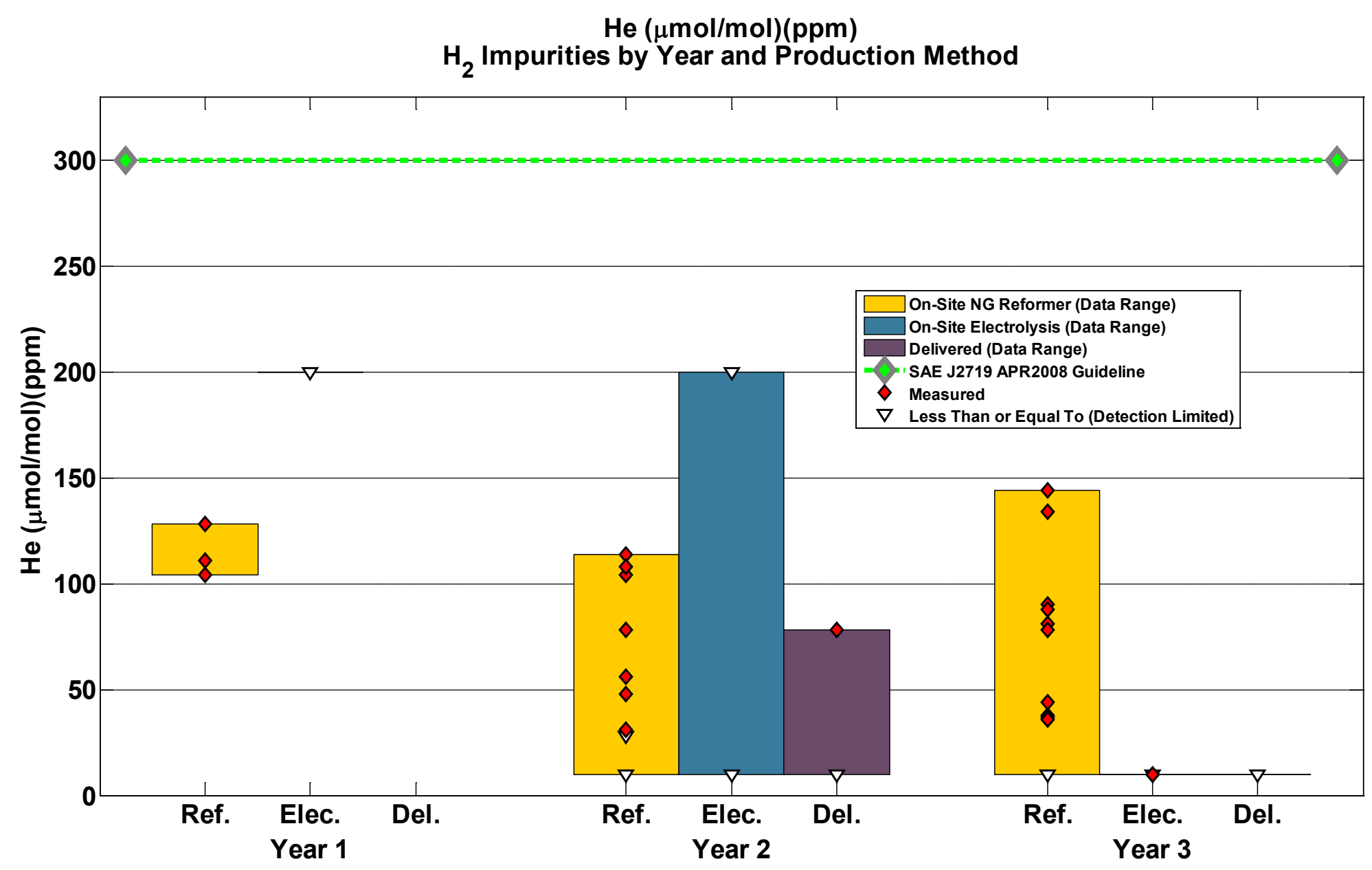

Data is from Learning Demonstration and California Fuel Cell Partnership testing

Year 1 is 2005Q3-2006Q2, Year 2 is 2006Q3-2007Q2, and Year 3 is 2007Q3-2008Q2 


\section{CDP\#28 Supplemental: Hydrogen}

\section{Impurities by Year and Production Method}

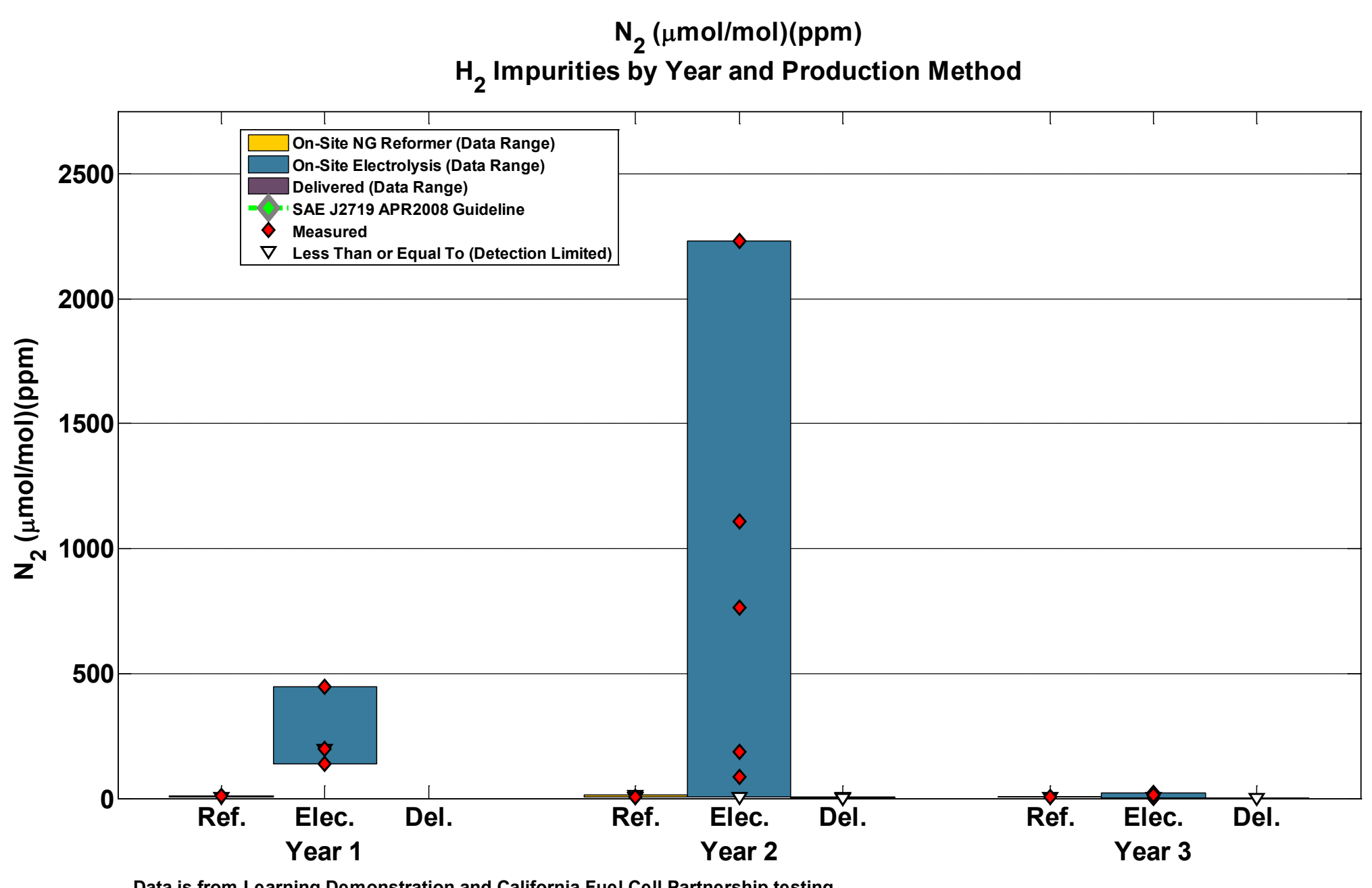

Data is from Learning Demonstration and California Fuel Cell Partnership testing

Year 1 is 2005Q3-2006Q2, Year 2 is 2006Q3-2007Q2, and Year 3 is 2007Q3-2008Q2 


\section{CDP\#28 Supplemental: Hydrogen}

\section{Impurities by Year and Production Method}

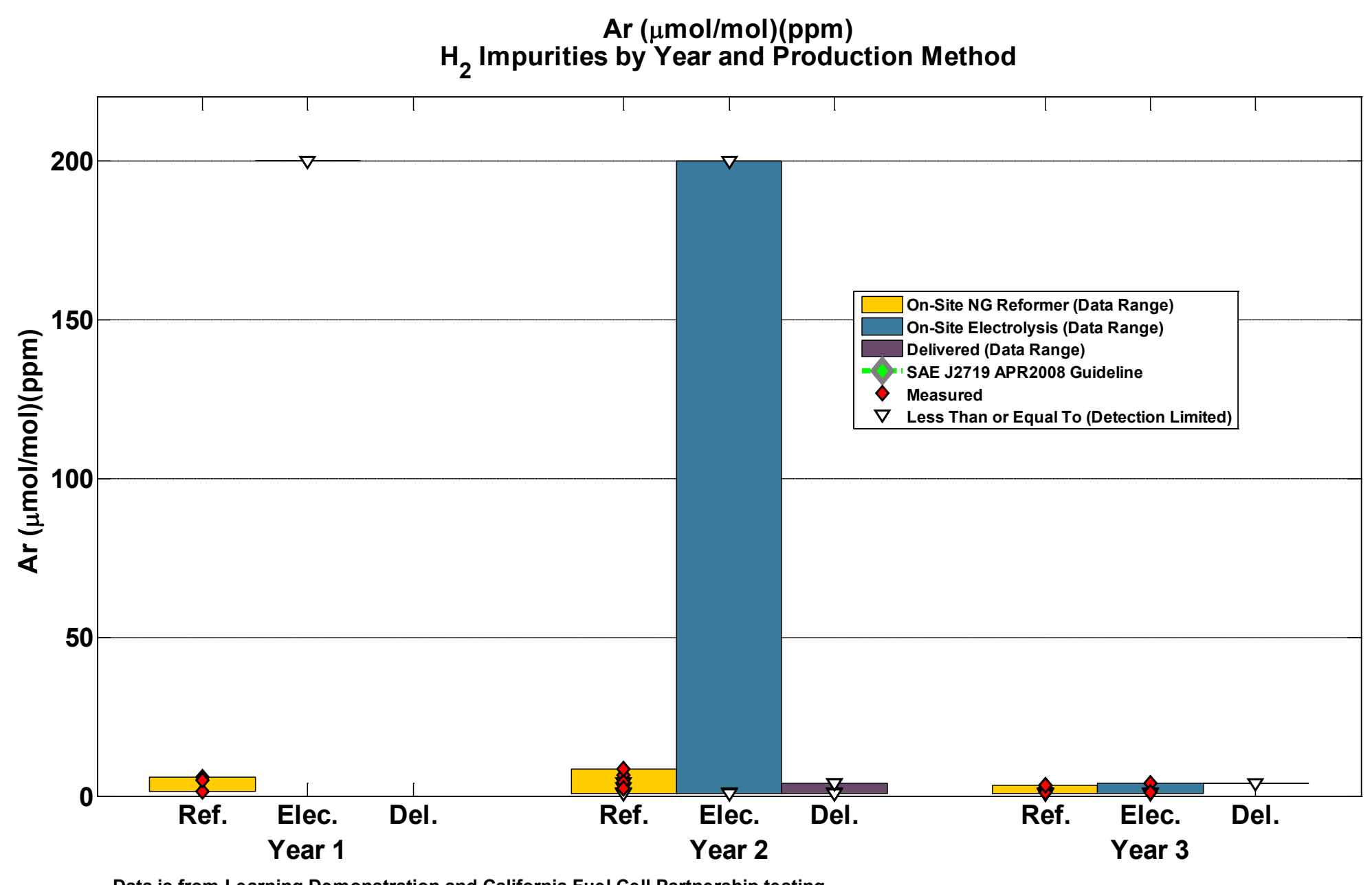

Data is from Learning Demonstration and California Fuel Cell Partnership testing

Year 1 is 2005Q3-2006Q2, Year 2 is 2006Q3-2007Q2, and Year 3 is 2007Q3-2008Q2 


\section{CDP\#28 Supplemental: Hydrogen}

\section{Impurities by Year and Production Method}

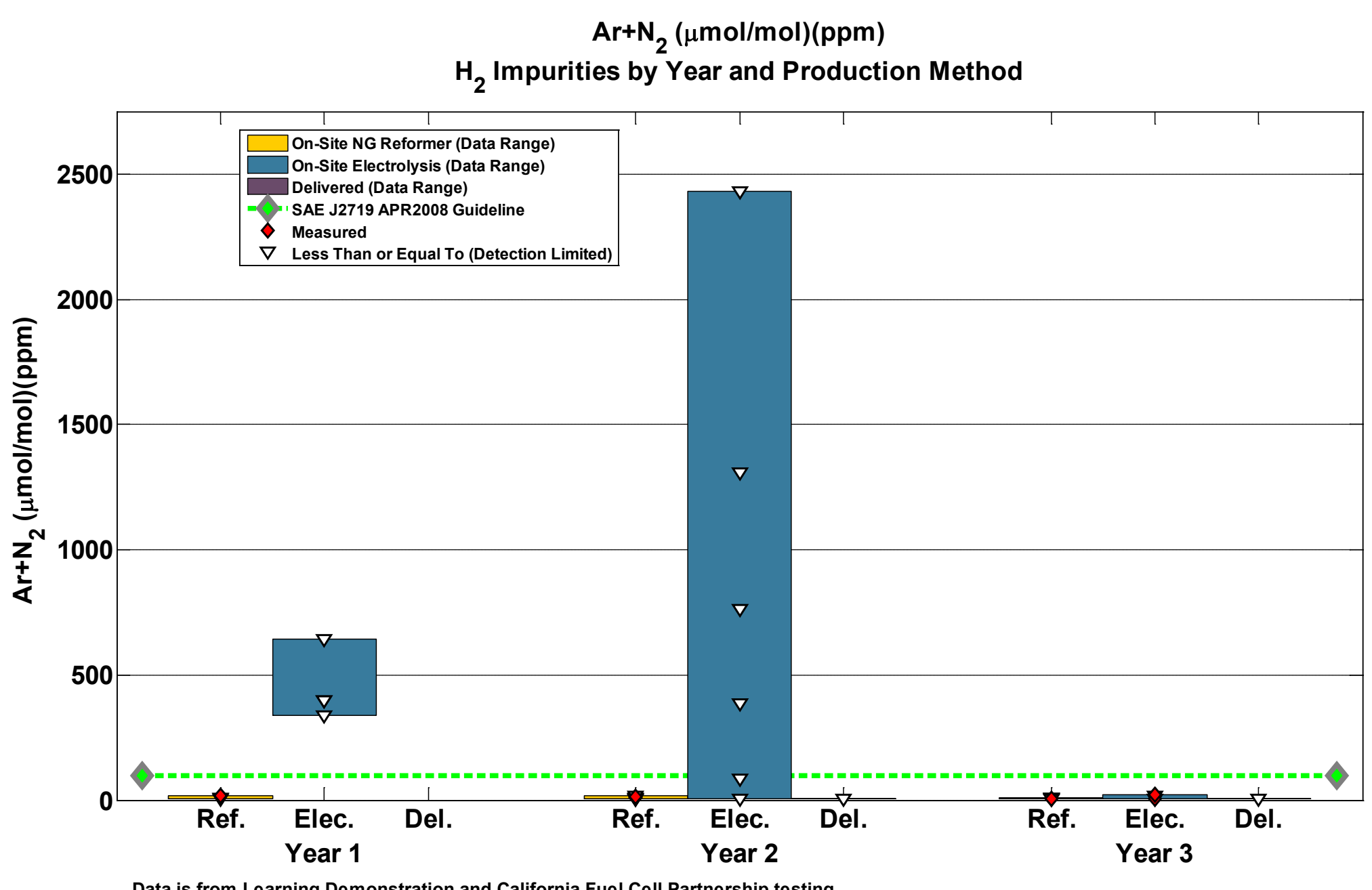

Data is from Learning Demonstration and California Fuel Cell Partnership testing

Year 1 is 2005Q3-2006Q2, Year 2 is 2006Q3-2007Q2, and Year 3 is 2007Q3-2008Q2 


\section{CDP\#28 Supplemental: Hydrogen}

\section{Impurities by Year and Production Method}

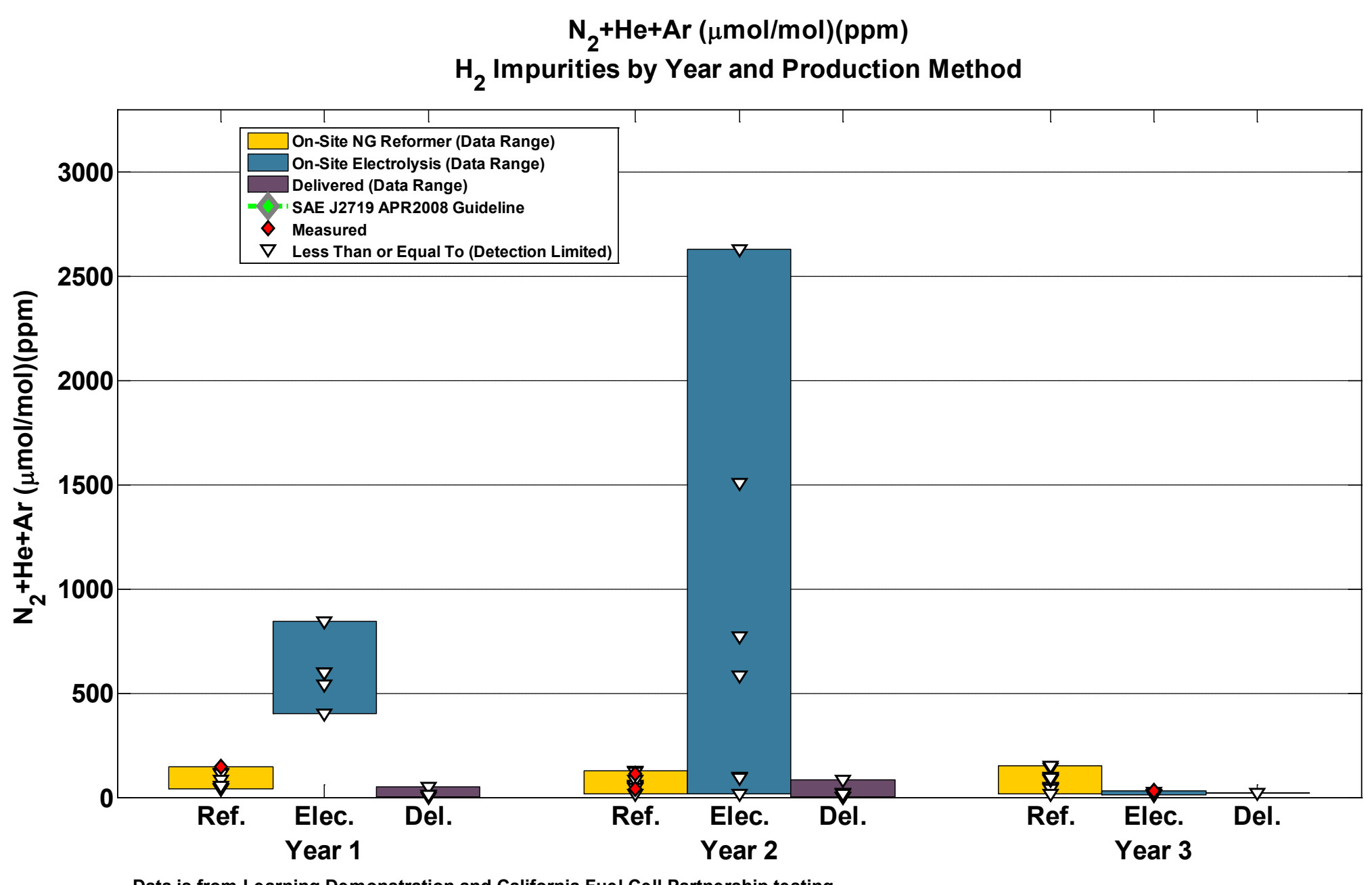

Data is from Learning Demonstration and California Fuel Cell Partnership testing

Year 1 is 2005Q3-2006Q2, Year 2 is 2006Q3-2007Q2, and Year 3 is 2007Q3-2008Q2 


\section{CDP\#28 Supplemental: Hydrogen}

\section{Impurities by Year and Production Method}

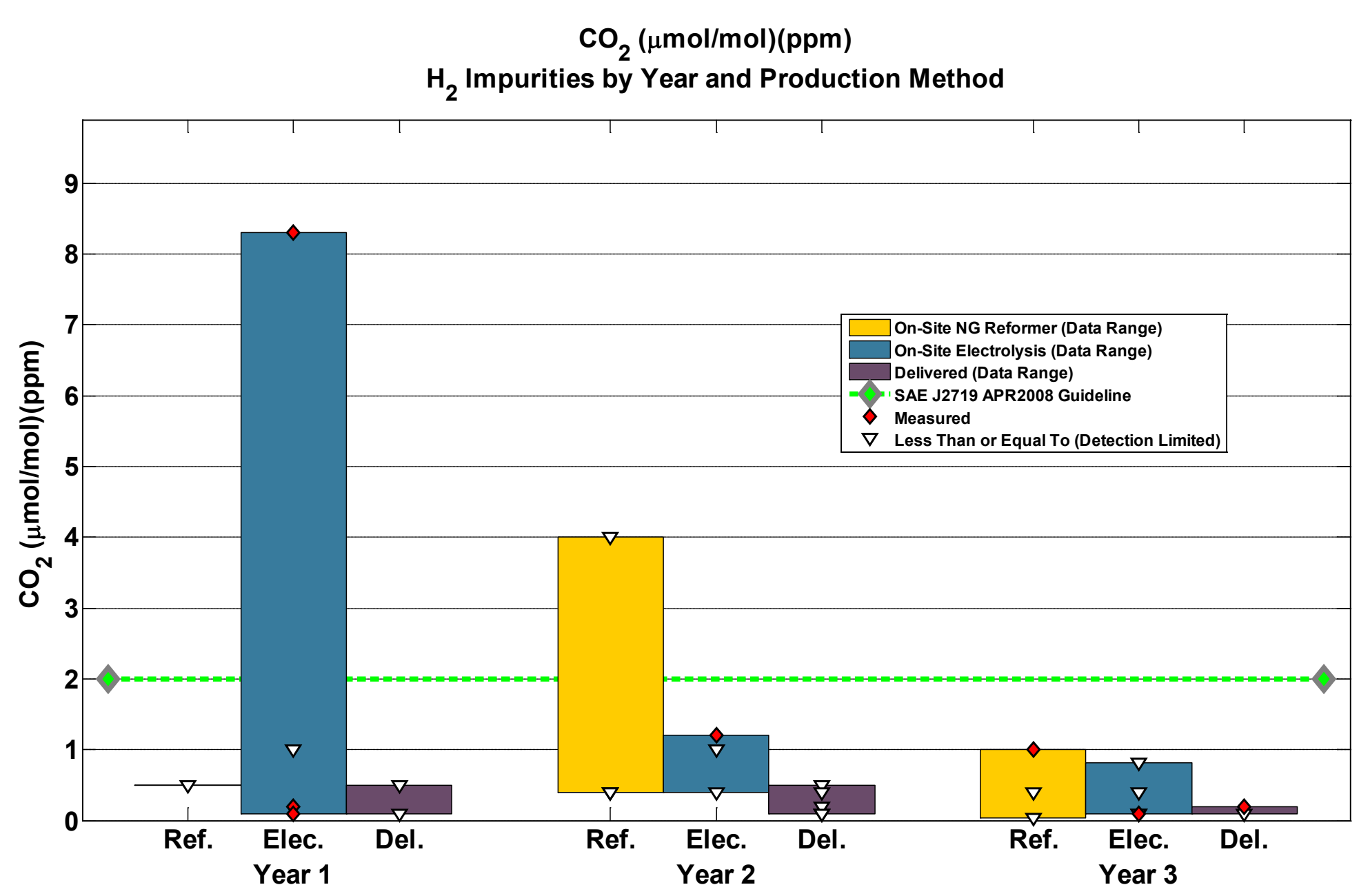

Data is from Learning Demonstration and California Fuel Cell Partnership testing

Year 1 is 2005Q3-2006Q2, Year 2 is 2006Q3-2007Q2, and Year 3 is 2007Q3-2008Q2 


\section{CDP\#28 Supplemental: Hydrogen}

\section{Impurities by Year and Production Method}

$\mathrm{CO}(\mu \mathrm{mol} / \mathrm{mol})(\mathrm{ppm})$
$\mathrm{H}_{2}$ Impurities by Year and Production Method

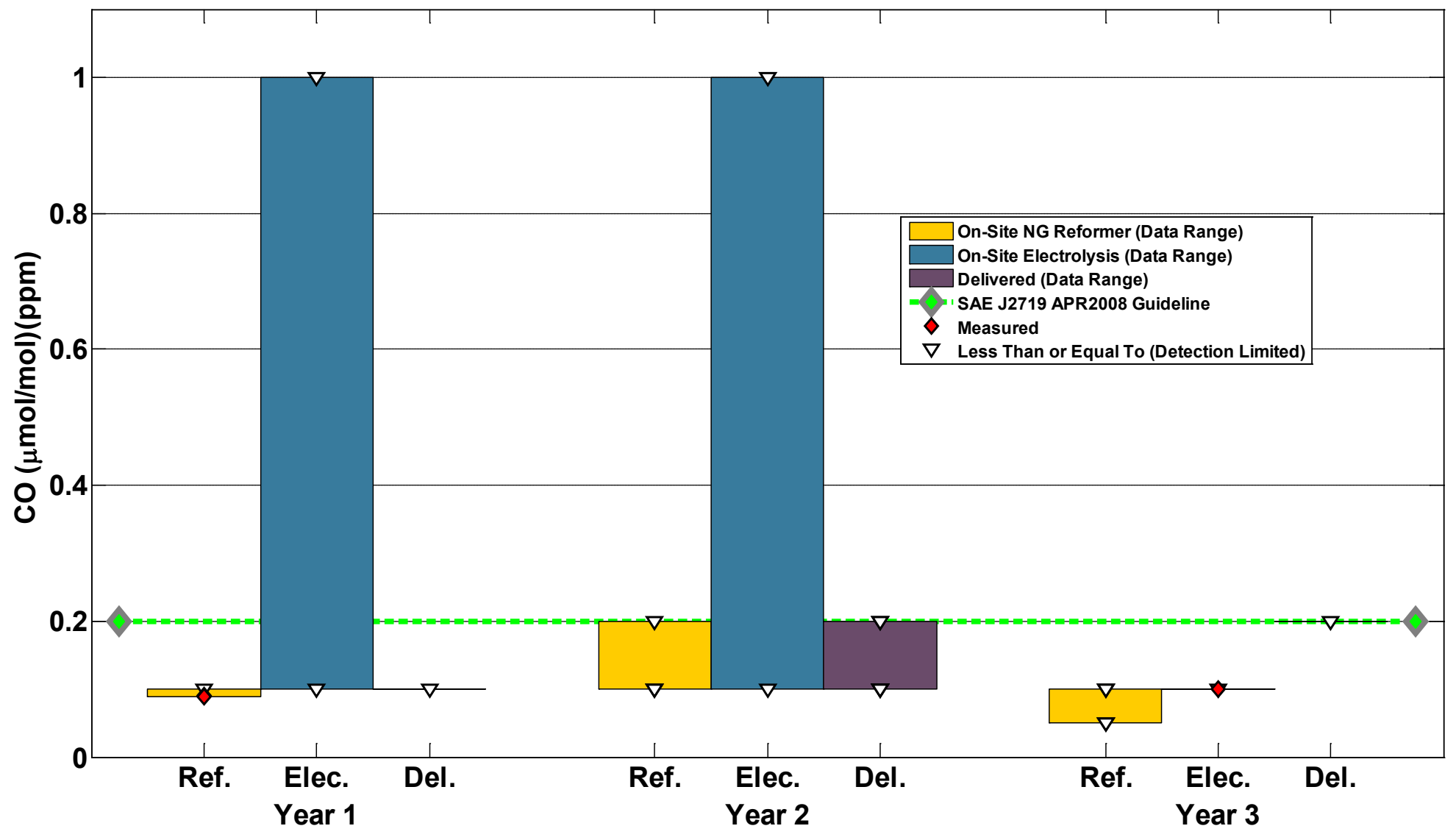

Data is from Learning Demonstration and California Fuel Cell Partnership testing Year 1 is 2005Q3-2006Q2, Year 2 is 2006Q3-2007Q2, and Year 3 is 2007Q3-2008Q2 


\section{CDP\#28 Supplemental: Hydrogen}

\section{Impurities by Year and Production Method}

Total $\mathrm{S}^{*}(\mathrm{nmol} / \mathrm{mol})(\mathrm{ppb})$

$\mathrm{H}_{2}$ Impurities by Year and Production Method

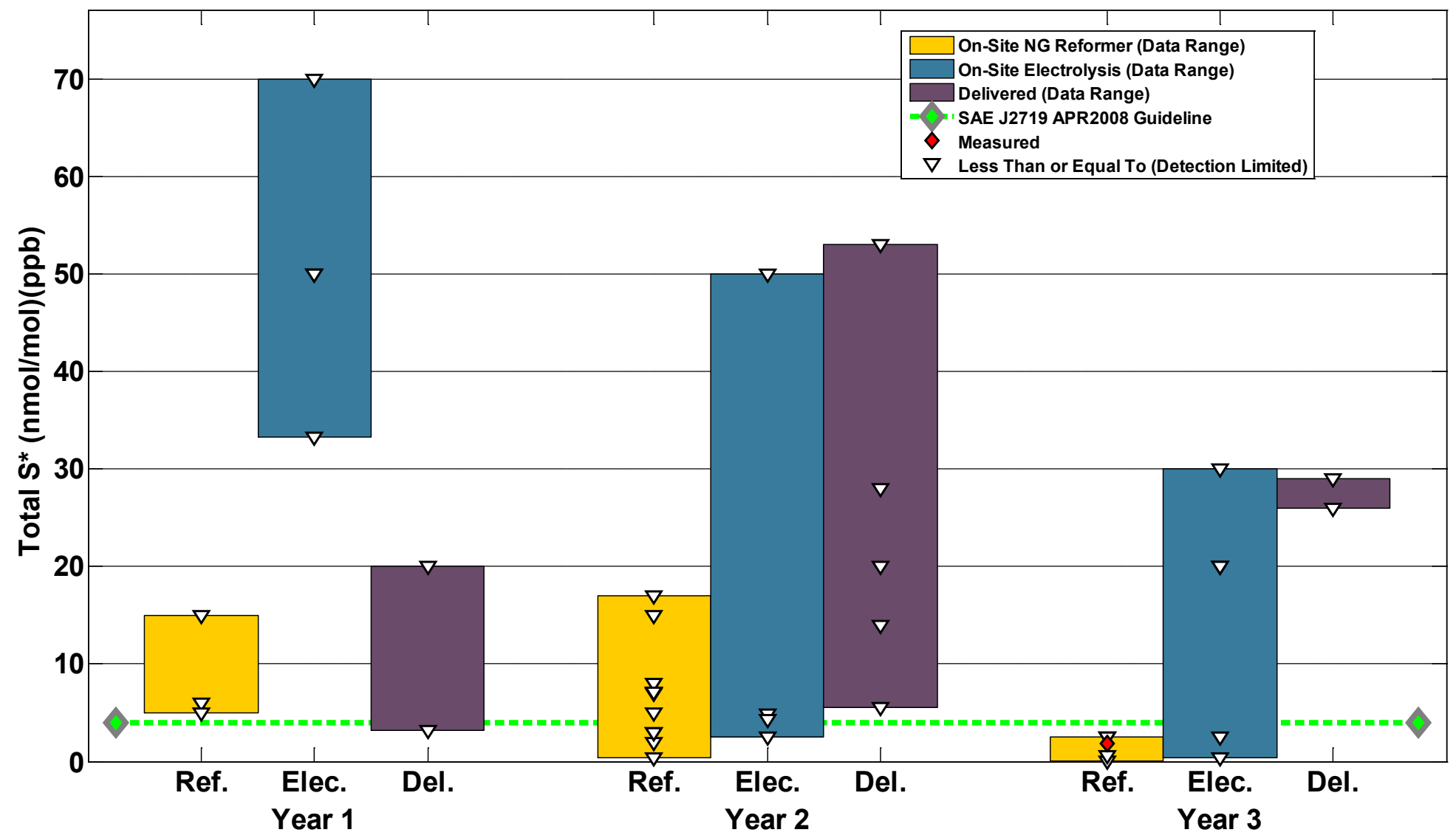

Data is from Learning Demonstration and California Fuel Cell Partnership testing

Year 1 is 2005Q3-2006Q2, Year 2 is 2006Q3-2007Q2, and Year 3 is 2007Q3-2008Q2

*Total S calculated from SO2, COS, H2S, CS2, and Methyl Mercaptan (CH3SH). 


\section{CDP\#28 Supplemental: Hydrogen}

\section{Impurities by Year and Production Method}

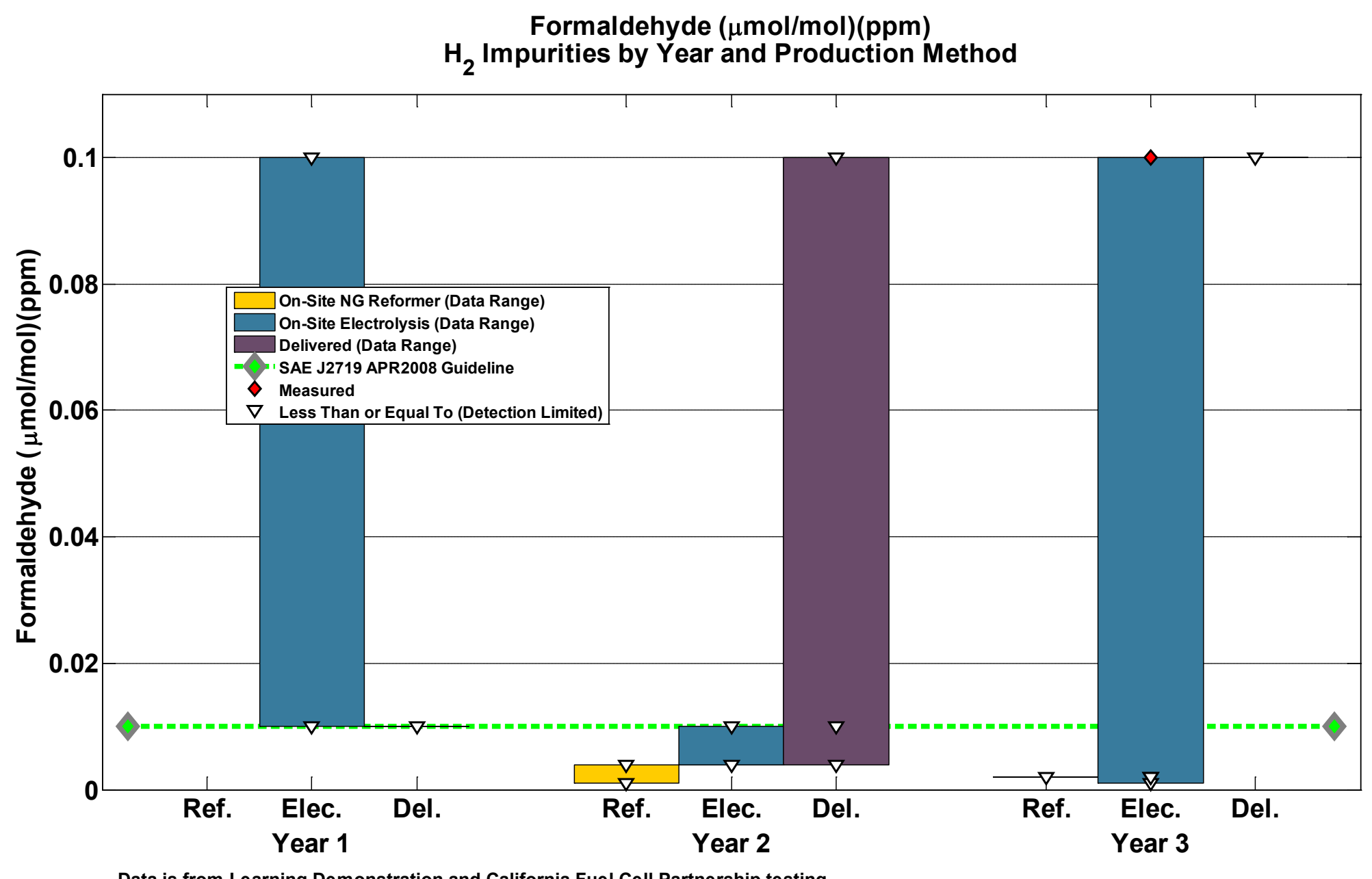

Data is from Learning Demonstration and California Fuel Cell Partnership testing

Year 1 is 2005Q3-2006Q2, Year 2 is 2006Q3-2007Q2, and Year 3 is 2007Q3-2008Q2 


\section{CDP\#28 Supplemental: Hydrogen}

\section{Impurities by Year and Production Method}

Formic acid ( $\mu \mathrm{mol} / \mathrm{mol})(\mathrm{ppm})$
$\mathrm{H}_{2}$ Impurities by Year and Production Method

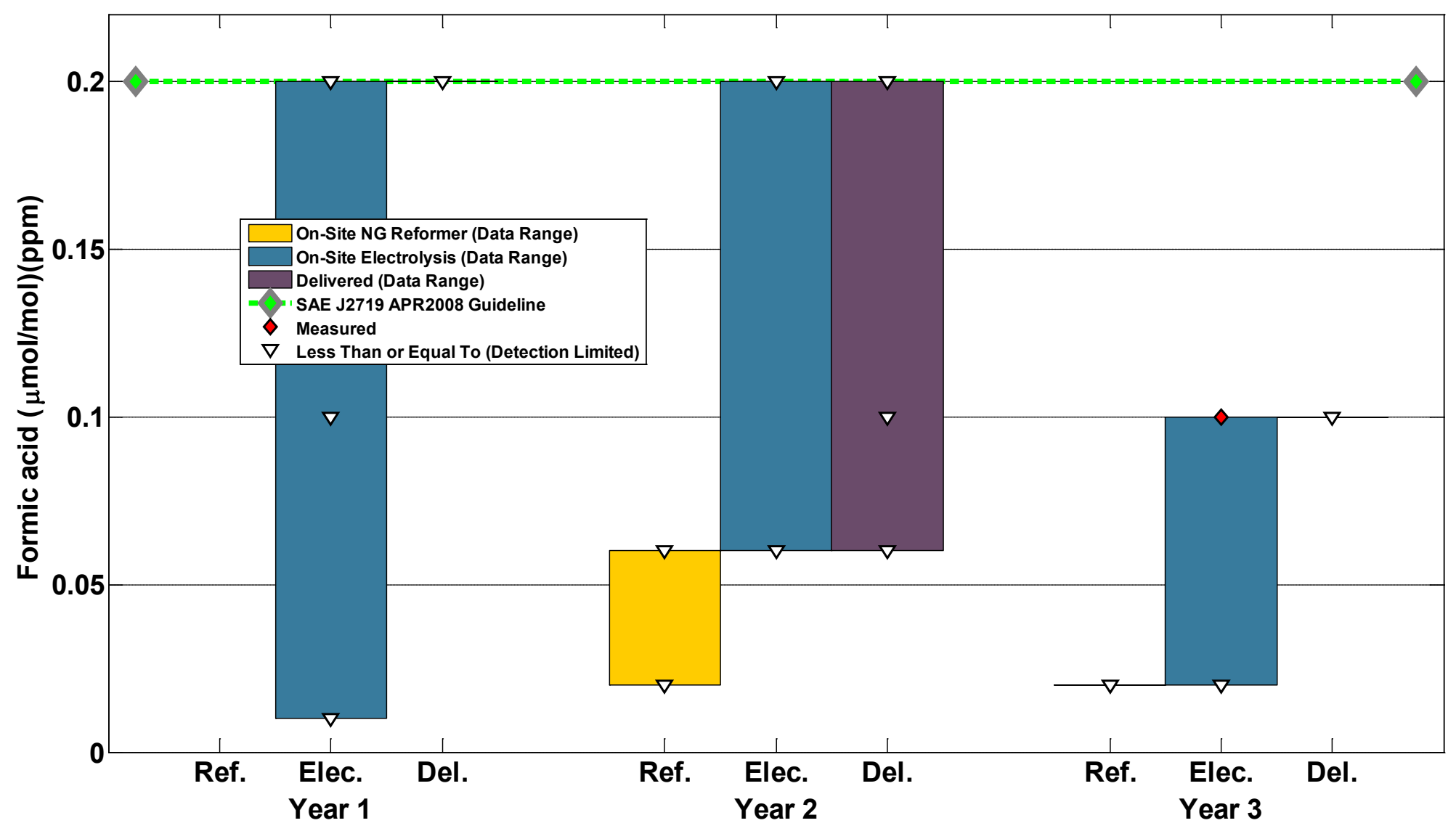

Data is from Learning Demonstration and California Fuel Cell Partnership testing Year 1 is 2005Q3-2006Q2, Year 2 is 2006Q3-2007Q2, and Year 3 is 2007Q3-2008Q2 


\section{CDP\#28 Supplemental: Hydrogen}

\section{Impurities by Year and Production Method}

$\mathrm{NH} 3(\mu \mathrm{mol} / \mathrm{mol})(\mathrm{ppm})$
$\mathrm{H}_{2}$ Impurities by Year and Production Method

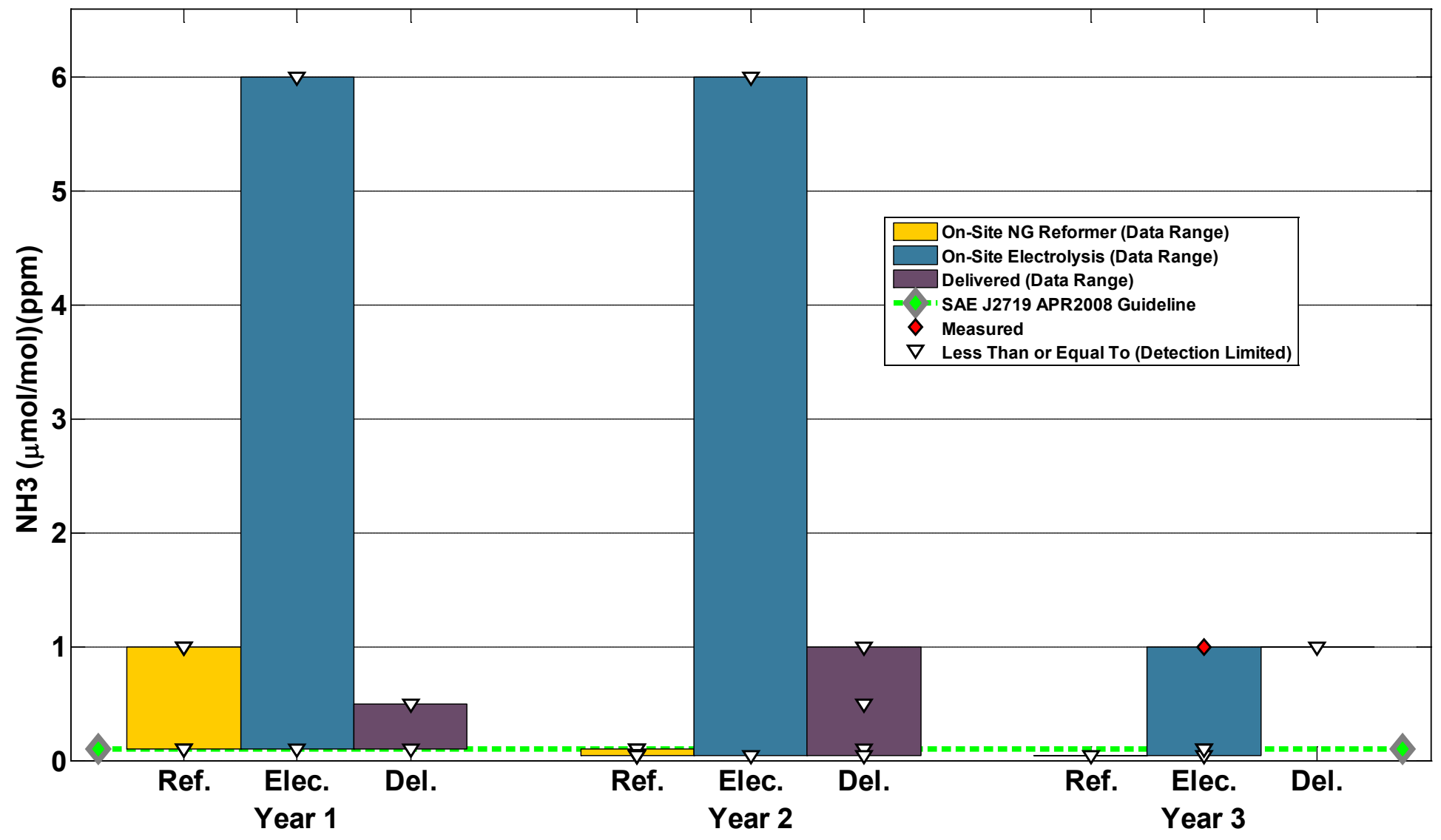

Data is from Learning Demonstration and California Fuel Cell Partnership testing Year 1 is 2005Q3-2006Q2, Year 2 is 2006Q3-2007Q2, and Year 3 is 2007Q3-2008Q2 


\section{CDP\#28 Supplemental: Hydrogen}

\section{Impurities by Year and Production Method}

\section{Total Halogenates $(\mu \mathrm{mol} / \mathrm{mol})(\mathrm{ppm})$ \\ $\mathrm{H}_{2}$ Impurities by Year and Production Method}

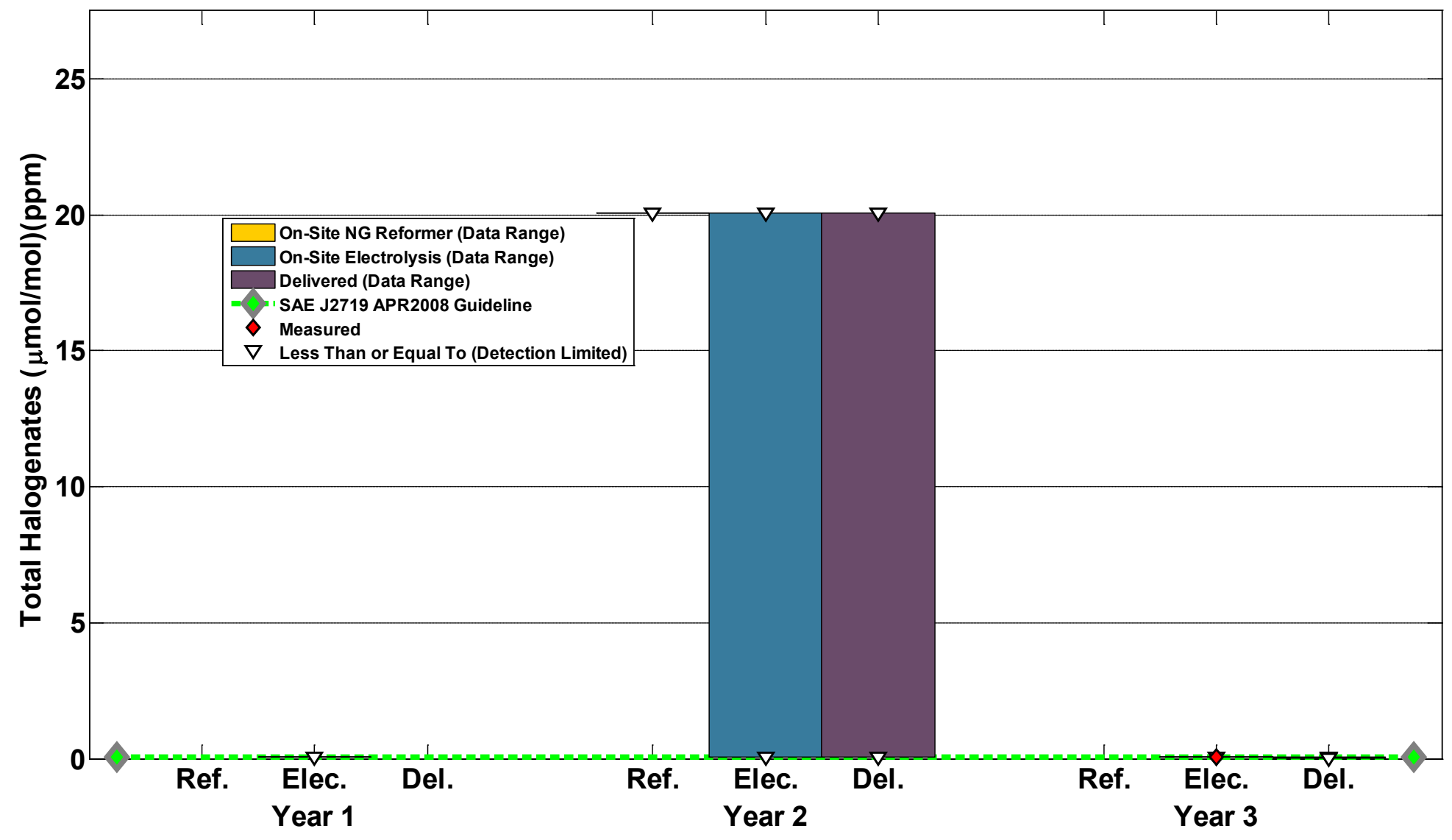

Data is from Learning Demonstration and California Fuel Cell Partnership testing

Year 1 is 2005Q3-2006Q2, Year 2 is 2006Q3-2007Q2, and Year 3 is 2007Q3-2008Q2 


\section{CDP\#28 Supplemental: Hydrogen}

\section{Impurities by Year and Production Method}

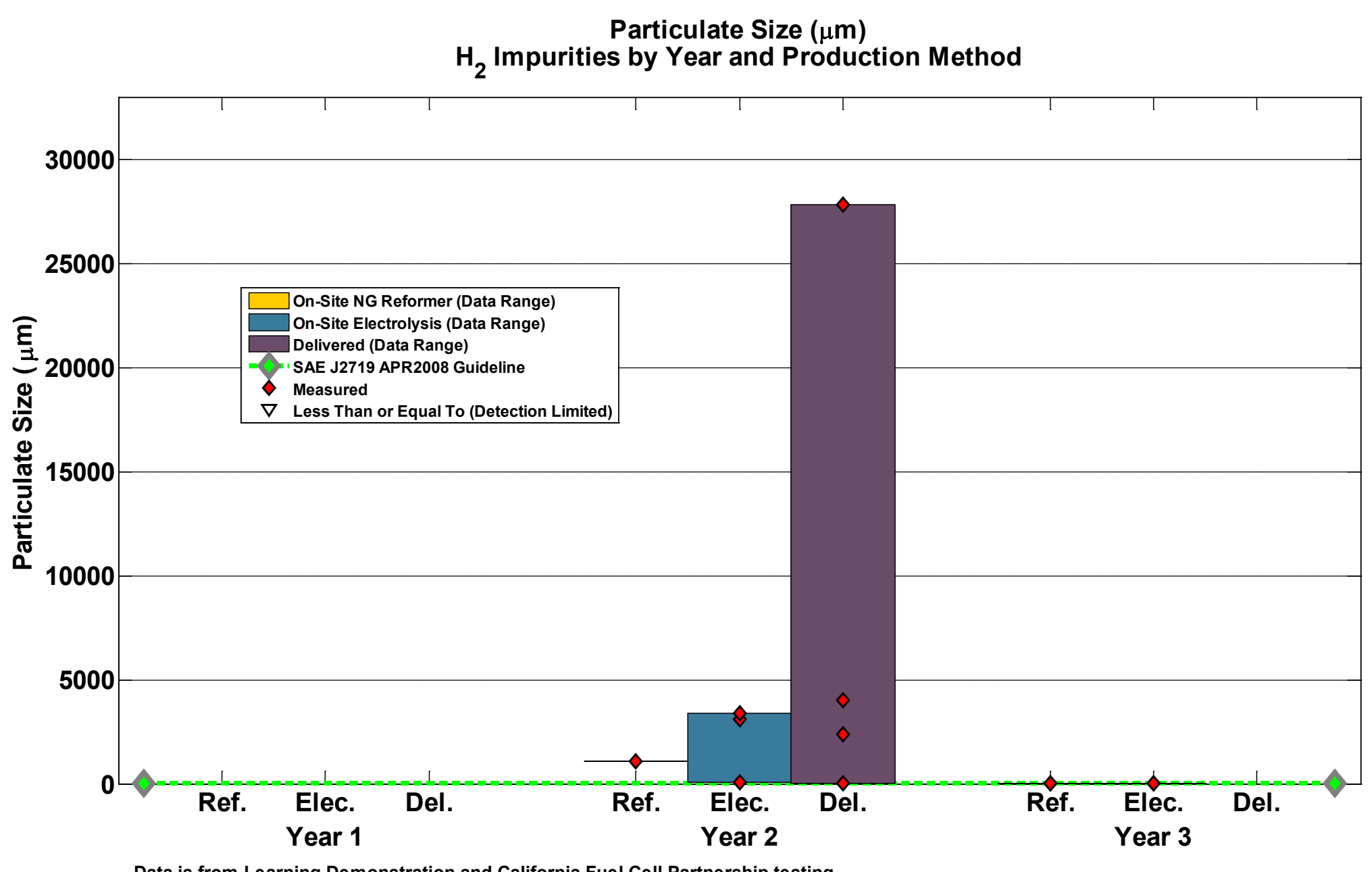

Data is from Learning Demonstration and California Fuel Cell Partnership testing

Year 1 is 2005Q3-2006Q2, Year 2 is 2006Q3-2007Q2, and Year 3 is 2007Q3-2008Q2 


\section{CDP\#29: Fueling Rates - Communication and Non-Communication Fills}

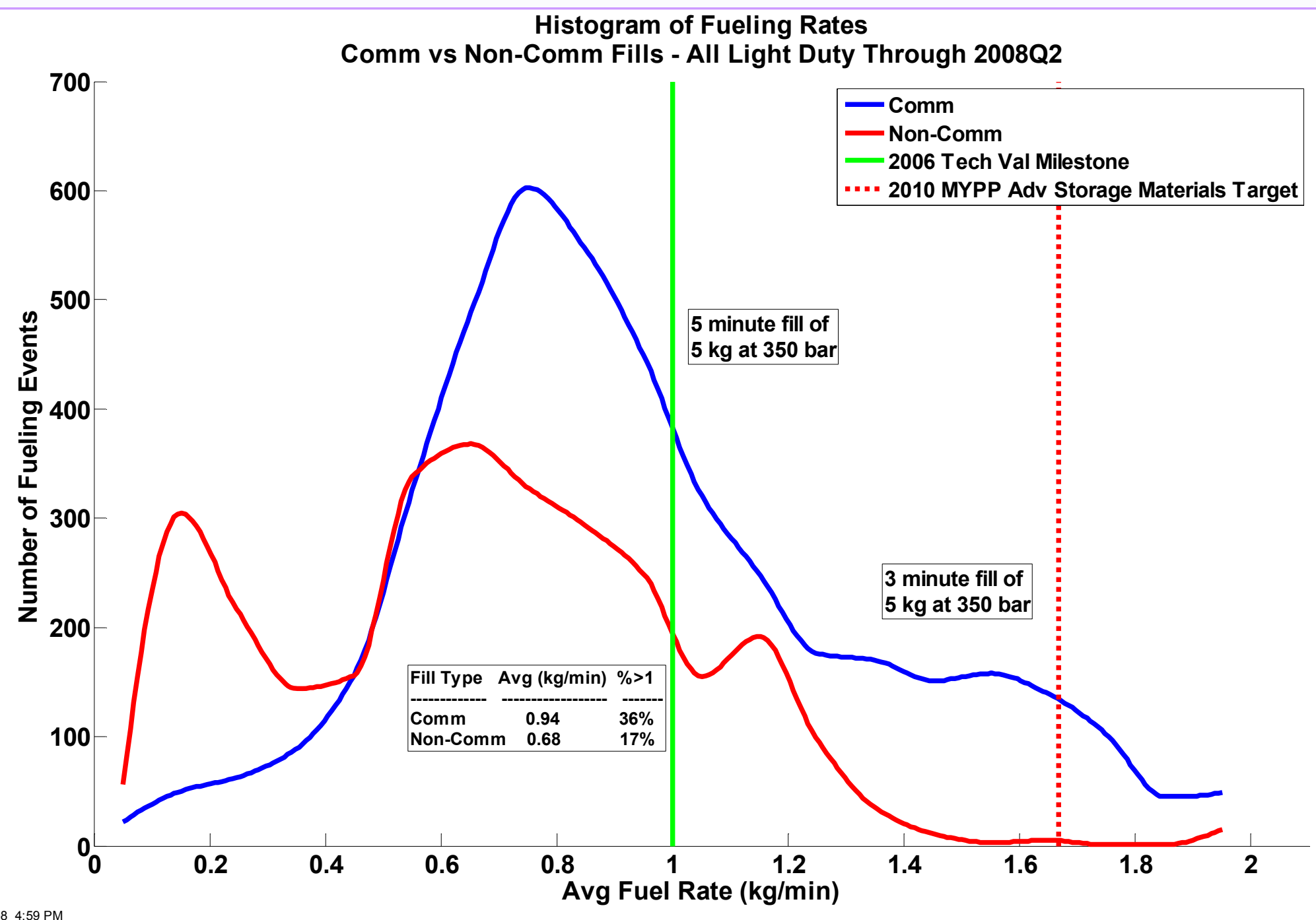




\section{CDP\#30: Infrastructure Maintenance}

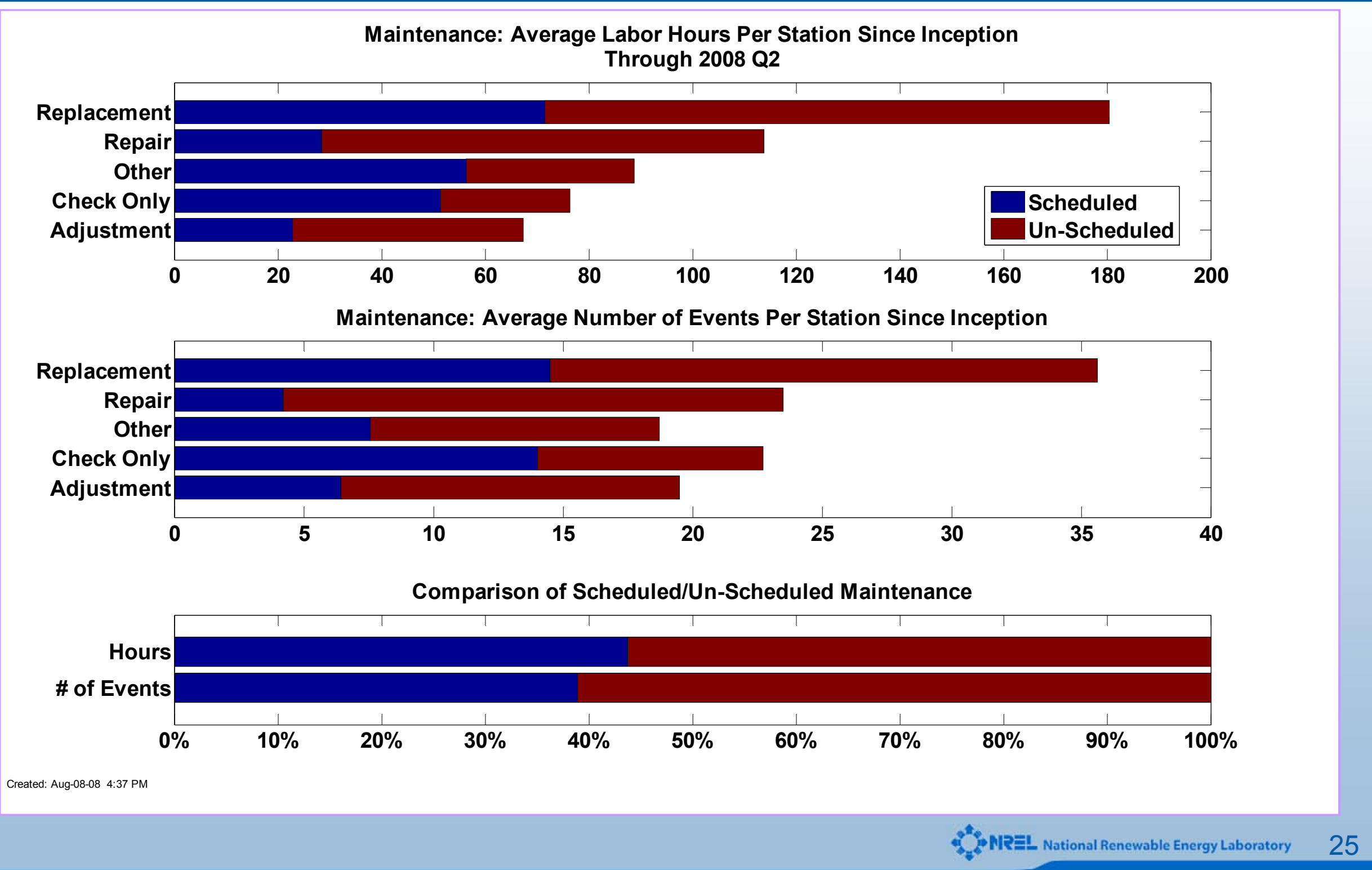




\section{CDP\#31: Number of Reporting Stations}

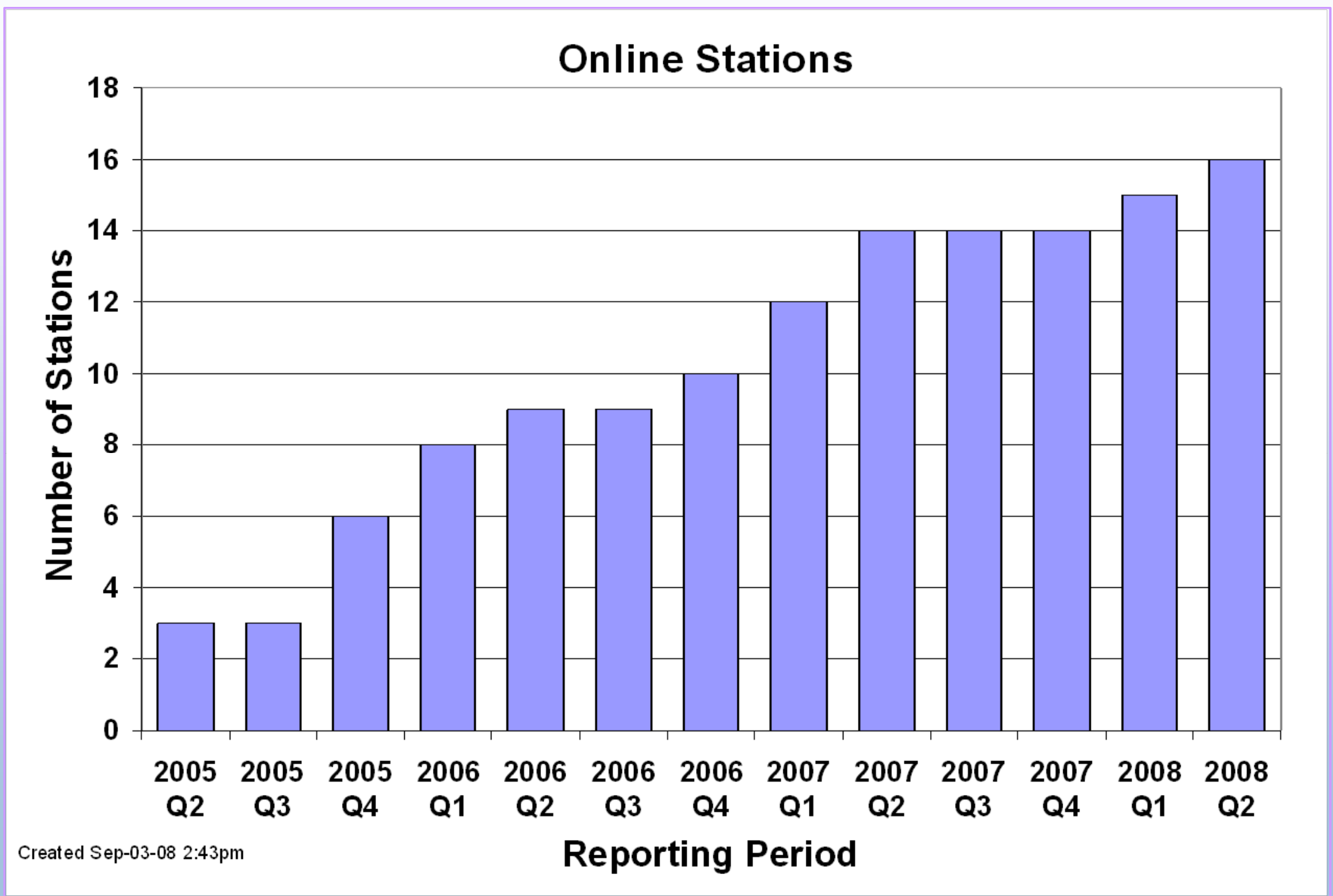




\section{CDP\#32: Infrastructure Hydrogen Production Methods}

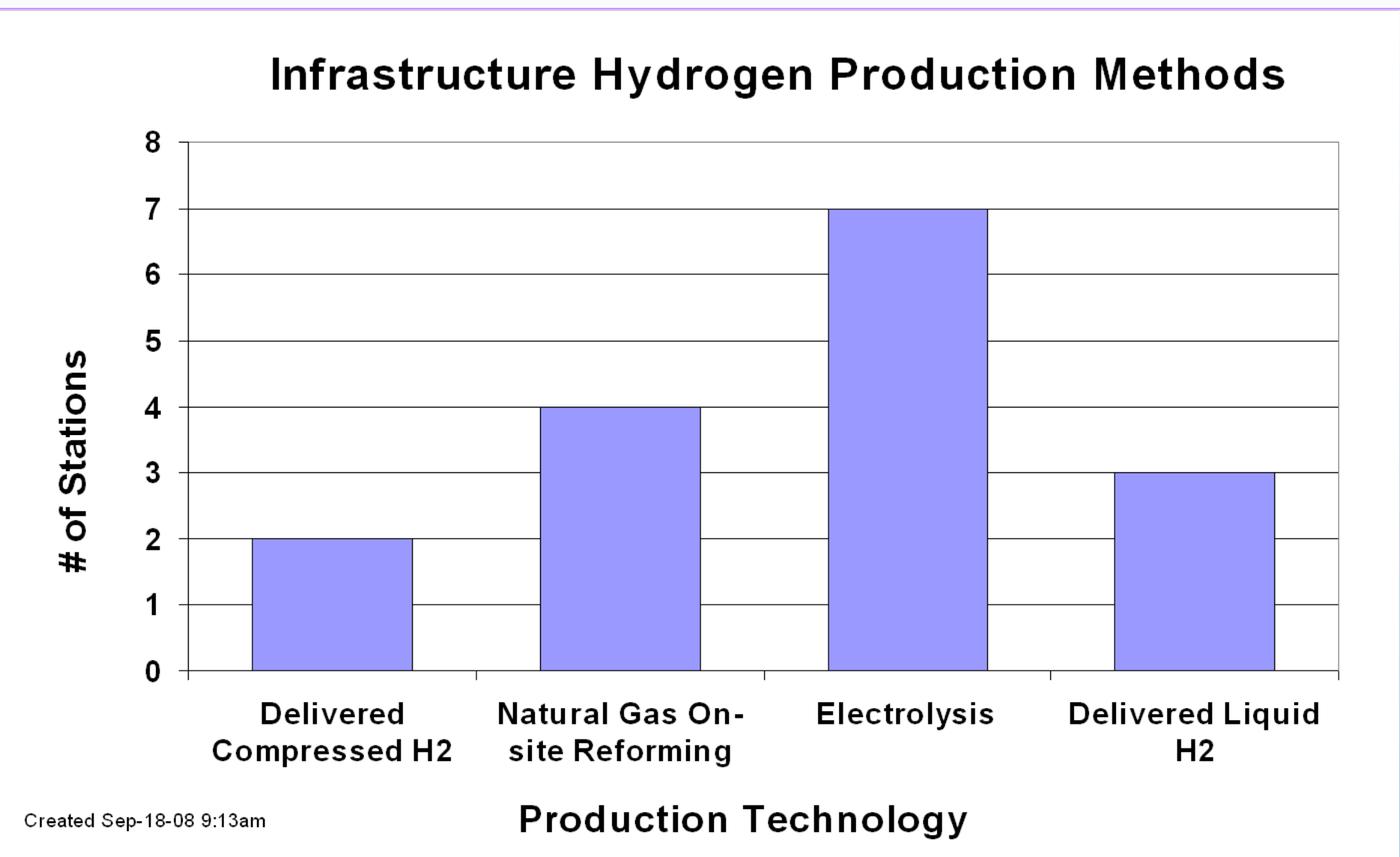




\section{CDP\#33: Percentage of Theoretical Range Traveled Between Refuelings}

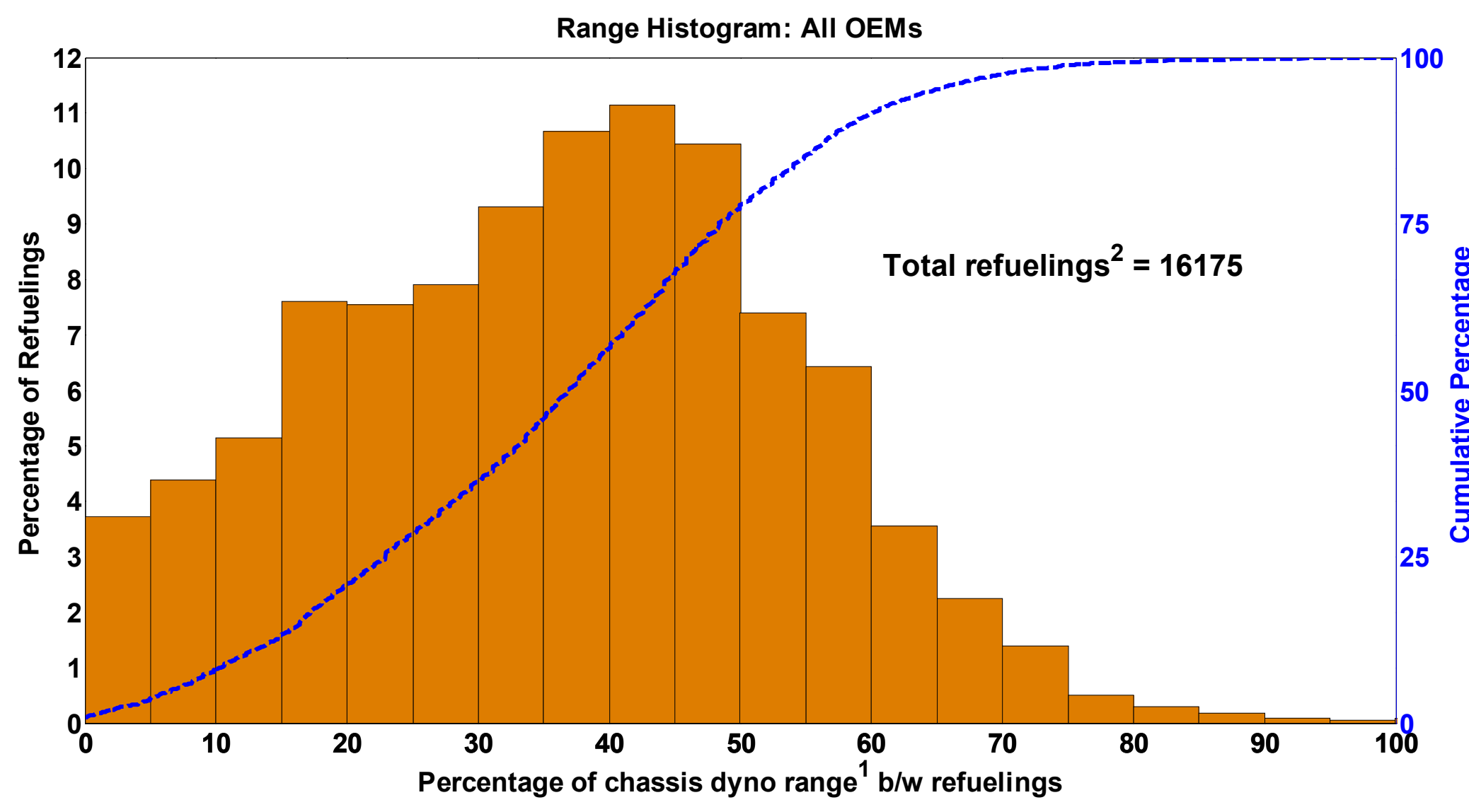

1. Range calculated using the combined City/Hwy fuel economy from dyno testing (not EPA adjusted) and usable fuel on board.

2. Some refueling events are not detected/reported due to data noise or incompleteness. 


\section{CDP\#34: Effective Vehicle Range}

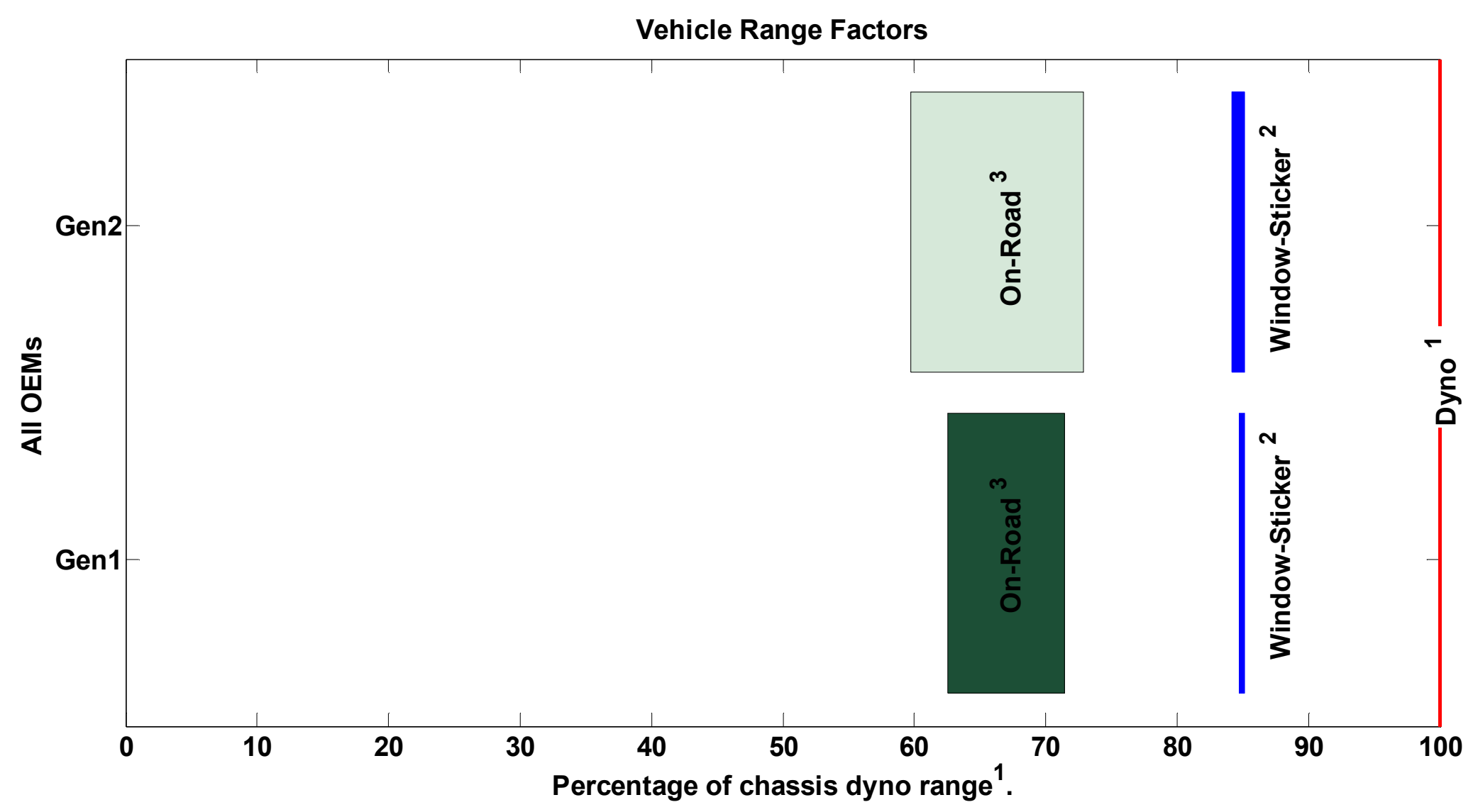

1. Calculated using the combined City/Hwy fuel economy from dyno testing (non-adjusted) and usable fuel on board.

2. Applying window-sticker correction factors for fuel economy: $0.78 \times$ Hwy and $0.9 \times$ City.

3. Using fuel economy from on-road data (excluding trips $>1$ mile, consistent with other data products). 


\section{CDP\#35: Average Refuelings Between Infrastructure Safety Reports}

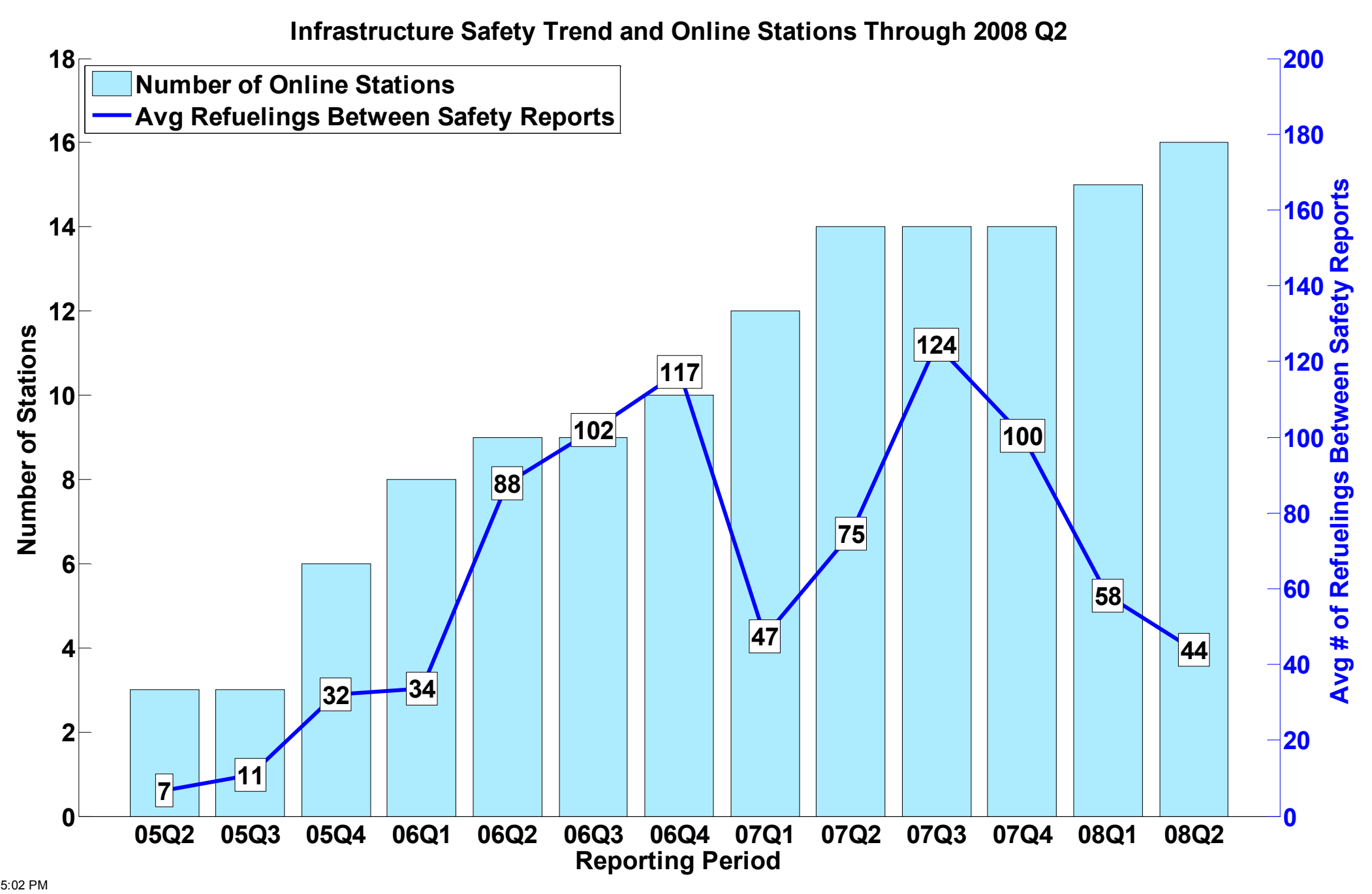




\section{CDP\#36: Type of Infrastructure Safety Report By Quarter}

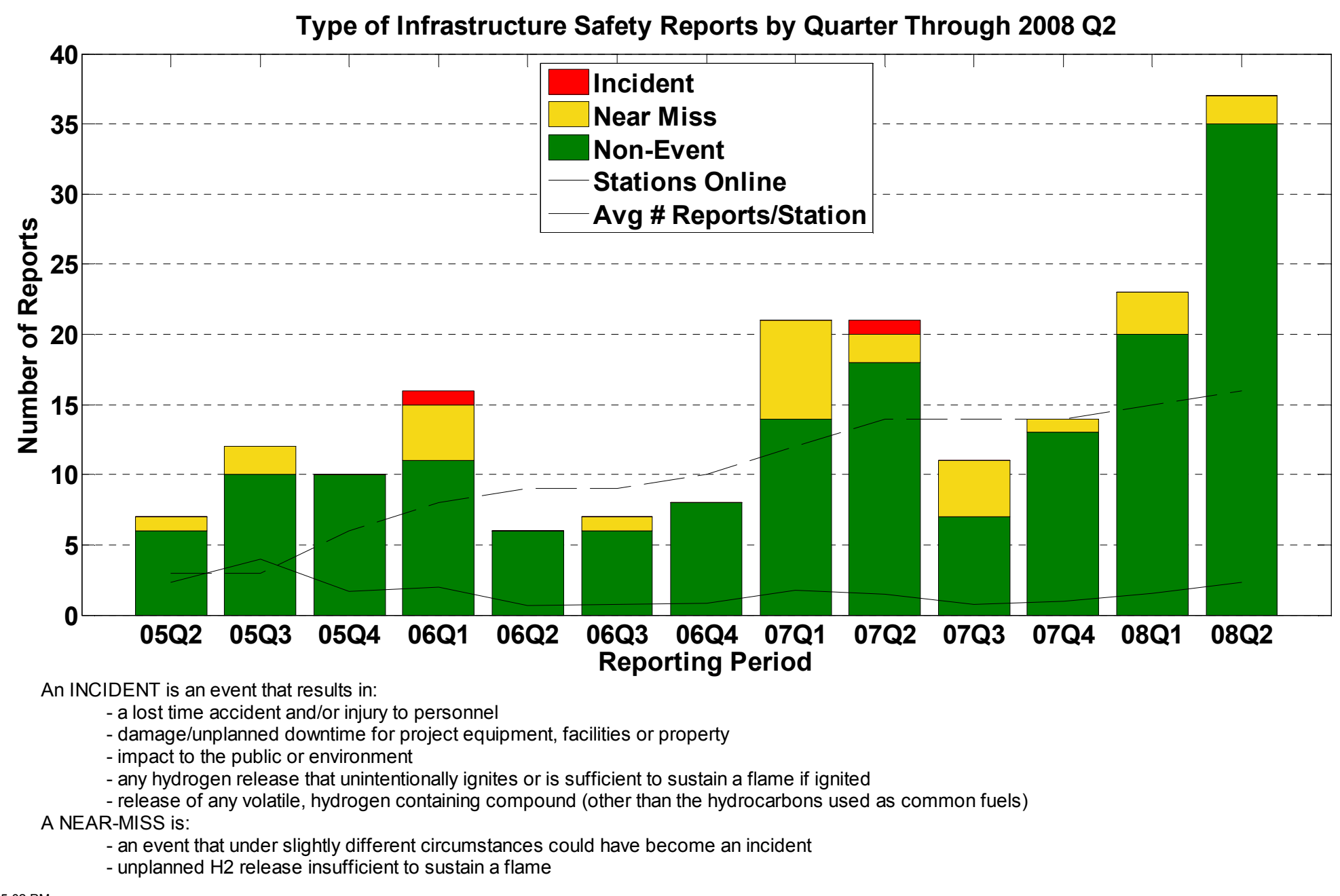




\section{CDP\#37: Primary Factors of Infrastructure Safety Reports}

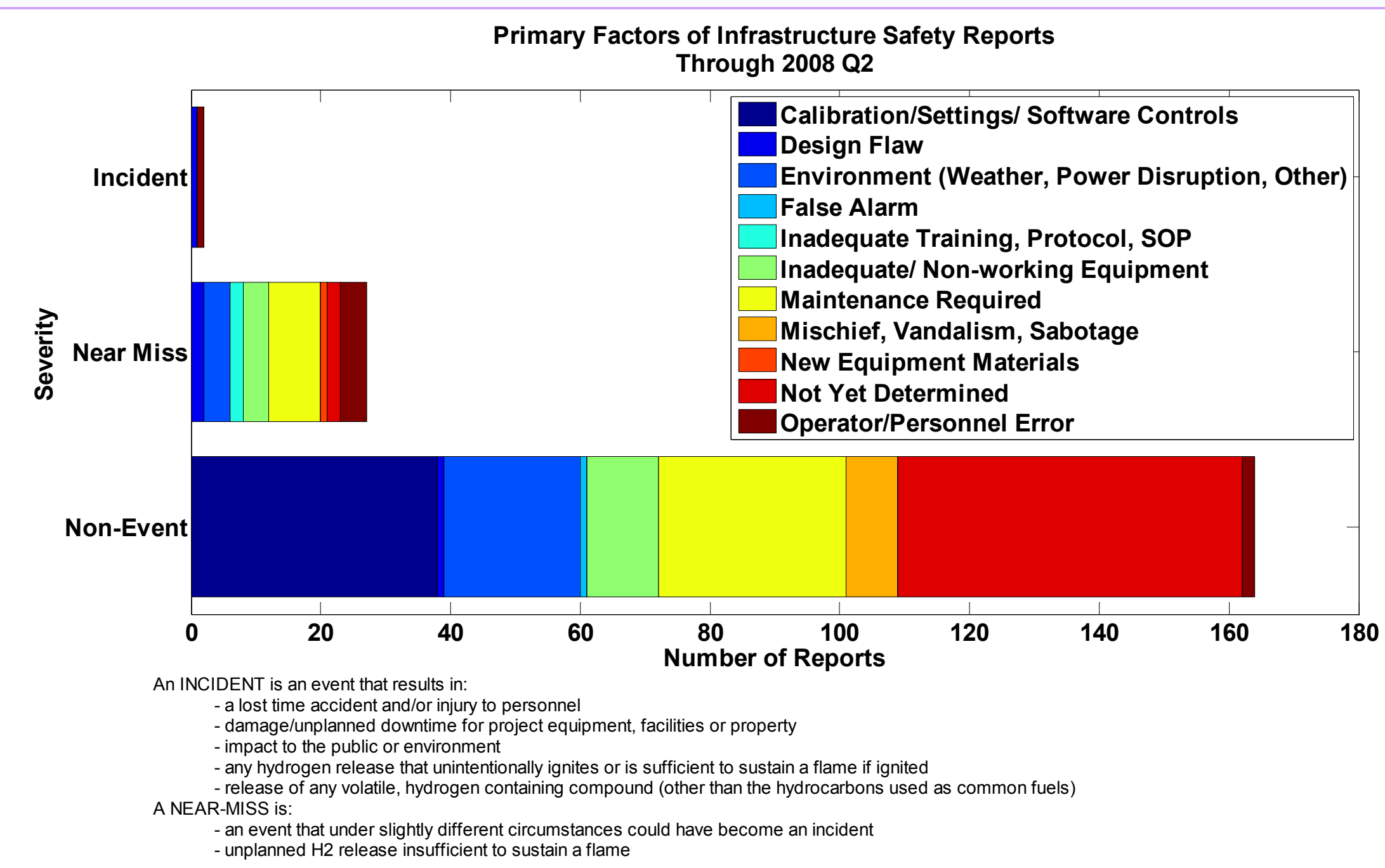




\section{CDP\#38: Refueling Times}

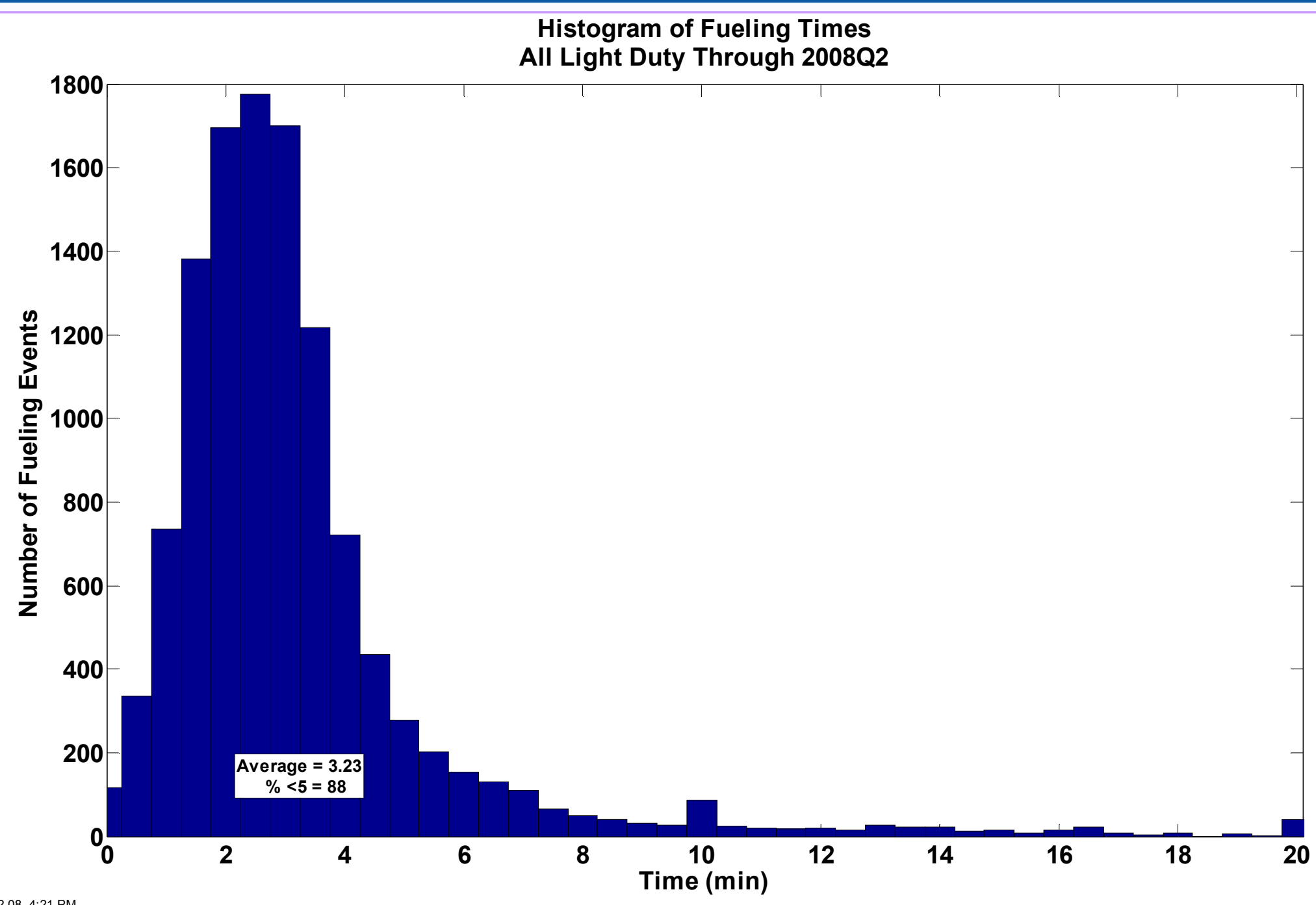




\section{CDP\#39: Refueling Amounts}

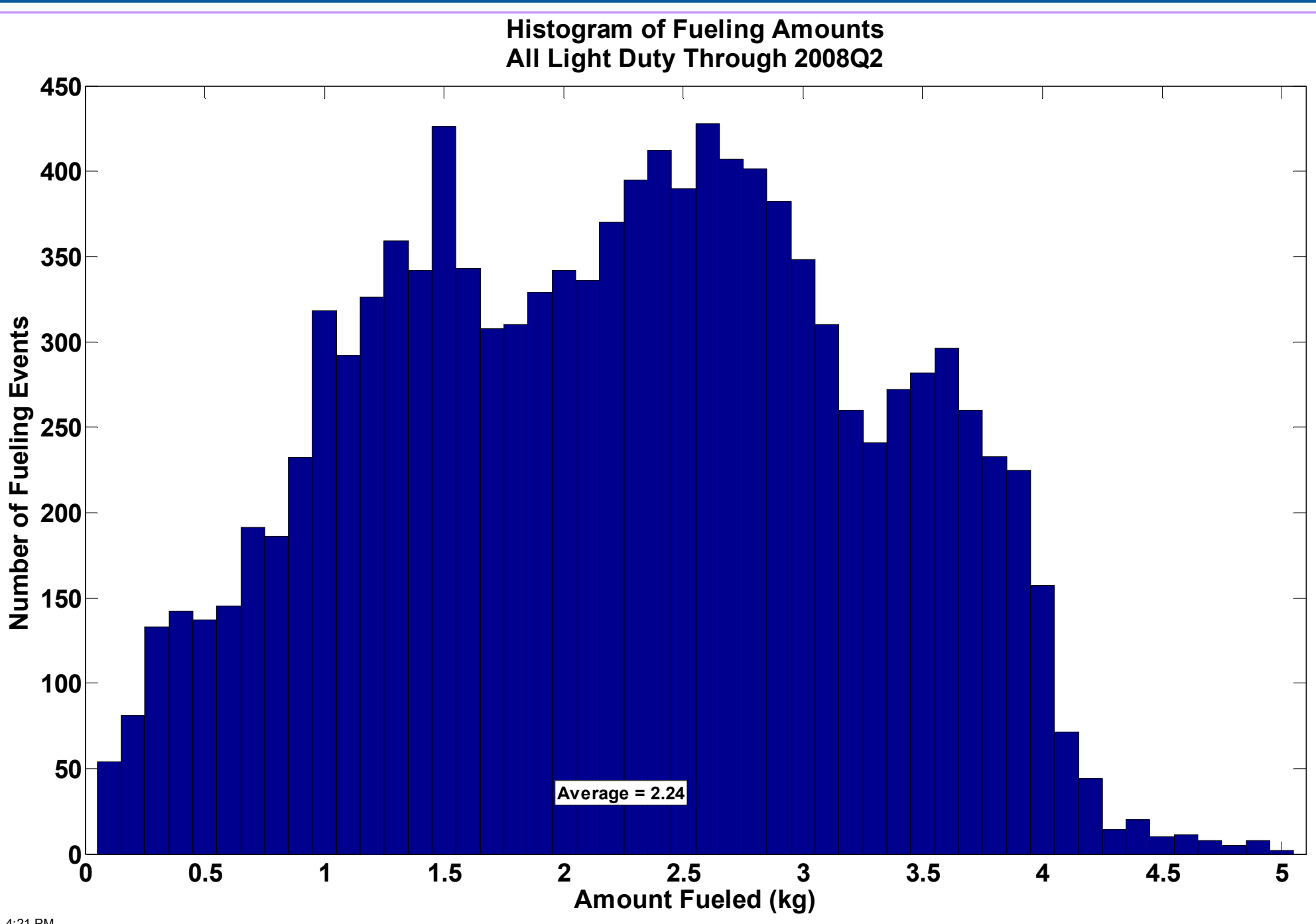




\section{CDP\#40: H2 Tank Level at Refueling}

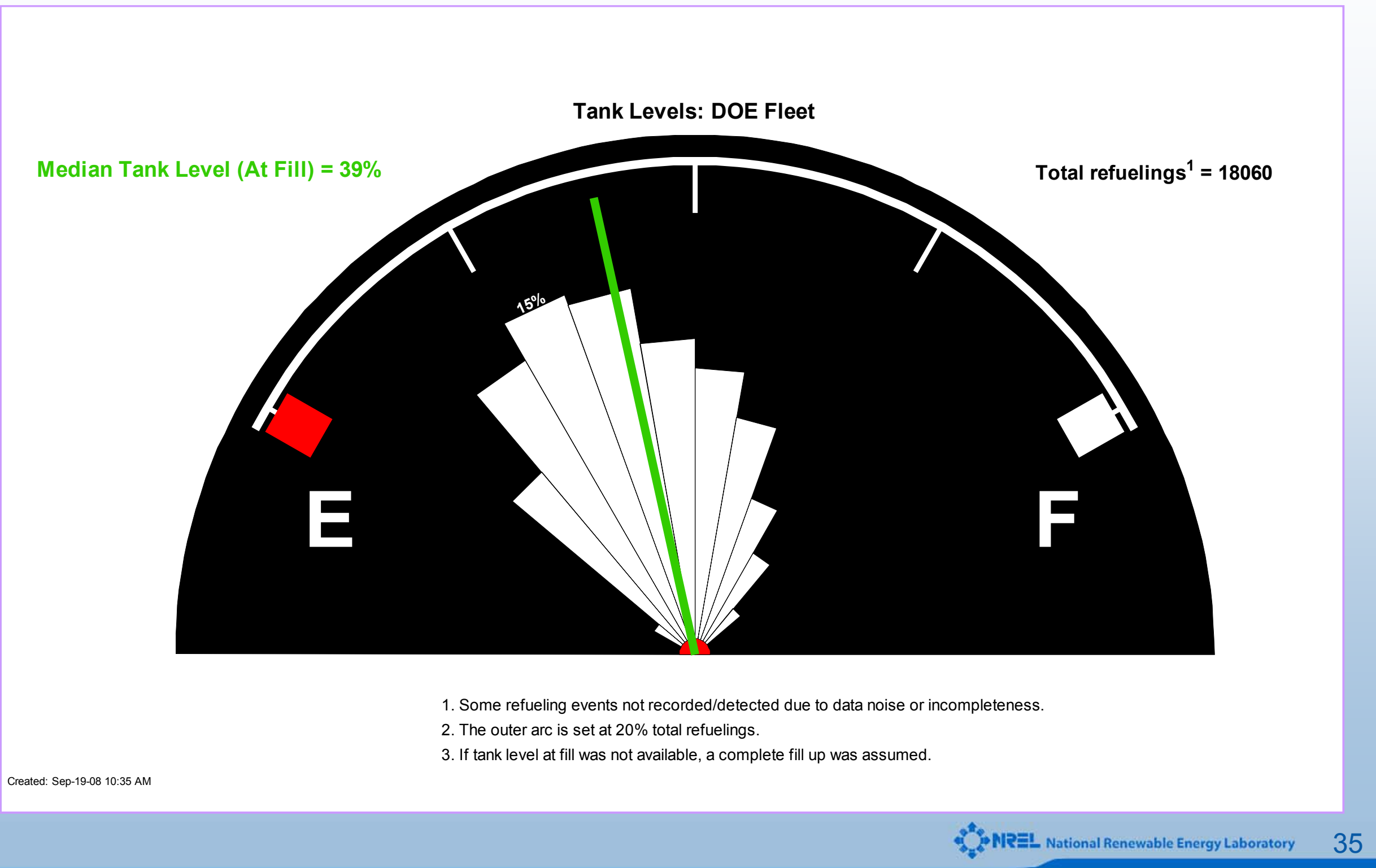




\section{CDP\#41: Refueling Tank Levels - Medians}

Tank Level Medians (At Fill): DOE Fleet, All Vehicles

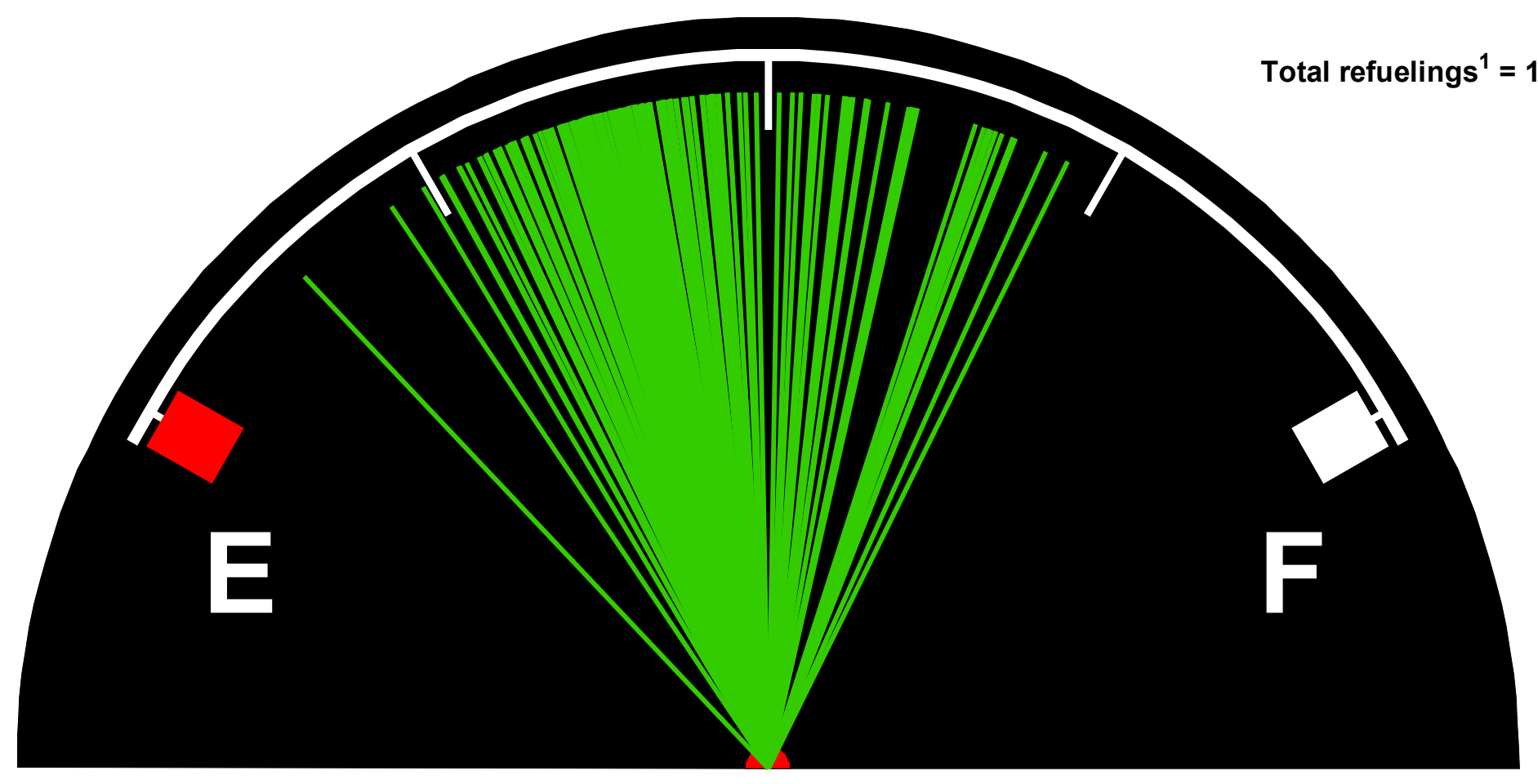

1. Some refueling events not recorded/detected due to data noise or incompleteness.

2. If tank level at fill was not available, a complete fill up was assumed. 


\section{CDP\#42: Refueling by Time of Day}

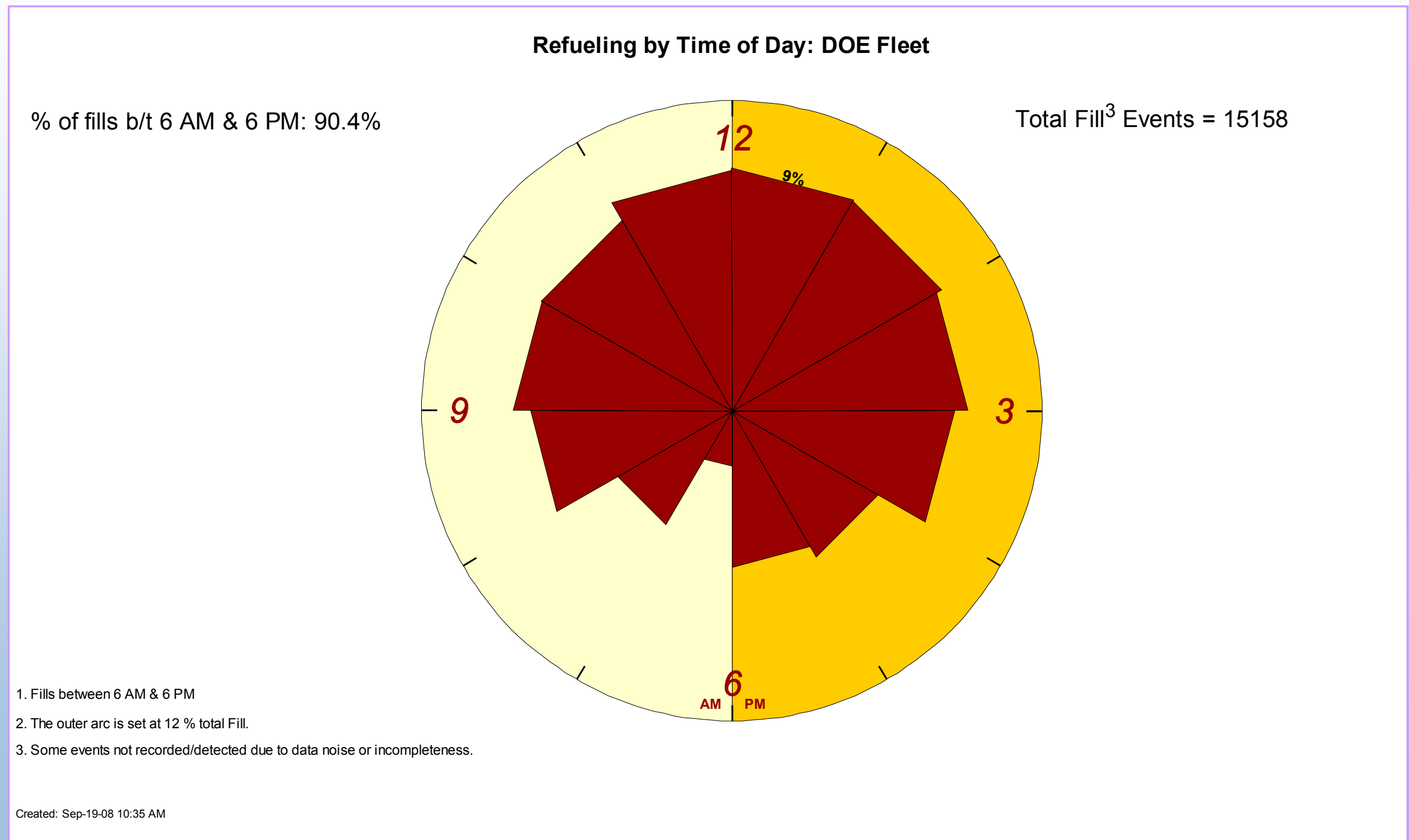




\section{CDP\#43: Refueling by Day of Week}

Fills by Day of Week: DOE Fleet

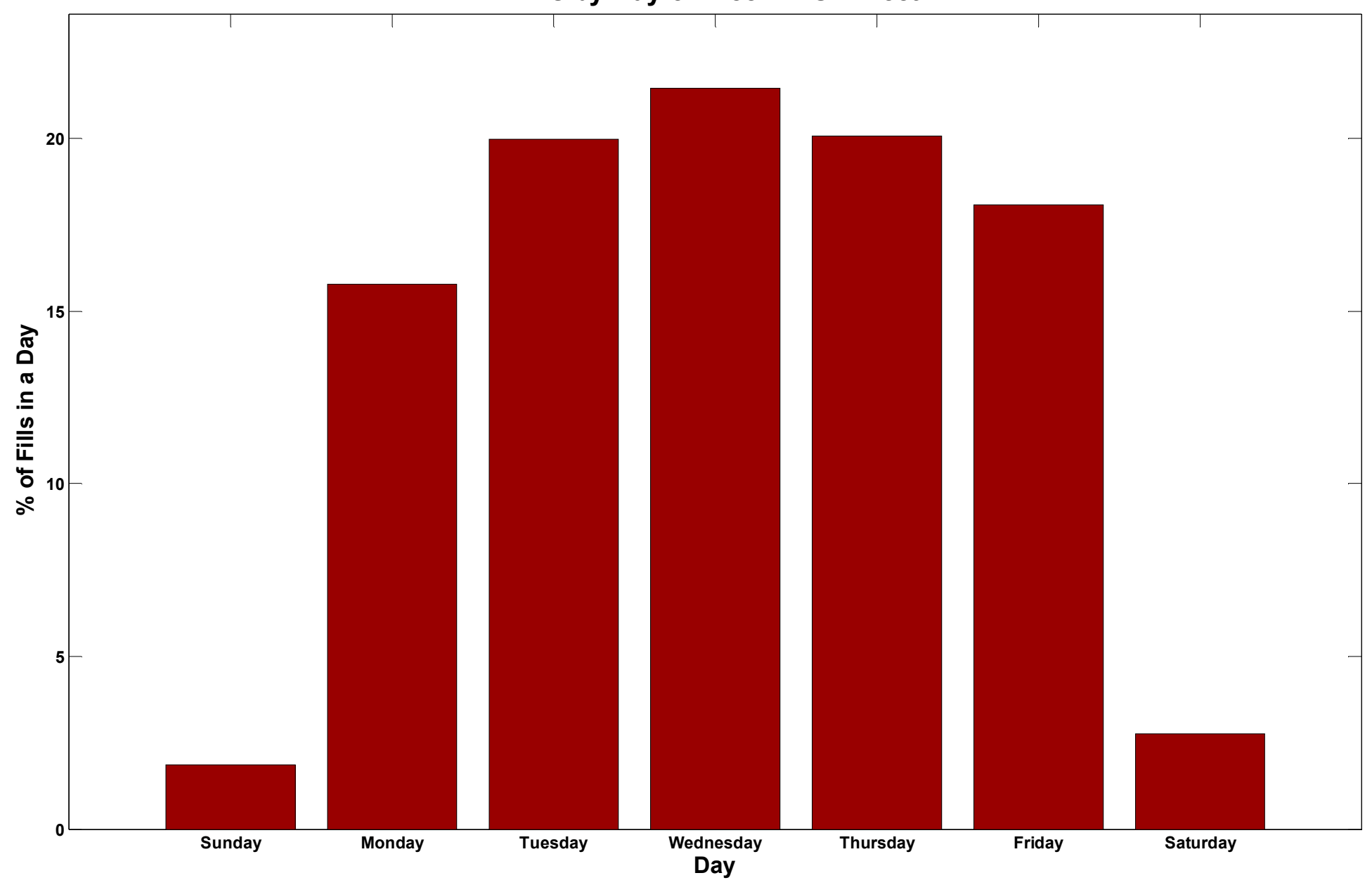




\section{CDP\#44: Driving Start Time - Day}

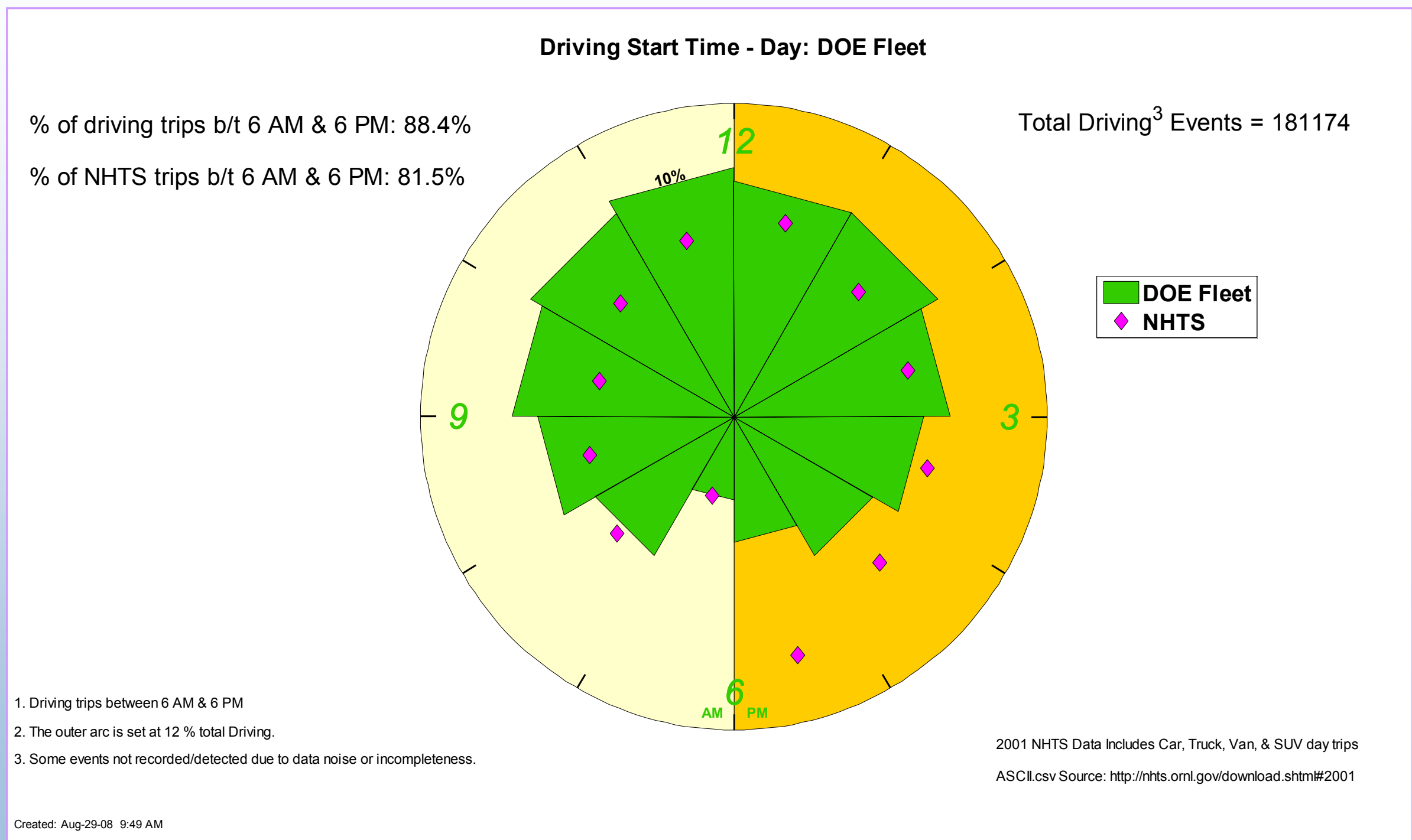




\section{CDP\#45: Driving by Day of Week}

Driving Trips by Day of Week: DOE Fleet

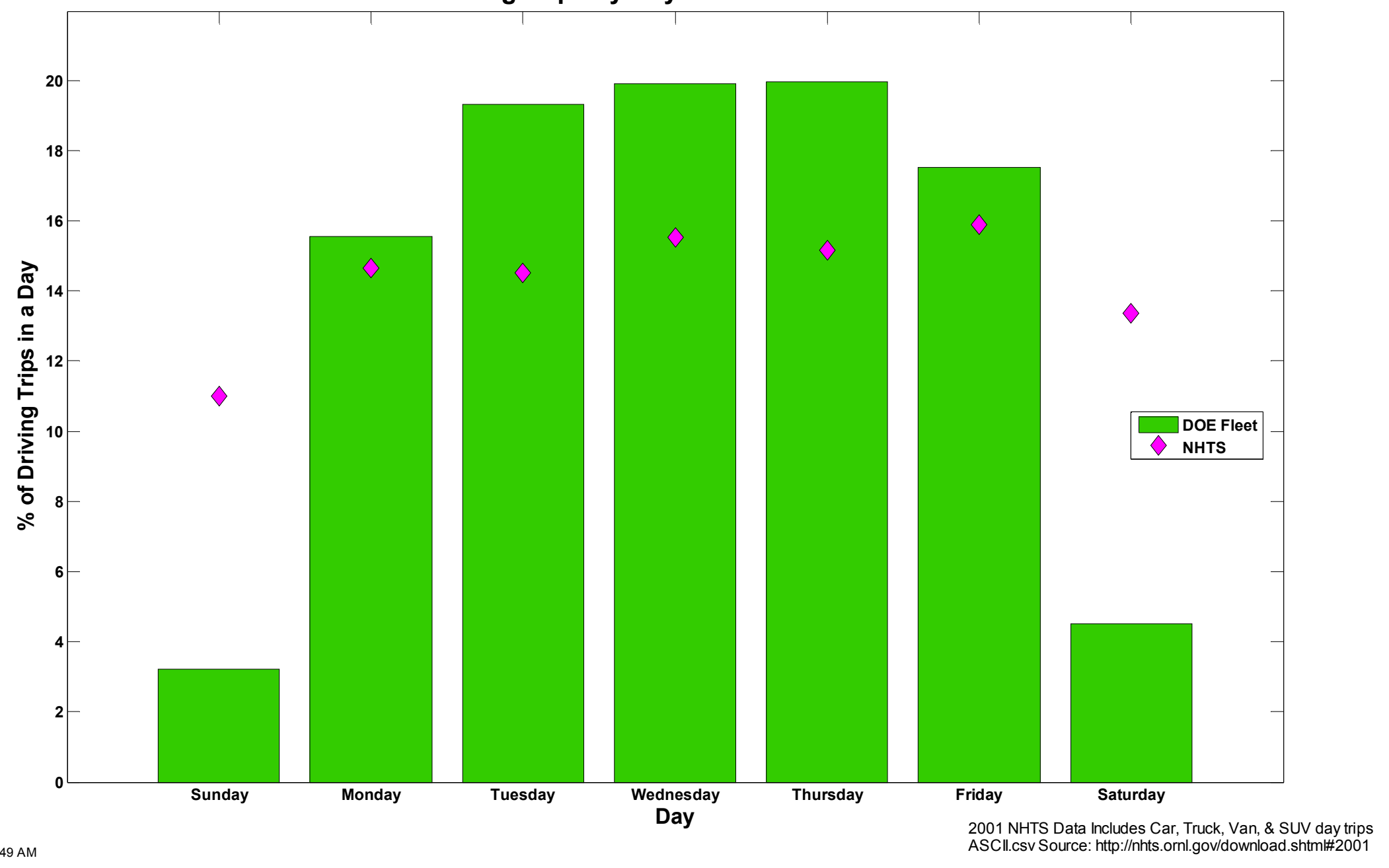




\section{CDP\#46: Fuel Cell System Operating Power}

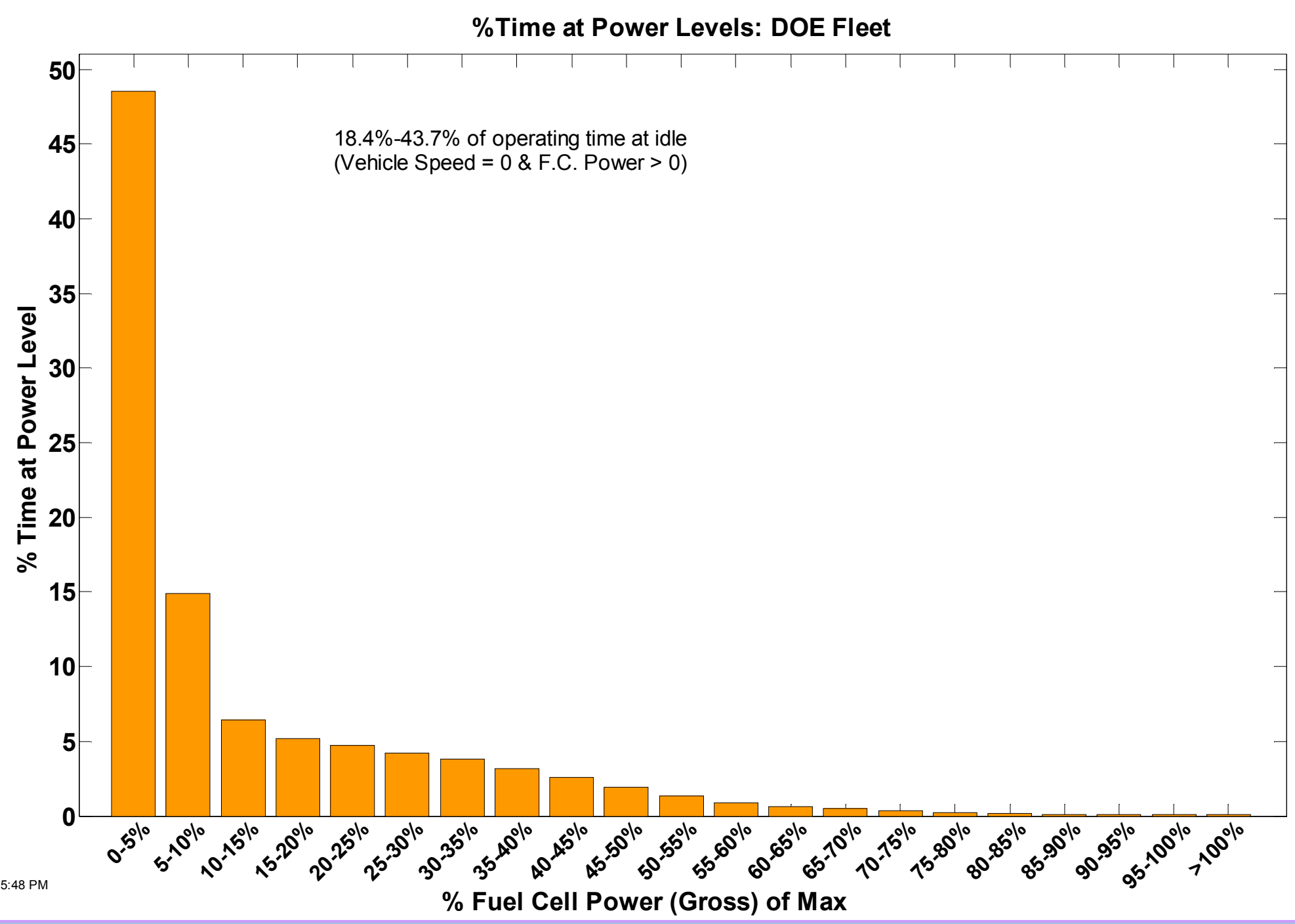




\section{CDP\#47: Trip Length}

Trip Length: DOE Fleet

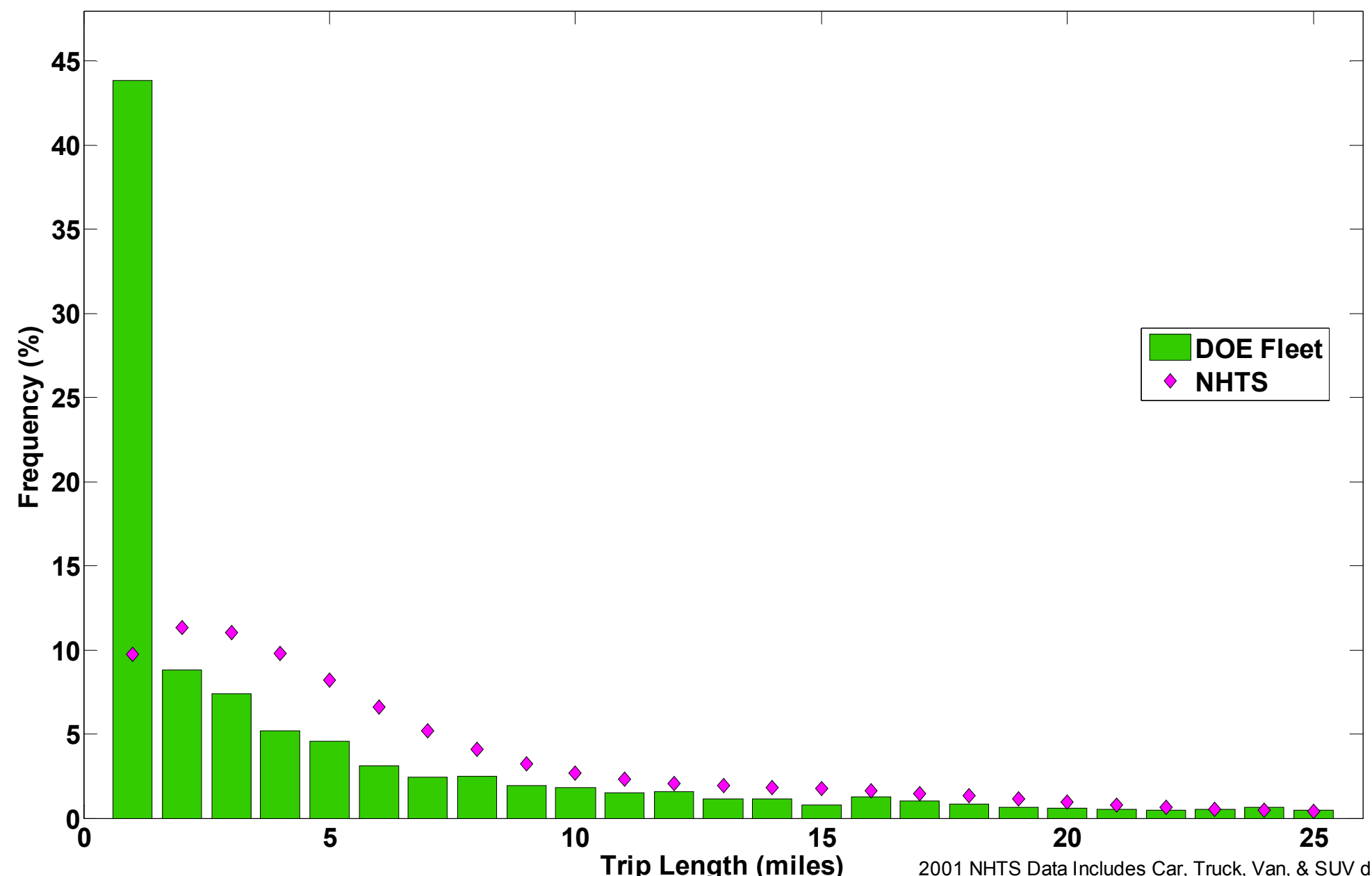

Trip Length (miles)

2001 NHTS Data Includes Car, Truck, Van, \& SUV day trips ASCII.csv Source: http://nhts.ornl.gov/download.shtml\#2001 


\section{CDP\#48: Primary Factors Affecting Learning Demo Fleet Fuel Cell Degradation}
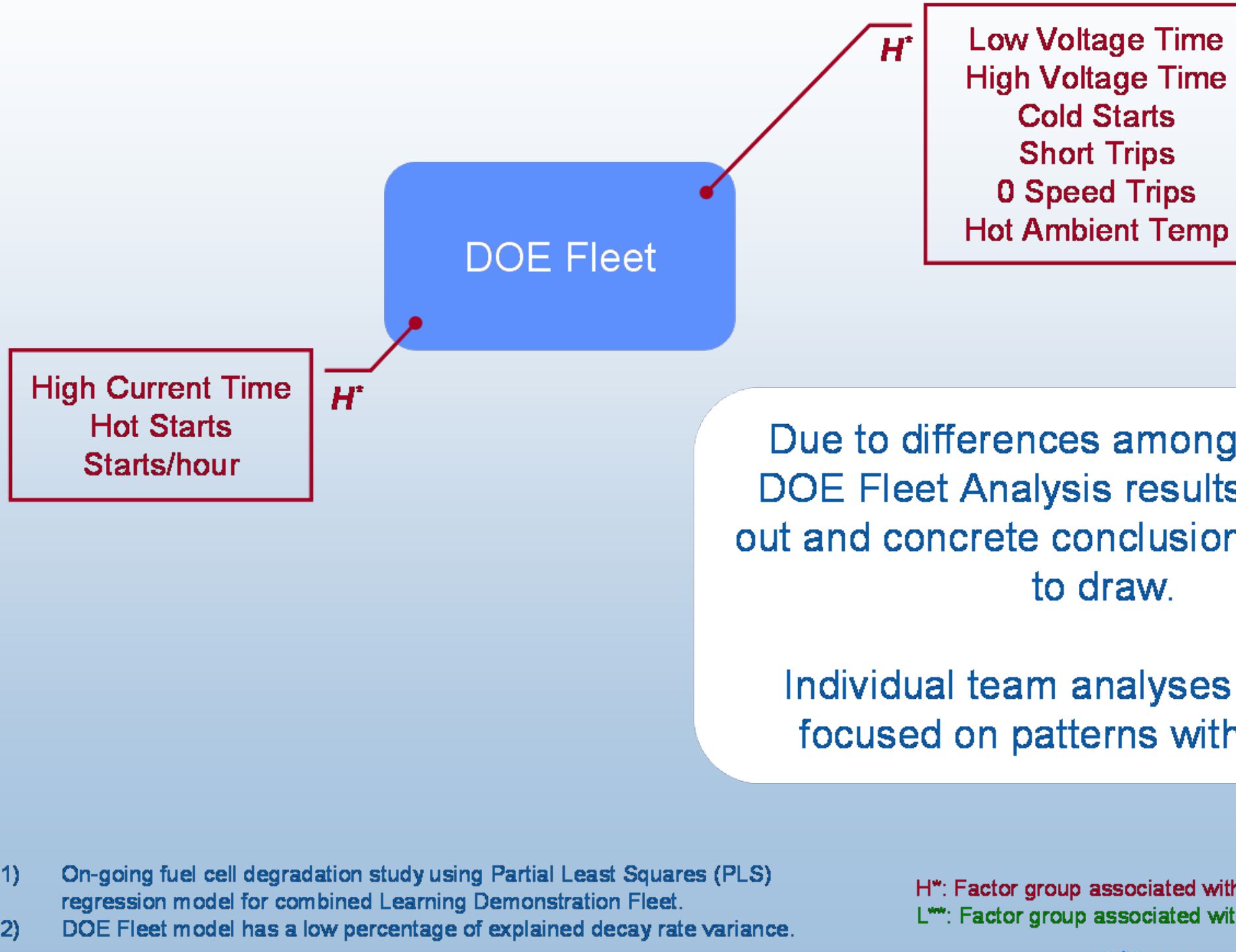

Due to differences among teams, the DOE Fleet Analysis results are spread out and concrete conclusions are difficult to draw.

Individual team analyses (CDP\#49) focused on patterns within a fleet. 


\section{CDP\#49: Primary Factors Affecting Learning Demo Team Fuel Cell Degradation}

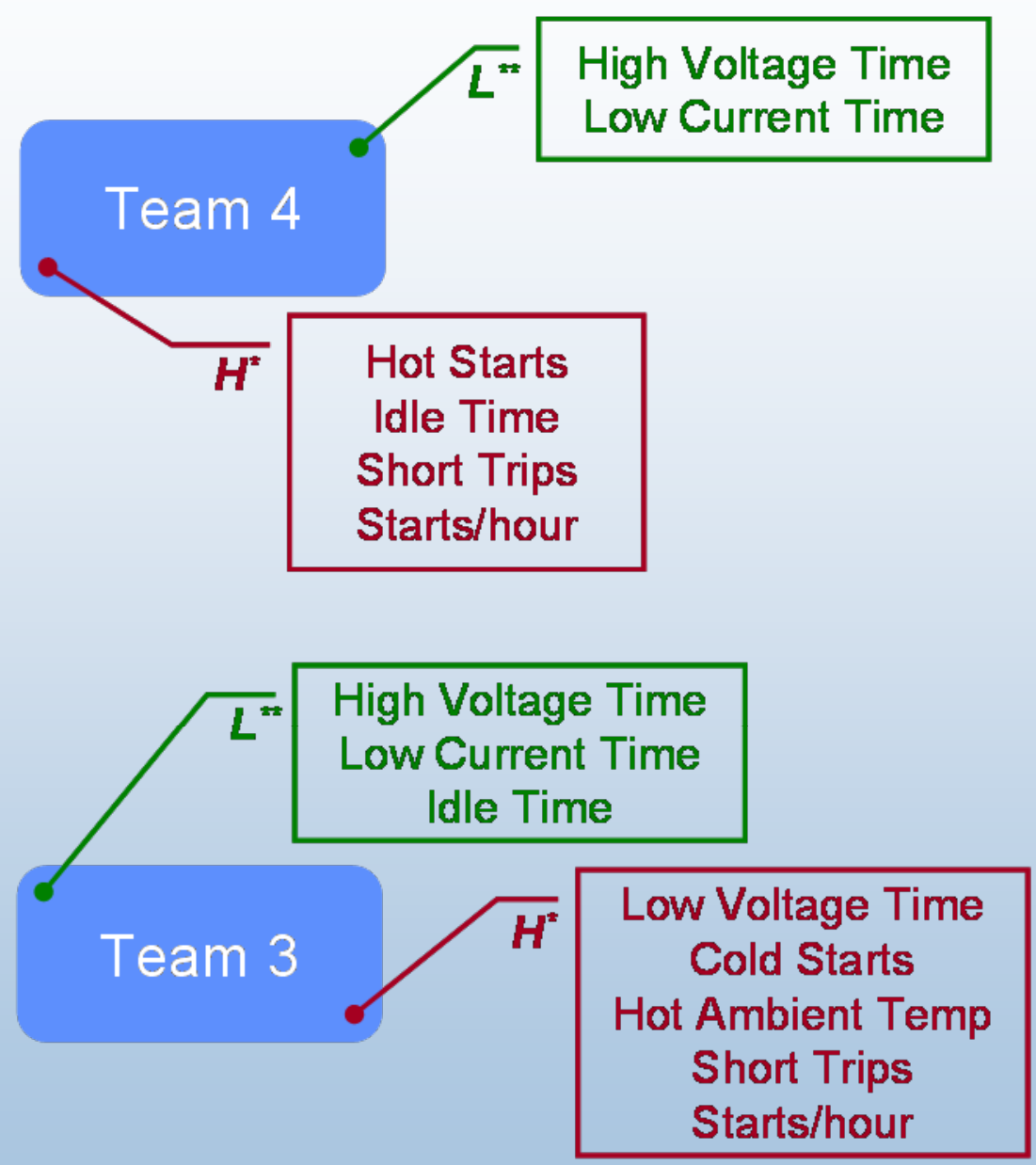

1) On-going fuel cell degradation study using Partial Least Squares (PLS) regression model for each team.

2) Teams' PLS models have a high percentage of explained decay rate variance, but the models are not robust and results are scattered.
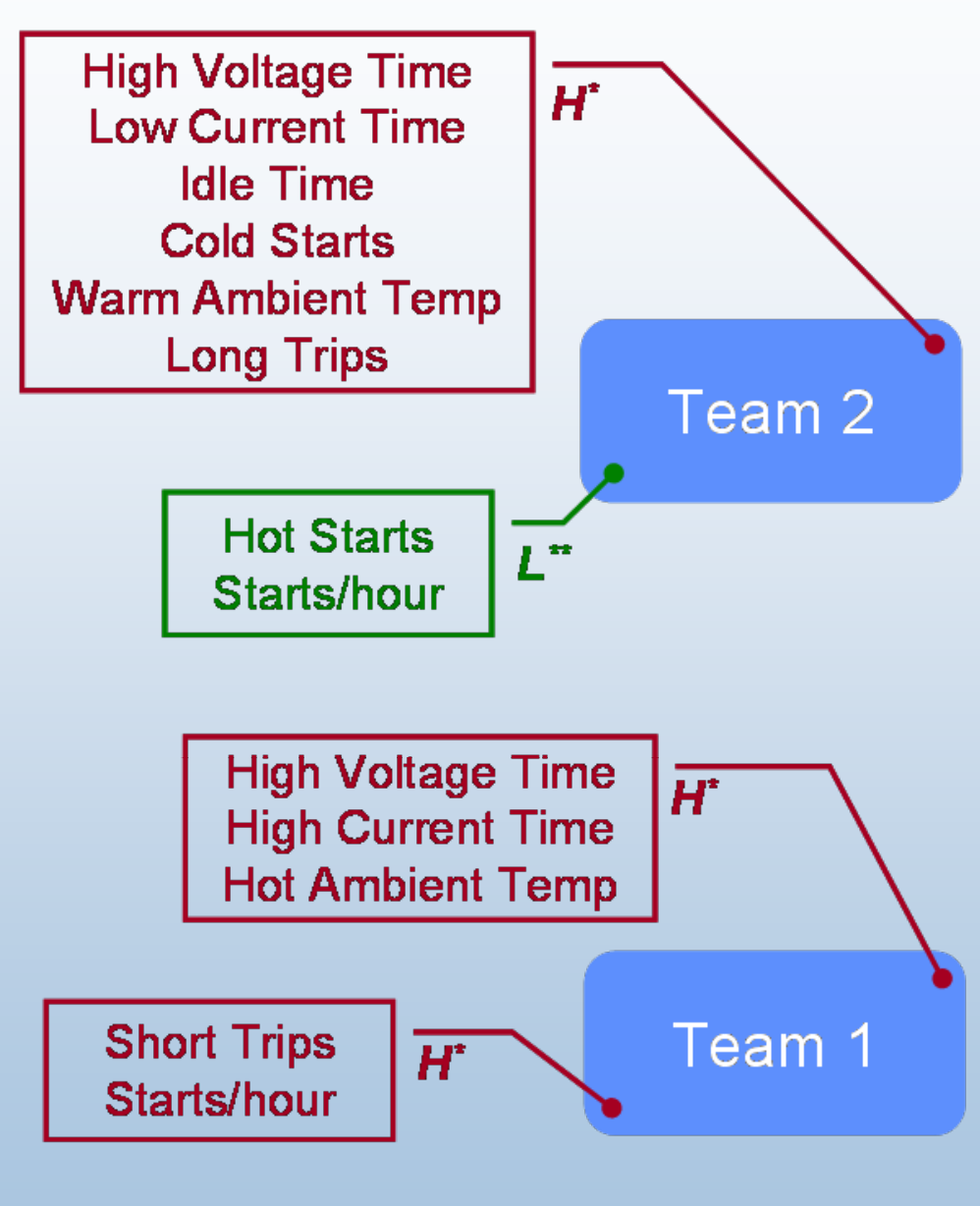

$\mathrm{H}^{*}$ : Factor group associated with high decay rate fuel cell stacks $L$ : Factor group associated with low decay rate fuel cell stacks 


\section{CDP\#50: Refueling by Time of Night}

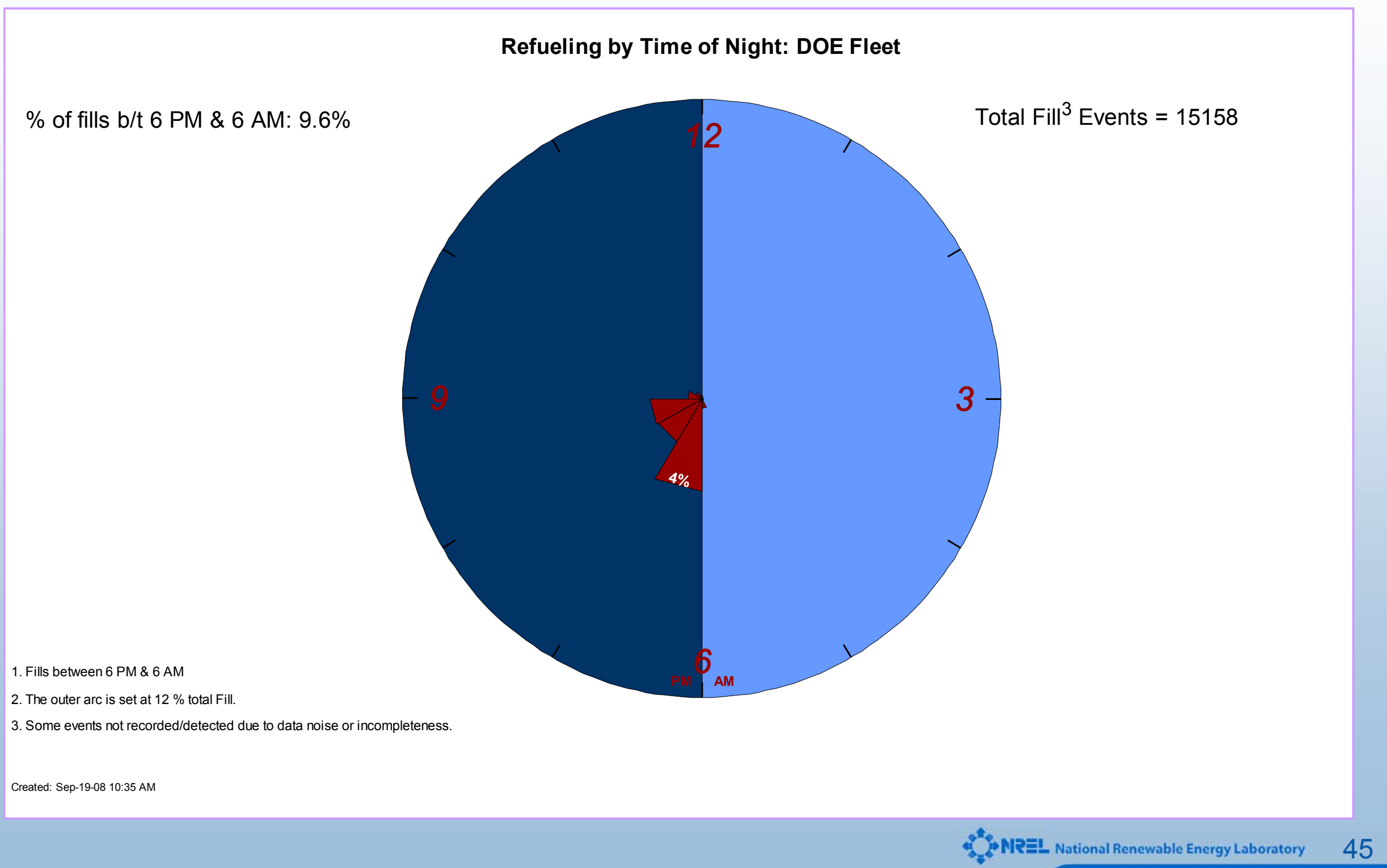




\section{CDP\#51: Driving Start Time - Night}

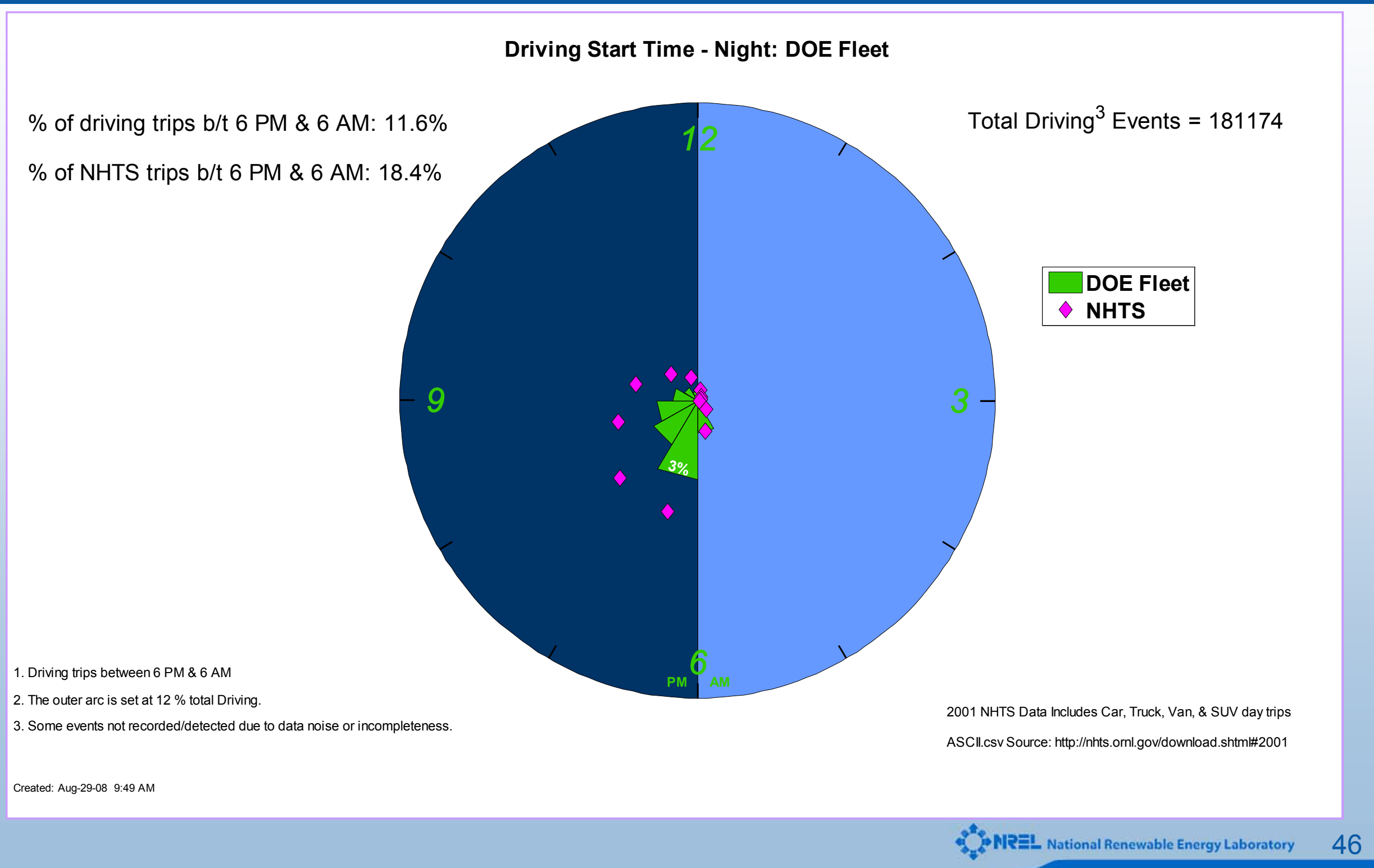




\section{CDP\#52: Refueling Data by Year}

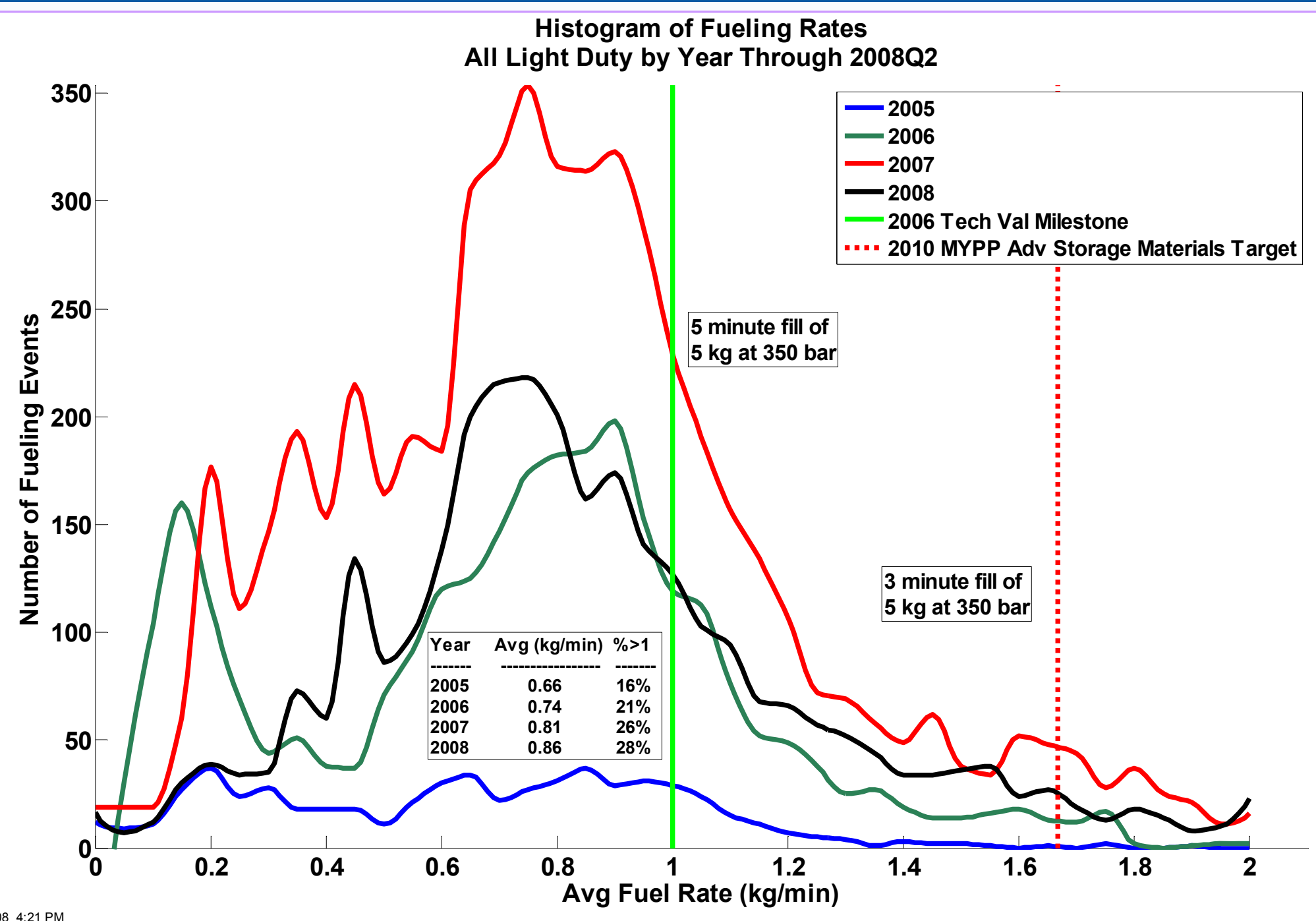




\section{CDP\#53: Fuel Cell System Energy within Power Levels}

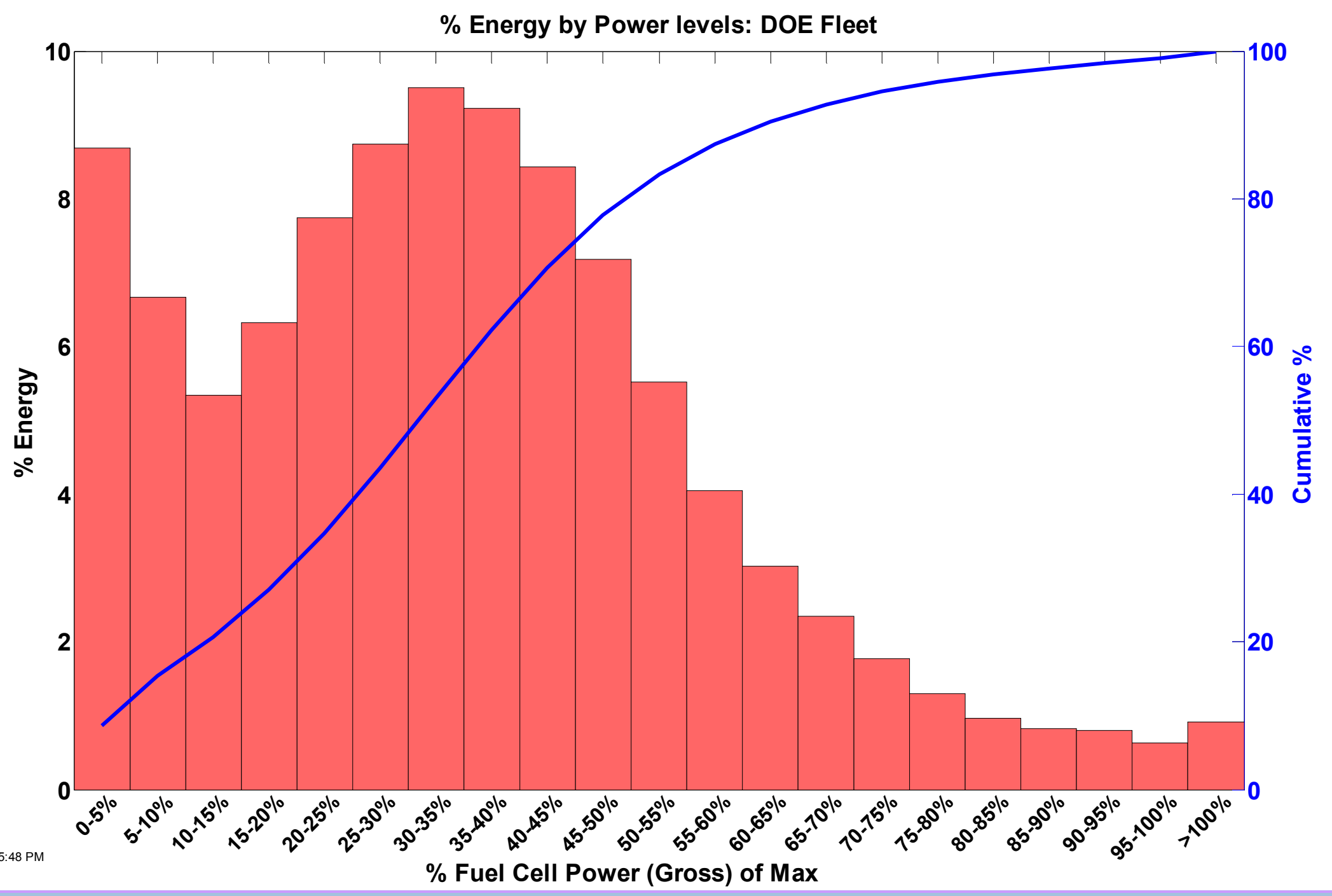




\section{CDP\#54: Time Between Trips}

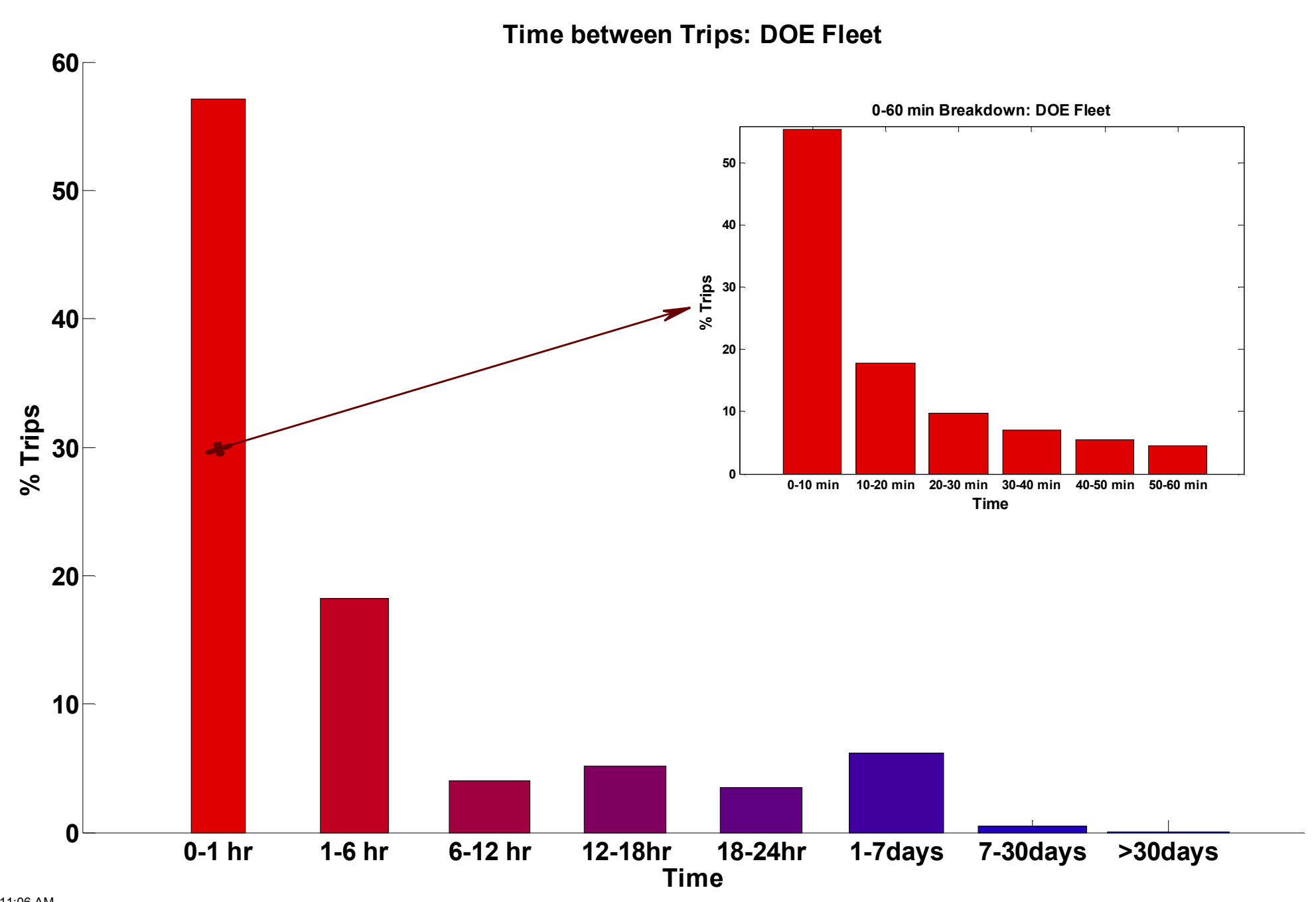




\section{CDP\#55: Fuel Cell System Energy}

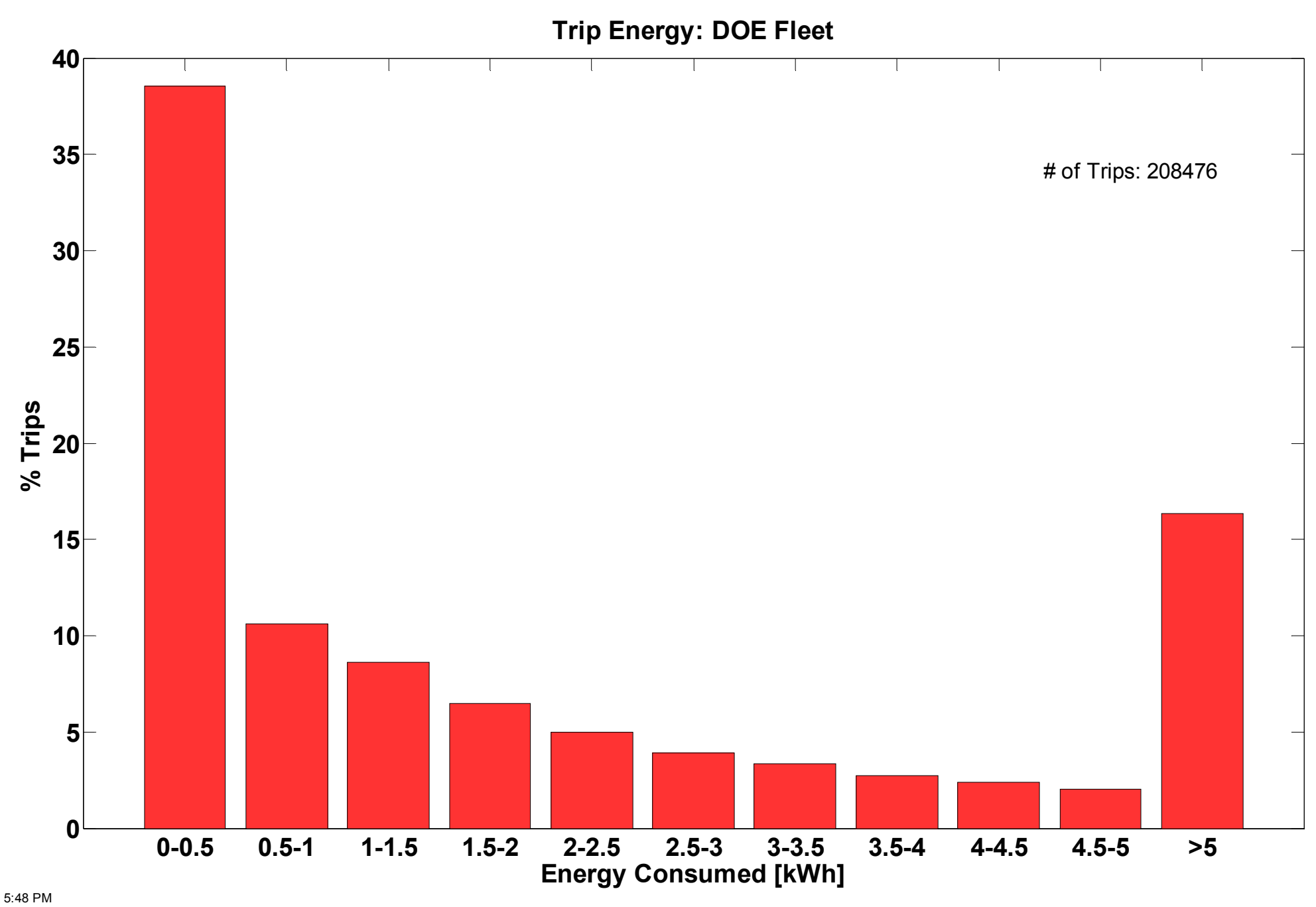




\section{CDP\#56: Daily Driving Distance}

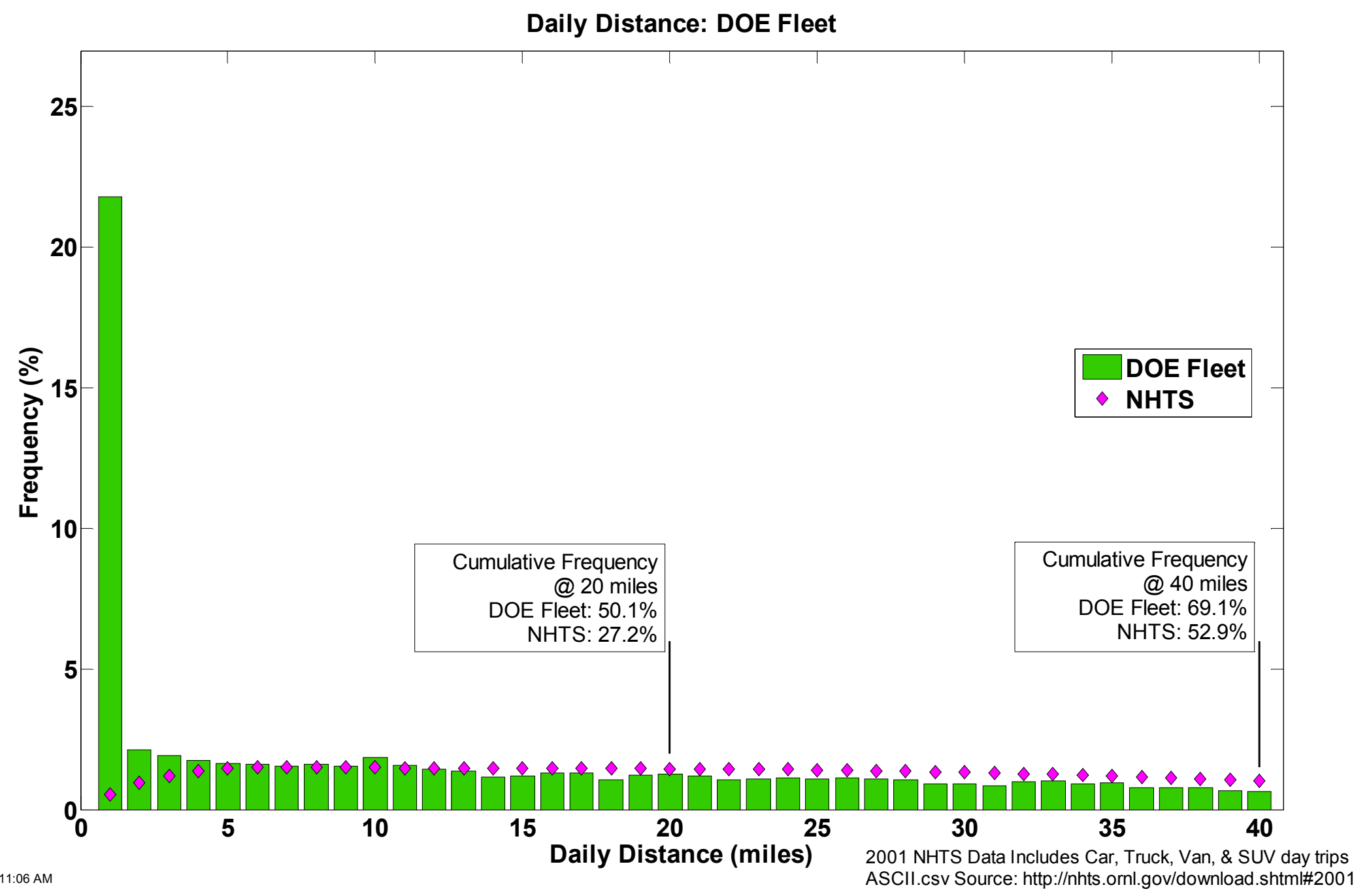




\section{CDP\#57: H2 Storage System Mass and Volume Breakdown}

Average Breakout of $\mathrm{H} 2$ Storage System Mass
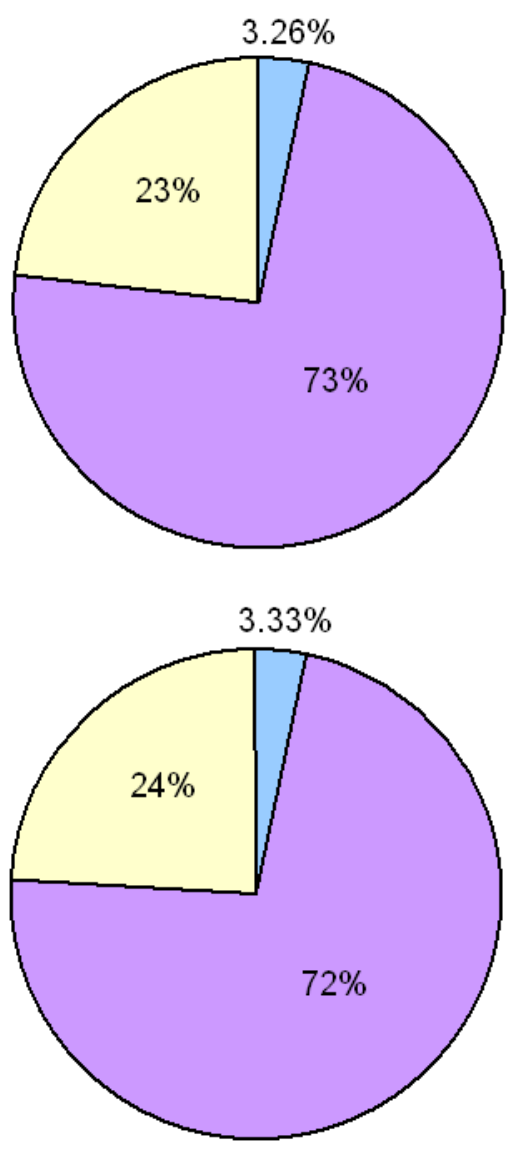

\section{$\square \mathrm{H} 2$ Mass (\%)}

Pressure Vessel Mass (\%)

\section{Average Breakout of $\mathrm{H} 2$ Storage System Volume}

350 bar

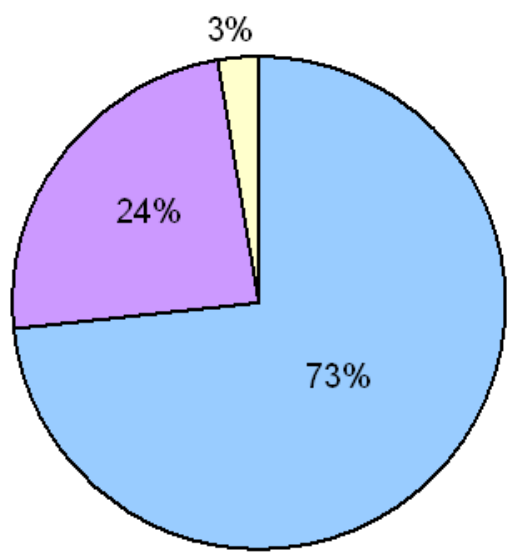

700 bar

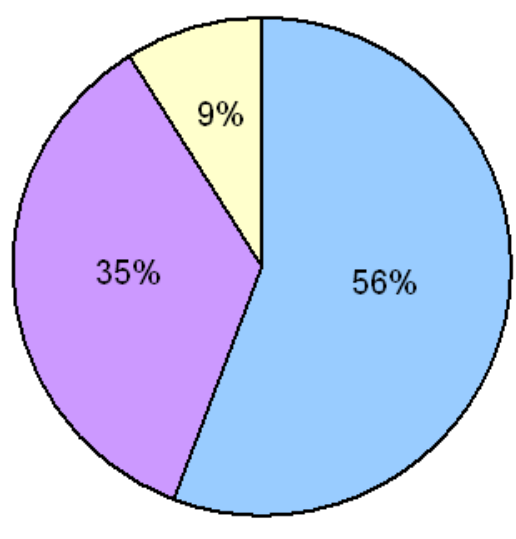

H2 Volume $(\%)$

$\square$ Pressure Vessel Volume $(\%)$

$\square$ Balance of Plant Volume (\%) 


\section{CDP\#58: Fuel Cell System Power Density}

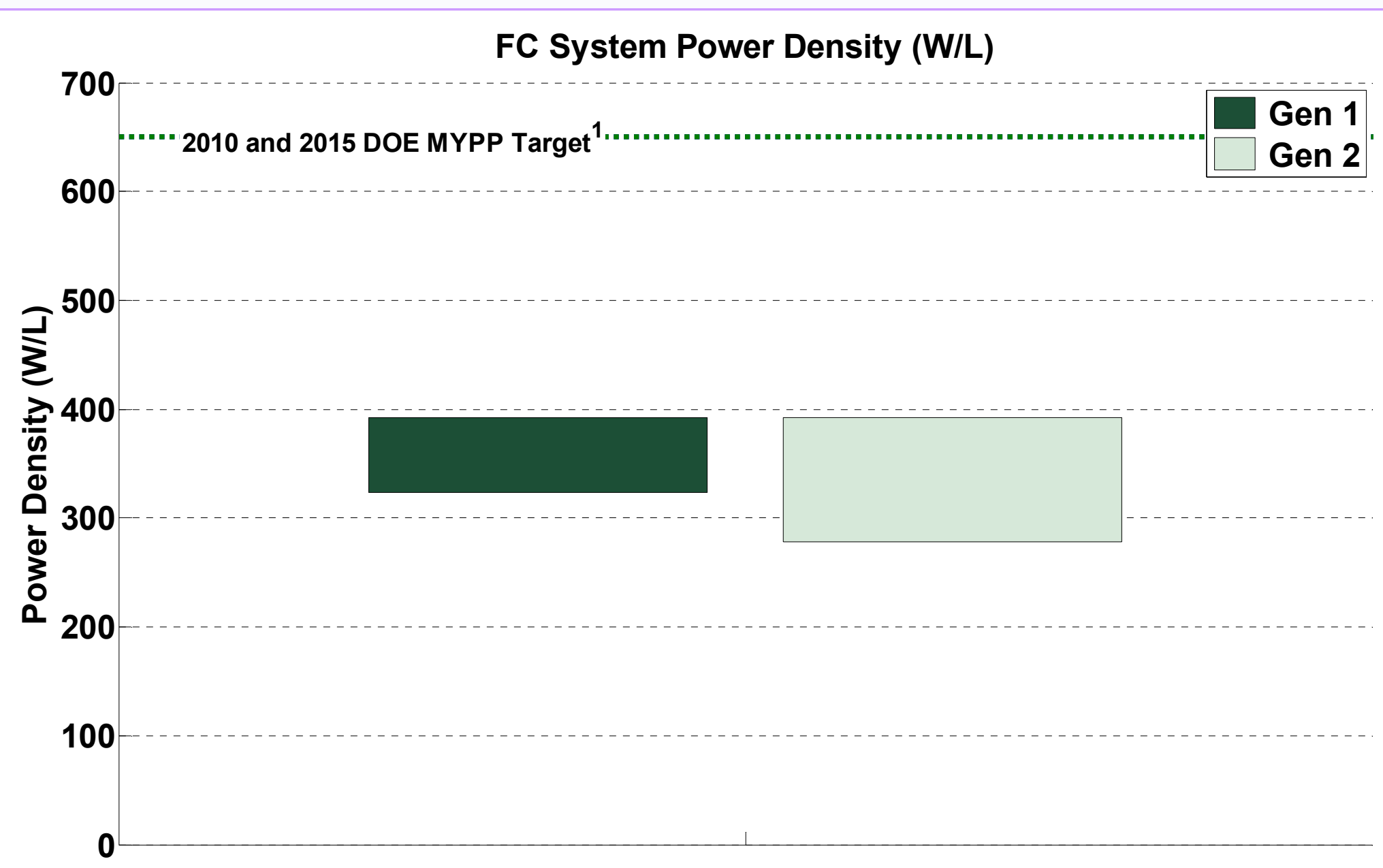

(1) Fuel cell system includes fuel cell stack and BOP but excludes H2 storage, power electronics, and electric drive. 


\section{CDP\#59: Fuel Cell System Specific Power}

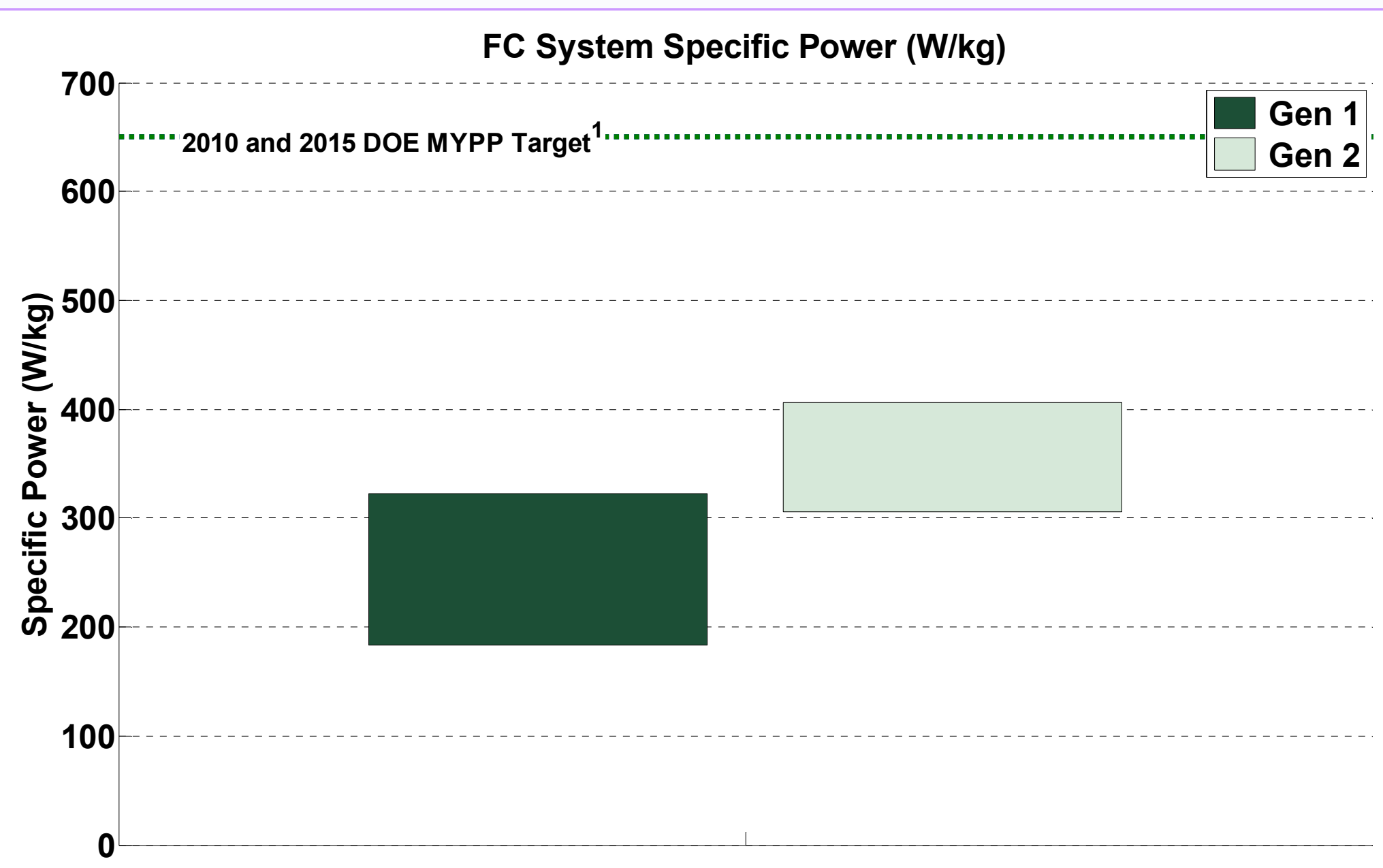

(1) Fuel cell system includes fuel cell stack and BOP but excludes H2 storage, power electronics, and electric drive. 


\section{CDP\#60: On-Site Hydrogen Production Efficiency vs. Capacity Utilization}

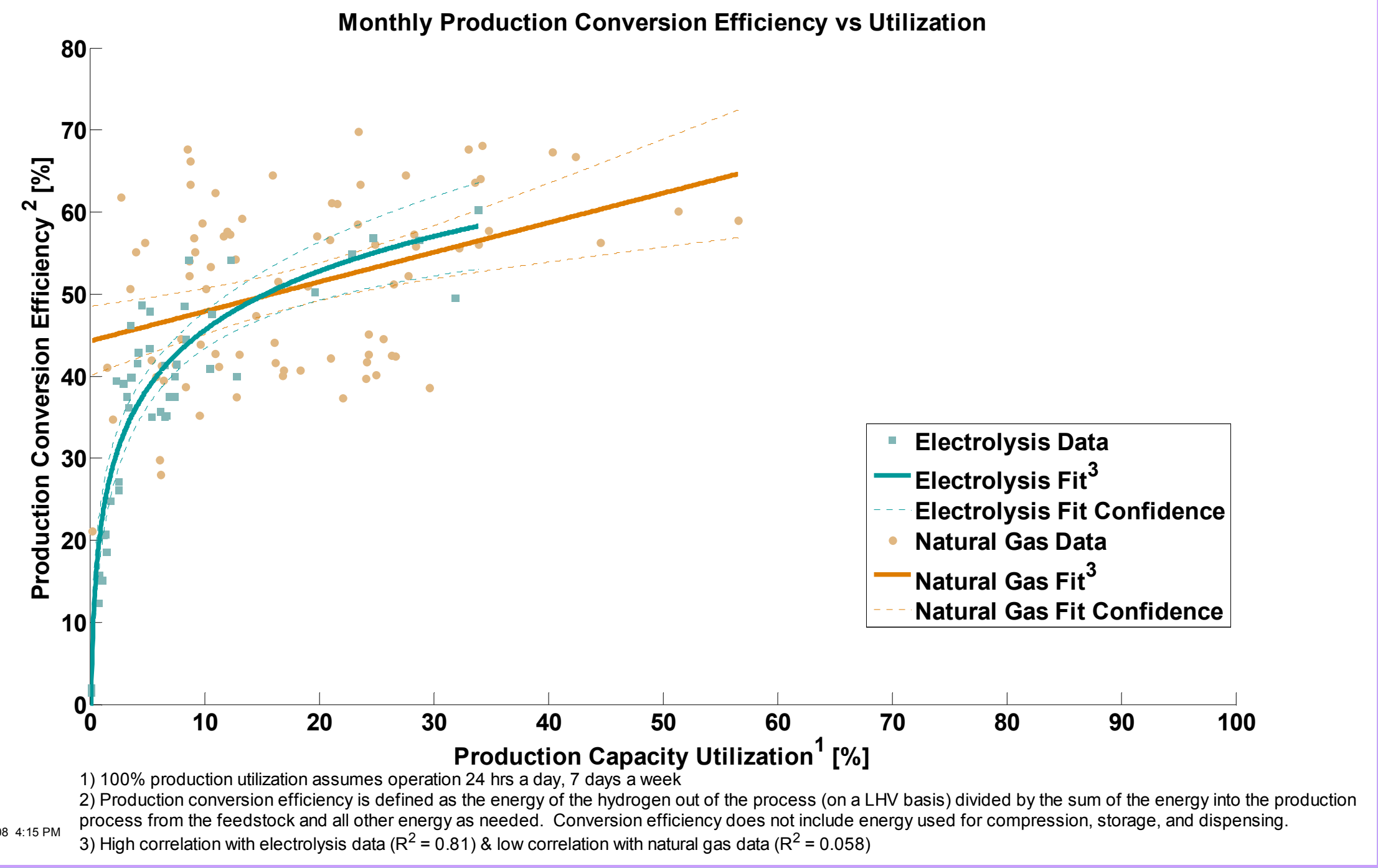




\section{CDP\#61: Refueling Station Compressor Efficiency}

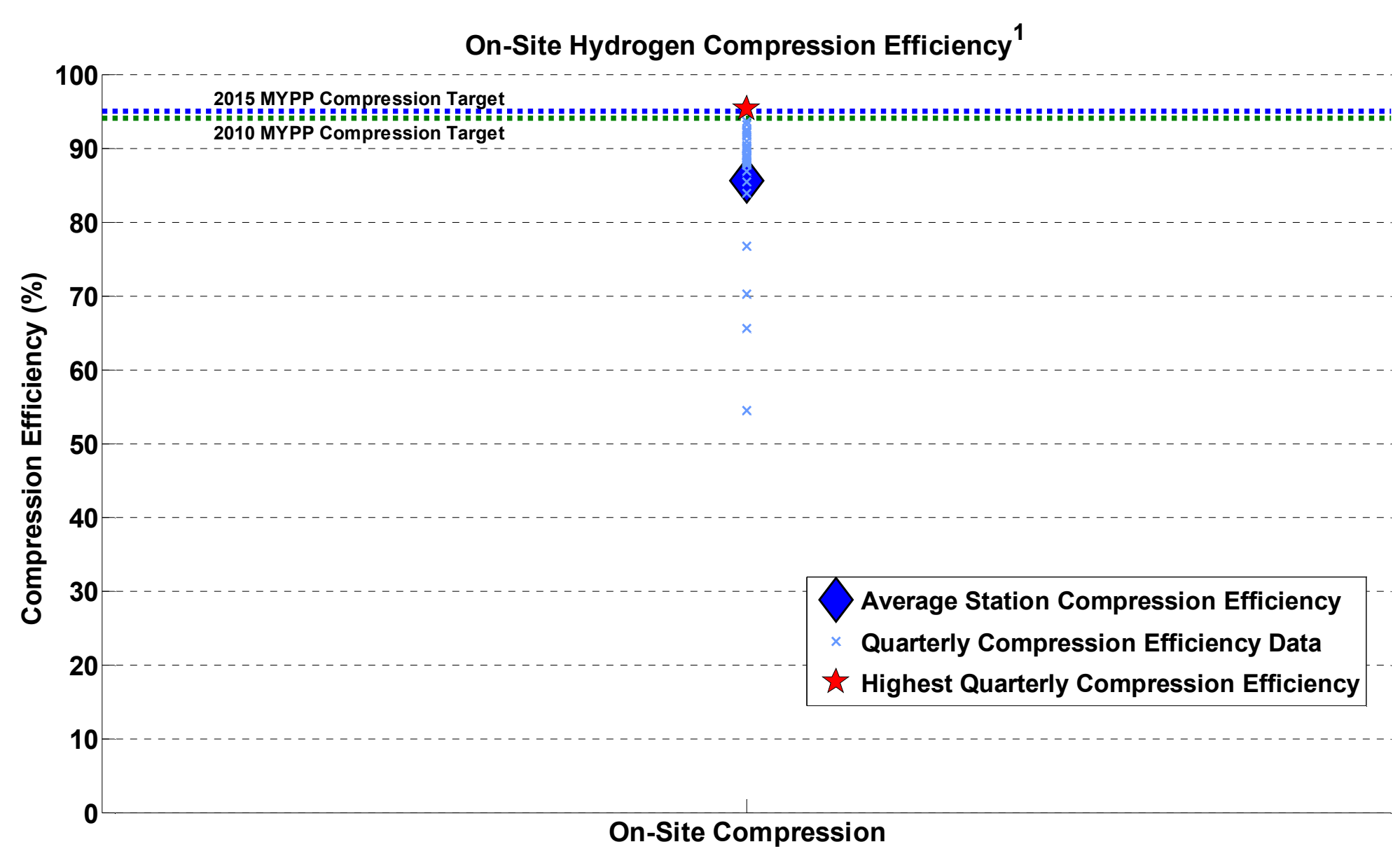

${ }^{1}$ Consistent with the MYPP, compression efficiency is defined as the energy of the hydrogen out of the process (on an LHV basis) divided by the sum of the energy of the hydrogen output plus all other energy needed for the compression process. Data shown for on-site hydrogen production and storage facilities only, not delivered hydrogen sites. 


\section{CDP\#62: Learning Demonstration Vehicle Greenhouse Gas Emissions}

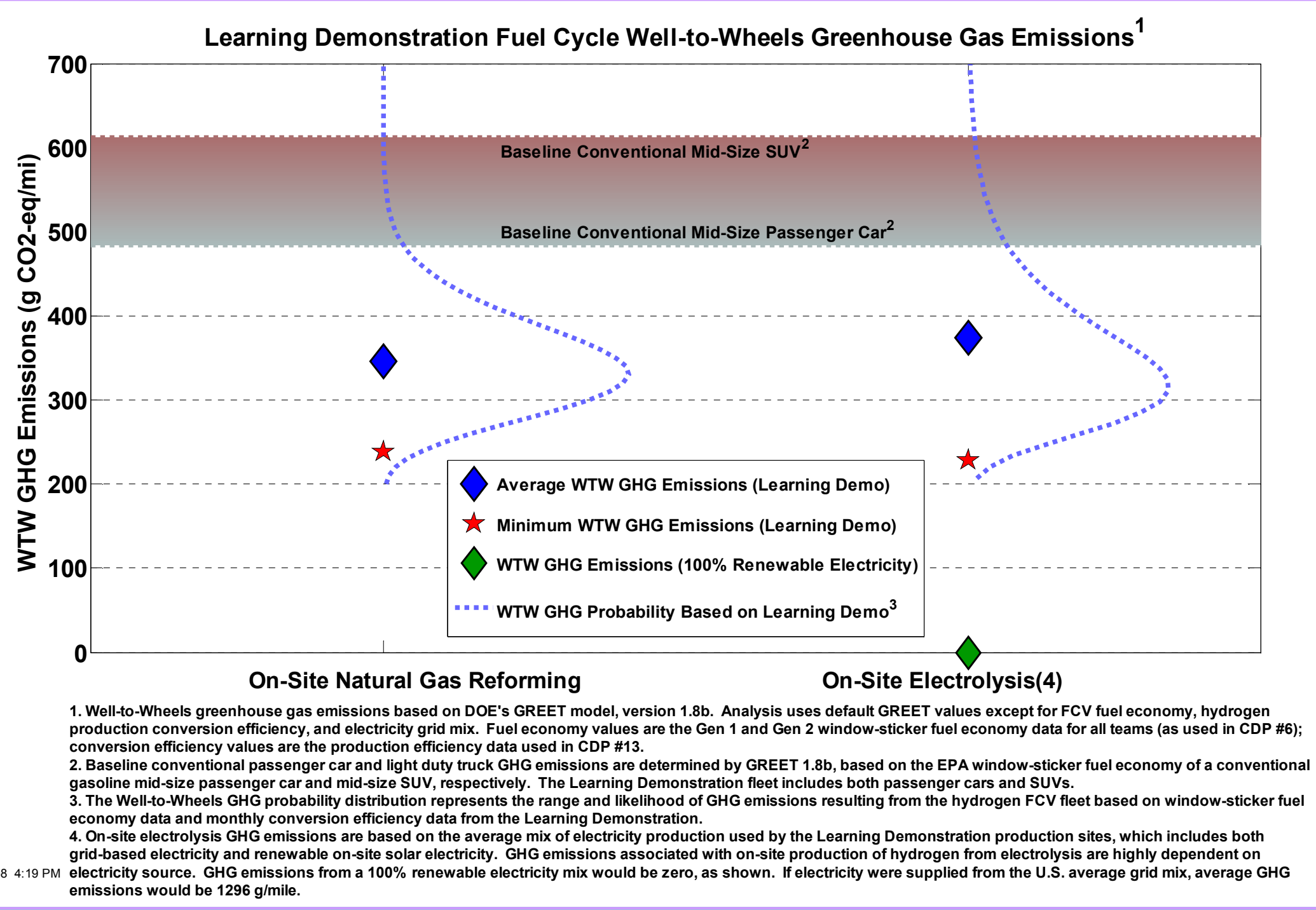

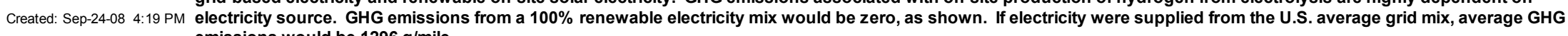
emissions would be $1296 \mathrm{~g} / \mathrm{mile}$. 


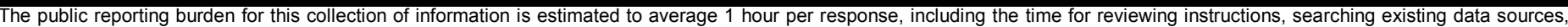

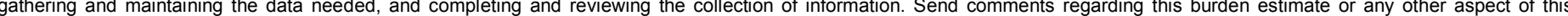

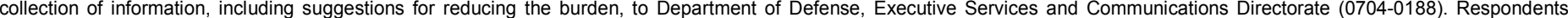

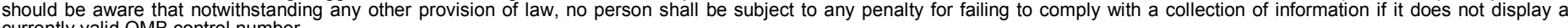
currently valid OMB control number.

PLEASE DO NOT RETURN YOUR FORM TO THE ABOVE ORGANIZATION.

\section{REPORT DATE (DD-MM-YYYY) \\ October 2008 \\ 2. REPORT TYPE \\ Technical Report}

4. TITLE AND SUBTITLE

Controlled Hydrogen Fleet and Infrastructure Demonstration and Validation Project: Fall 2008

\section{DATES COVERED (From - To)}

5a. CONTRACT NUMBER

DE-AC36-99-GO10337

5b. GRANT NUMBER

5c. PROGRAM ELEMENT NUMBER

5d. PROJECT NUMBER

NREL/TP-560-44256

5e. TASK NUMBER

$\mathrm{H} 2708100$

5f. WORK UNIT NUMBER

7. PERFORMING ORGANIZATION NAME(S) AND ADDRESS(ES)

National Renewable Energy Laboratory

1617 Cole Blvd.

Golden, CO 80401-3393
8. PERFORMING ORGANIZATION REPORT NUMBER

NREL/TP-560-44256

9. SPONSORING/MONITORING AGENCY NAME(S) AND ADDRESS(ES)

10. SPONSOR/MONITOR'S ACRONYM(S) NREL

11. SPONSORING/MONITORING AGENCY REPORT NUMBER

12. DISTRIBUTION AVAILABILITY STATEMENT

National Technical Information Service

U.S. Department of Commerce

5285 Port Royal Road

Springfield, VA 22161

13. SUPPLEMENTARY NOTES

14. ABSTRACT (Maximum 200 Words)

Graphs of composite data products produced by DOE's Controlled Hydrogen Fleet and Infrastructure Demonstration and Validation project through September 2008.

\section{SUBJECT TERMS}

hydrogen; hydrogen demonstration; hydrogen validation

\begin{tabular}{l}
\hline \multicolumn{3}{|l|}{ 16. SECURITY CLASSIFICATION OF: } \\
\begin{tabular}{|l|l|l|}
\hline a. REPORT & b. ABSTRACT & c. THIS PAGE \\
Unclassified & Unclassified & Unclassified \\
& & \\
\hline
\end{tabular}
\end{tabular}

17. LIMITATION
OF ABSTRACT
UL

18. NUMBER
OF PAGES

19a. NAME OF RESPONSIBLE PERSON

19b. TELEPONE NUMBER (Include area code) 